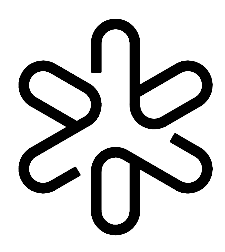

UNIVERSIDADE DE SÃO PAULO

INSTITUTO DE FÍSICA

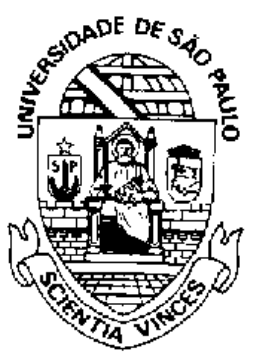

\title{
PREPARAÇÃO E CARACTERIZAÇÃO DE MANGANITAS (La,Pr)CaMnO
}

Sueli Hatsumi Masunaga

Orientador: Dr. Renato de Figueiredo Jardim

\author{
Dissertação de Mestrado apresentada \\ ao Instituto de Física da Universidade \\ de São Paulo para a obtenção do título \\ de Mestre em Ciências.
}

Comissão examinadora:

Dr. Renato de Figueiredo Jardim

Dr. Gerardo Fabian Goya

Dr. Miguel Alexandre Novak

São Paulo 
Dedico este trabalho ao Koiti pelo apoio, carinho e compreensão. 


\section{RESUMO}

Amostras policristalinas de $\mathrm{La}_{5 / 8-y} \mathrm{Pr}_{y} \mathrm{Ca}_{3 / 8} \mathrm{MnO}_{3} ; 0 \leq \mathrm{y} \leq 0.625$; foram produzidas pelo método da mistura estequiométrica de óxidos e tratadas termicamente ao ar a $1400^{\circ} \mathrm{C}$. As amostras foram caracterizadas através de medidas de difração de raios-X, resistividade elétrica $\rho(T)$, susceptibilidade magnética $\chi(T)$ e magnetorresistividade $\rho(T, H=50 \mathrm{kOe})$. Os resultados das análises dos diagramas de raios-X indicaram que os materiais são de fase única e que houve uma substituição efetiva de La por Pr no sítio A ao longo da série. Medidas de $\rho(\mathrm{T})$ e $\chi(\mathrm{T})$ revelaram que a temperatura de transição de fase metal-isolante $\mathrm{T}_{\mathrm{MI}}$ e temperatura de Curie $\mathrm{T}_{\mathrm{C}}$ decrescem com o aumento da concentração y e que a resistividade residual $\rho_{0}(\rho(T=10 \mathrm{~K}))$ é consideravelmente alta em amostras com y $\geq 0.35$. Ainda, com o decréscimo de $\mathrm{T}$, as amostras com $\mathrm{y} \geq 0.35$ transitam para uma fase de ordenamento de carga em $\mathrm{T}_{\mathrm{OC}} \sim 194 \mathrm{~K} \mathrm{e}$, em seguida, para uma fase metálica em $\mathrm{T}_{\mathrm{MI}}$. Essas medidas também sugerem a coexistência de fases ferromagnética-metálica FMM e de ordenamento de carga isolante OCI nesses materiais. Nas propriedades físicas macroscópicas, a fase FMM mostrou ser a dominante para os compostos com pequenas concentrações de $\operatorname{Pr}(\mathrm{y} \leq 0.25)$ e a fase OCI dominante para os compostos com altas concentrações de $\operatorname{Pr}(\mathrm{y} \geq 0.40)$. As medidas de $\rho(\mathrm{T}, \mathrm{H}=50 \mathrm{kOe})$ mostram que a magnitude da resistividade elétrica decresce drasticamente nas vizinhanças de $\mathrm{T}_{\mathrm{MI}}$ sob a aplicação de um campo magnético externo. A magnitude de MR $(\mathrm{MR}=(\rho(\mathrm{H}=0)-\rho(\mathrm{H}=50 \mathrm{kOe})) / \rho(\mathrm{H}=50 \mathrm{kOe}))$ entre os extremos da série $(y=0$ e 0.625$)$ varia até sete ordens de grandeza, sendo que o máximo valor 
de MR para amostras com $\mathrm{y}=0$ é de $\sim 0.75$ e naquelas com $\mathrm{y}=0.625$ é $\sim 3.4 \times 10^{6}$. O diagrama de fases deste composto evidencia uma região crítica $(0.30 \leq \mathrm{y} \leq 0.40)$ onde os valores de $\mathrm{T}_{\mathrm{MI}}, \mathrm{T}_{\mathrm{C}}, \mathrm{MR}$ e $\rho_{0}$ variam abruptamente como função de y, sendo que em outras regiões tal variação é mais suave. A variação significativa desses quatro valores indica uma competição mais forte entre as fases coexistentes ocorre na região crítica. Algumas características marcantes podem ser observadas nas amostras da região crítica tais como: a presença de um segundo "pico", abaixo de $\mathrm{T}_{\mathrm{MI}}$, em $\sim 90 \mathrm{~K} \mathrm{e} \sim 72 \mathrm{~K}$ na curva de $\rho(\mathrm{T})$ de amostras com $\mathrm{y}=0.30$ e 0.35 , histerese térmica mais pronunciada em $\rho(T)$ e $\chi(T)$, MR torna-se "colossal", relaxação significativa da resistividade elétrica com o tempo, entre outras. Assim, as propriedades de transporte e magnéticas nessa região crítica são dominadas pela forte competição entre as fases coexistentes. 


\section{ABSTRACT}

Polycrystalline samples of $\mathrm{La}_{5 / 8-\mathrm{y}} \mathrm{Pr}_{\mathrm{y}} \mathrm{Ca}_{3 / 8} \mathrm{MnO}_{3} ; 0 \leq \mathrm{y} \leq 0.625$; were synthesized by the solid-state reaction method and sintered in air at $1400^{\circ} \mathrm{C}$. These compounds were studied by measurements of X-ray powder diffraction, magnetic susceptibility $\chi(T)$, and electrical resistivity $\rho(T, H)$. X-ray powder diffraction measurements indicated single phase materials and an effective substitution of La by Pr. Results from $\rho(\mathrm{T})$ and $\chi(\mathrm{T})$ revealed that increasing $\mathrm{y}$ in this series results in a rapid reduction of both the insulator to metal transition temperature $\mathrm{T}_{\mathrm{MI}}$ and the Curie temperature $\mathrm{T}_{\mathrm{C}}$. Such a rapid decrease in $\mathrm{T}_{\mathrm{MI}}$ with increasing $\mathrm{y}$ is also accompanied by the occurrence of a new transition temperature, termed $\mathrm{T}_{\mathrm{CO}}$, which is related to the transition to the charge ordered $\mathrm{CO}$ state. Such a temperature, which is essentially independent of $\mathrm{y}$, occurs at $\mathrm{T}_{\mathrm{CO}} \sim 194 \mathrm{~K}$ and is mainly observed in samples with $y \geq 0.35$. The other feature is the presence of a large residual resistivity electrical $\rho\left(\rho_{0}=\rho(10 \mathrm{~K})\right)$ for large $\mathrm{y}(\mathrm{y} \geq 0.35)$ at low-T even though $\rho(\mathrm{T})$ suggests a metallic behavior below $\mathrm{T}_{\mathrm{MI}}$. The temperature for the maximum magnetoresistance effect occurs near $\mathrm{T}_{\mathrm{MI}}$, that shifts to higher $\mathrm{T}$ with increasing field. The MR is defined here as $(\rho(\mathrm{H}=0)-\rho(\mathrm{H}=50 \mathrm{kOe})) / \rho(\mathrm{H}=$ $50 \mathrm{kOe}$ ) and is enhanced by seven orders of magnitude from $\sim 0.75$ up to $\sim$ $3.4 \times 10^{6}$ in samples with $\mathrm{y}=0$ and $\mathrm{y}=0.625$, respectively. Some features like the thermal hysteresis observed in both $\rho(\mathrm{T})$ and $\chi(\mathrm{T})$ curves indicate the coexistence of different phases in a range of y concentration, i. e., the ferromagnetic-metallic FMM and the charge ordered-insulating COI domains. The FMM is stable for $\mathrm{y} \leq 0.25$, but the COI state becomes dominant for $y \geq 0.40$. There is a critical region in the phase diagram, ranging from 
$y=0.30$ to 0.40 , where the magnitude of the $T_{M I}, T_{C}, M R$, and $\rho_{0}$ were found to display abrupt changes with increasing y. Some anomalous features like a second peak in $\rho(\mathrm{T})$ below $\mathrm{T}_{\mathrm{MI}}$, a two-step increasing in $\chi(\mathrm{T})$, a "colossal" MR effect and others are observed for compositions belonging to this critical region. Our combined data suggest that the general physical properties of these compounds in such a critical region are dominated by the strong competition between coexisting ferromagnetic-metallic and charge orderedinsulating phases. 


\section{Agradecimentos}

Primeiramente gostaria de agradecer ao Prof. Dr. Renato de Figueiredo Jardim pela excelente orientação e oportunidade de realizar este trabalho.

Ao Dr. Reginaldo Muccillo pela colaboração na realização das medidas de difração de raios-X.

Aos meus pais Hatsue e Chotoku Yara pelo apoio, carinho e educação.

Aos meus sogros Tereza e Senzi Masunaga pelo apoio e carinho.

Aos meus irmãos Marina, Mônica, Patrícia, Paulo, Hélio e Henrique pela amizade.

Aos colegas do laboratório: Alessandro, Ernesto, Fábio, José Antônio, Márcia, Pedro, Solange, Vinicius e Zulmara pela amizade e apoio.

Aos técnicos do departamento de Física dos Materiais e Mecânica pela ajuda e pela amizade.

A toda família e aos amigos que conheci ao longo da vida e que me acompanharam e apoiaram no desenrolar deste trabalho.

Ao CNPq pelo apoio financeiro (Contrato No. 134026/03-9). 


\section{INDICE}

\section{CAPITULO 1}

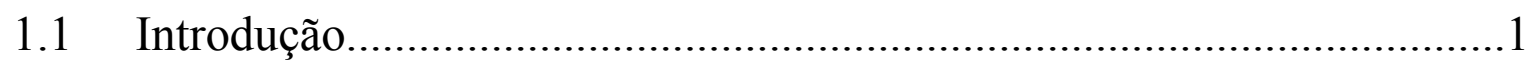

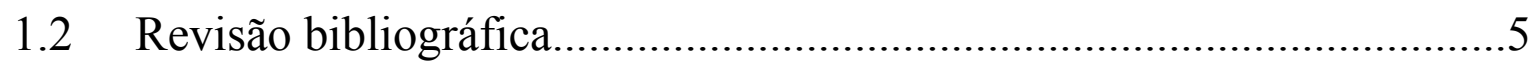

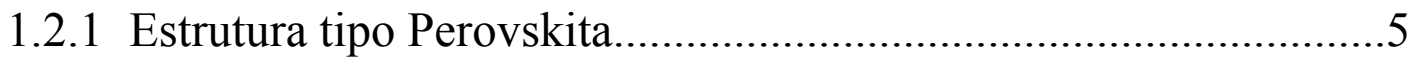

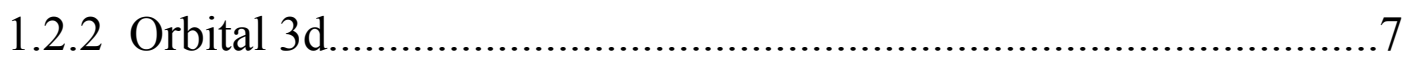

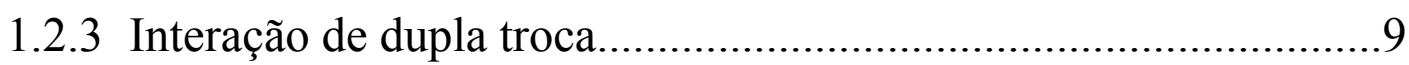

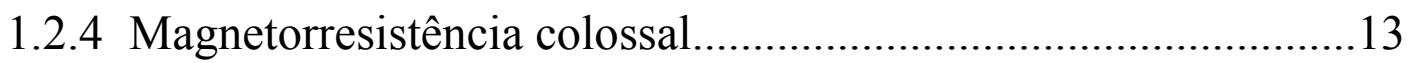

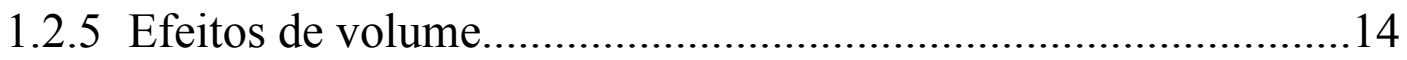

1.2.6 Ordenamento de carga e orbital.................................................15

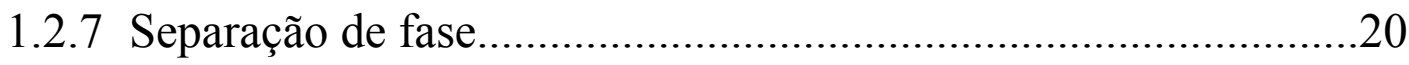

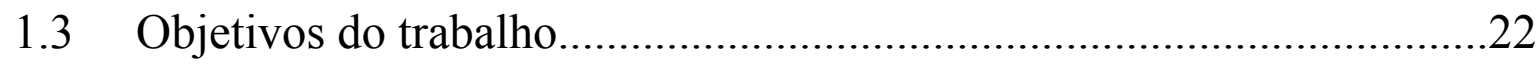

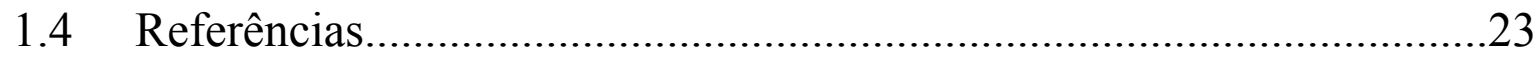

\section{CAPITULO 2}

Descrição Experimental

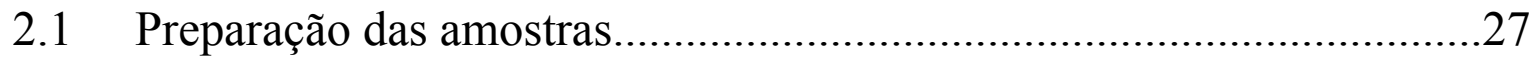

2.2 Caracterização por difração de raios-X..................................................28

2.2.1 Refinamento da estrutura cristalina através do método Rietveld...28

2.3 Medidas de resistividade elétrica.......................................................30

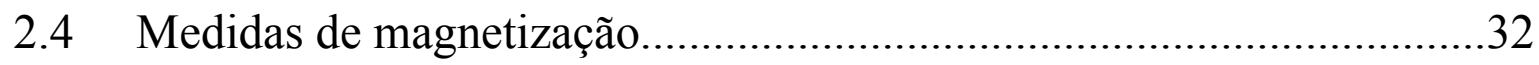

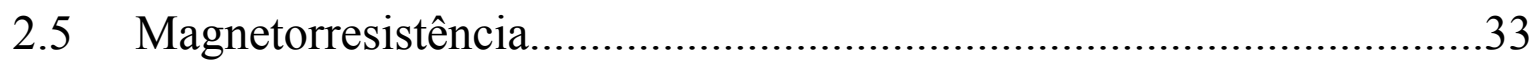

2.6 Relaxação da resistência elétrica.............................................................34

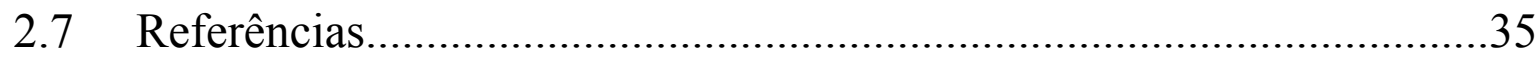




\section{CAPITULO 3}

Resultados e Discussões

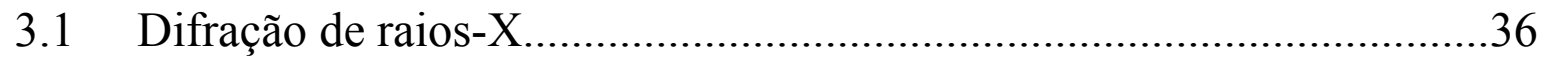

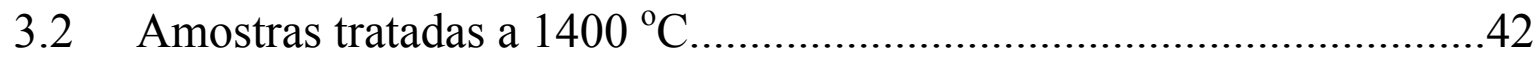

3.2.1 Caracterização por difração de raios-X........................................43

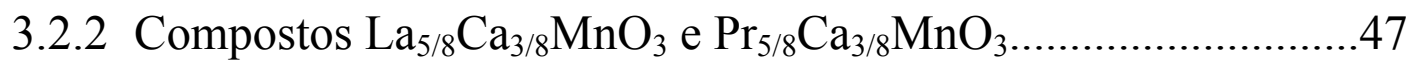

3.2.3 Caracterização através de medidas de resistividade elétrica e de

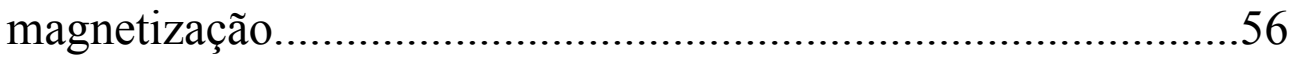

3.2.3.a Propriedades das amostras com $\mathrm{y} \leq 0.25 \ldots \ldots \ldots \ldots \ldots \ldots \ldots \ldots . . .63$

3.2.3.b Propriedades das amostras com $\mathrm{y} \geq 0.40 \ldots \ldots \ldots \ldots \ldots \ldots \ldots . . . .66$

3.2.3.c Propriedades das amostras com $0.30 \leq \mathrm{y} \leq 0.40 \ldots \ldots \ldots \ldots . . .69$

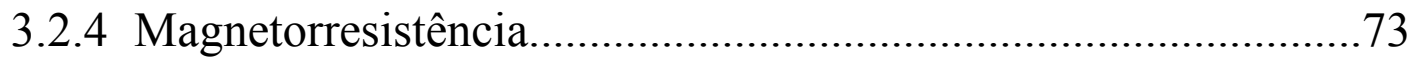

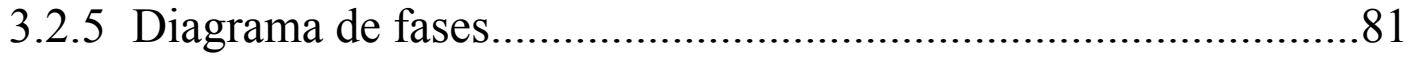

3.2.6 Relaxação da resistência elétrica na região crítica.......................91

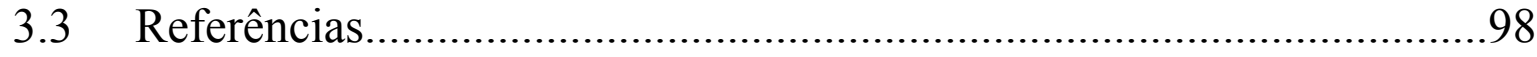

\section{CAPITULO 4}

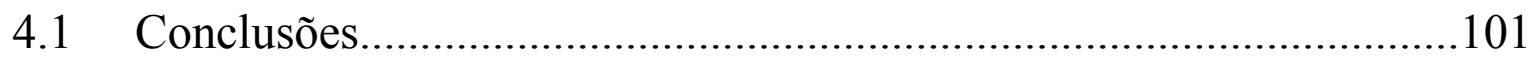

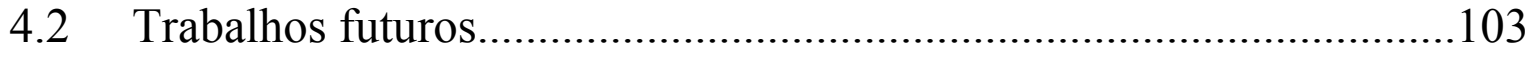




\section{Lista de Figuras}

\section{CAPITULO 1 - Introdução}

Figura 1.1 - Resistividade elétrica como função da temperatura em campos magnéticos aplicados de 0,1 e 12 Tesla.

Figura 1.2 - Diagramas de fases como função da concentração $\mathrm{x}$ dos compostos cerâmicos de (a) $\operatorname{Pr}_{1-\mathrm{x}} \mathrm{Ca}_{\mathrm{x}} \mathrm{MnO}_{3}$ e (b) $\mathrm{La}_{1-\mathrm{x}} \mathrm{Ca}_{\mathrm{x}} \mathrm{MnO}_{3}$. As fases presentes são: ferromagnética-isolante (FMI), ferromagnética-metálica (FMM), antiferromagnético-isolante (AFMI), ordenamento de carga (CO), paramagnéticaisolante (PMI) e "cluster glass"(CG). Temperaturas de transição: temperatura de Curie $\left(\mathrm{T}_{\mathrm{C}}\right)$, de ordenamento de carga $\left(\mathrm{T}_{\mathrm{CO}}\right)$ e Néel $\left(\mathrm{T}_{\mathrm{N}}\right)$.

Figura 1.3 - (a) Esquema da estrutura perovskita $\mathrm{ABO}_{3}$ : (b) ideal ou cúbica, (c) ortorrômbica e $(\mathrm{d})$ romboédrica.

Figura 1.4 - Diagrama de níveis eletrônicos do íon $\mathrm{Mn}^{3+}\left(3 \mathrm{~d}^{4}\right)$ : (a) os níveis são degenerados no caso do íon livre (simetria esférica); (b) íon sujeito a um campo cristalino com simetria octaédrica, levando a uma dupla degenerescência do nível $\mathrm{e}_{\mathrm{g}}$ e tripla do nível $\mathrm{t}_{2 \mathrm{~g}}$; (c) a degenerescência dos níveis é quebrada pela ação de um campo cristalino de simetria ortorrômbica, devido à distorção do tipo Jahn-Teller.

Figura 1.5 - Esquema da interação de dupla-troca elaborado por Zener.

Figura 1.6 - Esquema da interação de dupla troca. (a) Composto não dopado $\mathrm{LaMnO}_{3}$ com ordenamento AF. (b) Ordenamento paralelo dos spins em baixas temperaturas, resultado na interação forte de dupla-troca. (c) Configuração aleatória em $\mathrm{T} \sim \mathrm{T}_{\mathrm{C}}$, resultando em interação fraca de dupla troca. (d) A aplicação de um campo magnético externo favorece o alinhamento dos spins, fortalecendo a interação de dupla-troca em relação ao caso $(c)$. (e, f) Ilustração do conceito de DT a amplitude de transferência dos elétrons $e_{g}$ como função do alinhamento dos spins.

Figura 1.7 - Configurações de ordenamento de carga e orbital para $\mathrm{La}_{1-\mathrm{x}} \mathrm{Ca}_{\mathrm{x}} \mathrm{MnO}_{3}$ com: (a) $x=0$; (b) $x=1 / 2$ e (c) $x=2 / 3$. Os círculos abertos são os íons $\mathrm{Mn}^{4+}$ e os fechados os íons $\mathrm{Mn}^{3+}$ com ordenamento orbital dos elétrons $\mathrm{e}_{\mathrm{g}}$.

Figura 1.8 - Vista esquemática do plano xy da fase magnética do tipo CE.

Figura 1.9 - Ordenamento orbital, de carga e de spin do tipo CE 17 (antiferromagnético), muito comum em manganitas para $x \approx 1 / 2$. Pode-se ver também o ordenamento orbital $\mathrm{e}_{\mathrm{g}}$ dos sítios de $\mathrm{Mn}^{3+}$ e os sítios do $\mathrm{Mn}^{4+}$ que são indicados por círculos fechados.

Figura 1.10 - Esquema da influência do tamanho dos íons do sítio A na amplitude 
de "hopping” entre dois íon de Mn.

\section{CAPITULO 2 - Descrição Experimental}

Figura 2.1 - Esquema simplificado do arranjo experimental para obtenção de medidas de resistividade elétrica de uma amostra.

\section{CAPITULO 3 - Resultados e Discussões}

Figura 3.1.1 - Diagramas de difração de raios-X para os compostos $\mathrm{La}_{5 / 8-\mathrm{y}} \mathrm{Pr}_{\mathrm{y}} \mathrm{Ca}_{3 / 8} \mathrm{MnO}_{3}$ com $\mathrm{y}=0.20$ após dois tratamentos térmicos: antes e depois da formação da fase única. $\mathrm{O}$ asterisco indica a presença de uma fase adicional na amostra tratada a $1200{ }^{\circ} \mathrm{C}$, por $12 \mathrm{~h}$. Após três tratamentos térmicos a $1200{ }^{\circ} \mathrm{C}$ por $12 \mathrm{~h}$ cada, observou-se a formação da fase única do composto, representada pelo diagrama em vermelho.

Figura 3.1.2 - Diagramas de difração de raios- $X$ para os compostos $\mathrm{La}_{5 / 8-y} \mathrm{Pr}_{\mathrm{y}} \mathrm{Ca}_{3 / 8} \mathrm{MnO}_{3}$ com $\mathrm{y}=0.30$ submetidos a diferentes temperaturas de sinterização. Reflexões pertencentes à radiação $K_{\beta}$ foram identificadas e são indicadas pela seta. $\mathrm{O}$ detalhe mostra o deslocamento, para ângulos maiores do pico mais intenso, localizado em $\sim 32.9^{\circ}$, como função crescente da temperatura de sinterização.

Figura 3.1.3 - Volume da cela unitária da amostra com y $=0.30$ como função da temperatura de sinterização.

Figura 3.1.4 - Detalhes dos diagramas de difração de raios-X para os compostos $\mathrm{La}_{5 / 8-y} \mathrm{Pr}_{\mathrm{y}} \mathrm{Ca}_{3 / 8} \mathrm{MnO}_{3}$ com $\mathrm{y}=0.30$ submetidos a diferentes temperaturas de sinterização. Reflexões pertencentes à radiação $\mathrm{K}_{\alpha 2}$ tornam-se mais definidas para $\mathrm{T}_{\mathrm{S}}$ maiores.

Figura 3.2.1 - Diagramas de difração de raios-X para a série $\mathrm{La}_{5 / 8-\mathrm{y}} \mathrm{Pr}_{\mathrm{y}} \mathrm{Ca}_{3 / 8} \mathrm{MnO}_{3}$ sinterizada a $\mathrm{T}_{\mathrm{S}}=1400{ }^{\circ} \mathrm{C}$.

Figura 3.2.2 - (a) Evolução dos parâmetros de rede $a, b$ e $c$ e (b) do volume da cela unitária ao longo da série $\mathrm{La}_{5 / 8-y} \mathrm{Pr}_{\mathrm{y}} \mathrm{Ca}_{3 / 8} \mathrm{MnO}_{3}$.

Figura 3.2.3 - Detalhes dos diagramas de DRX indicam as reflexões dos planos (200), (121) e (002). As setas indicam as posições calculadas das reflexões dos planos para a amostra com y $=0$ e 0.625 . Essas duas amostras foram escolhidas por 
apresentarem maior distância angular entre duas reflexões, veja Tabela 3.2.1.

Figura 3.2.4 - (a) Curvas de susceptibilidade magnética obtidas no processo de ZFC (símbolo aberto) e de FC (símbolo fechado). (b) Curvas de resistividade elétrica como função da temperatura, obtidas nos processos de aquecimento (símbolo aberto) e de resfriamento (símbolo fechado) para a amostra LCMO. As temperaturas de transição indicadas pelas setas são: $T_{M I}$ (metal-isolante) e $T_{C}$ (temperatura de Curie).

Figura 3.2.5 - (a) Curvas de susceptibilidade magnética obtidas no processo de ZFC (símbolo aberto) e de FC (símbolo fechado). (b) Curvas de resistividade elétrica como função da temperatura, obtidas nos processos de aquecimento (símbolo aberto) e de resfriamento (símbolo fechado) para a amostra PCMO. As temperaturas de transição indicadas são: $\mathrm{T}_{\mathrm{MI}}$ (metal-isolante), $\mathrm{T}_{\mathrm{C}}$ (temperatura de Curie), $\mathrm{T}_{\mathrm{OC}}$ (ordenamento de carga/orbital) e $\mathrm{T}_{\mathrm{N}}$ (temperatura de ordenamento antiferromagnética). $O$ detalhe mostra a derivada de $\rho(T)$ como função da temperatura.

Figura 3.2.6 - Curvas de resistividade elétrica como função da temperatura obtidas no processo de resfriamento para as amostras com y $=0.625$ sinterizadas a $1350 \mathrm{e}$ $1400{ }^{\circ} \mathrm{C}$.

Figura - 3.2.7 Curvas de (a) susceptibilidade magnética e (b) resistividade elétrica como função da temperatura para a série $\mathrm{La}_{5 / 8-\mathrm{y}} \mathrm{Pr}_{\mathrm{y}} \mathrm{Ca}_{3 / 8} \mathrm{MnO}_{3}$. As curvas mostradas com símbolos abertos foram obtidas no processo de ZFC ou de aquecimento da amostra e os fechados no processo de FC ou de resfriamento. Esses processos térmicos estão indicados por setas. As temperaturas $\mathrm{T}_{\mathrm{C}}, \mathrm{T}_{\mathrm{MI}}$ e $\mathrm{T}_{\mathrm{OC}}$ para algumas amostras também estão indicadas por setas.

Figura 3.2.8 - Derivada d $\rho / d T$ como função da temperatura para a determinação de: (a) temperaturas de transição de fase metal-isolante, indicadas por setas verticais, nas amostras representativas com y $=0,0.10$ e 0.20 ; (b) temperatura de ordenamento de carga para as amostras com y $=0.35,0.40$ e 0.625 . As linhas pontilhadas estão indicadas para melhor visualização dos pontos experimentais.

Figura 3.2.9 - Curvas de resistividade elétrica como função da temperatura para as amostras com y $=0,0.10,0.20$ e 0.25 . As curvas mostradas com símbolos abertos foram obtidas no processo de aquecimento da amostra e os fechados no processo de resfriamento. $\mathrm{T}_{\mathrm{MI}}$ e $\rho_{0}$ estão indicadas por setas.

Figura 3.2.10 - (a) Curvas de $\chi(\mathrm{T})$ obtidas no processo de ZFC (símbolo aberto) e 66 FC (símbolo fechado) para as amostras com y $=0.40$ e 0.625 . As temperaturas de ordenamento de carga $\mathrm{T}_{\mathrm{OC}}$ são indicadas por setas. (b) Curvas de $\rho(\mathrm{T})$ para as amostras com y $=0.40$ e 0.625 . As curvas mostradas com símbolos abertos foram obtidas no processo de aquecimento da amostra e os fechados no processo de resfriamento. $\mathrm{T}_{\mathrm{MI}}, \mathrm{T}_{\mathrm{OC}}$ e $\rho_{0}$ estão indicadas por setas verticais. 
Figura 3.2.11 - (a) Curvas de $\chi(\mathrm{T})$ obtidas no processo ZFC (símbolo aberto) e FC (símbolo fechado) para as amostras com y $=0.25,0.30$ e 0.35 . (b) Curvas de $\rho(T)$ obtidas nos processos de aquecimento (símbolo aberto) e resfriamento (símbolo fechado) das amostras com y $=0.30,0.35$ e $0.40 . \mathrm{T}_{\mathrm{MI}}$ e $\mathrm{T}_{\mathrm{OC}}$ são indicadas por setas. Os asteriscos indicam anomalias que ocorrem abaixo de $T_{M I}$ nas curvas de $\rho(T)$.

Figura 3.2.12 - Curvas de resistividade elétrica como função da temperatura, obtidas nos processos de aquecimento (curva em vermelho) e resfriamento (preto) nas amostras sob um campo magnético externo aplicado $\mathrm{H}$, indicado na figura, para a série $\mathrm{La}_{5 / 8-\mathrm{y}} \mathrm{Pr}_{\mathrm{y}} \mathrm{Ca}_{3 / 8} \mathrm{MnO}_{3}$. Os processos térmicos estão indicados por setas. As setas verticais indicam a resistividade elétrica residual $\rho_{0}$, definida como $\rho(\mathrm{T}=10 \mathrm{~K})$.

Figura 3.2.13 - Curvas de resistividade elétrica normalizadas via $(\rho(T) / \rho(350 \mathrm{~K}))$ como função da temperatura obtidas no processo de resfriamento (indicado por setas em algumas curvas) das amostras de $\mathrm{La}_{5 / 8-\mathrm{y}} \mathrm{Pr}_{\mathrm{y}} \mathrm{Ca}_{3 / 8} \mathrm{MnO}_{3}$ e sob a aplicação de um campo magnético externo de $\mathrm{H}=50 \mathrm{kOe}$.

Figura 3.2.14 - Curvas de magnetorresistência como função da temperatura para a série $\mathrm{La}_{5 / 8-\mathrm{y}} \mathrm{Pr}_{\mathrm{y}} \mathrm{Ca}_{3 / 8} \mathrm{MnO}_{3}$, obtidas no processo de resfriamento das amostras. A magnetorresistência foi obtida de acordo com a relação 2.5.1.

Figura 3.2.15 - Diagramas de fases como função da concentração y e do raio iônico médio do sítio $\mathrm{A}<\mathrm{r}_{\mathrm{A}}>$ de (a) $\mathrm{T}_{\mathrm{MI}}(\boldsymbol{\square}), \mathrm{T}_{\mathrm{C}}(\boldsymbol{\Delta})$, MR ( $(\star)$ e $\rho_{0}(\bullet)$; e (b) $\mathrm{T}_{\mathrm{MI}}^{\text {resf }}$ (ㅁ), $\mathrm{T}_{\mathrm{MI}}{ }^{\text {aquec }}(\mathbf{\square}), \mathrm{T}_{\mathrm{OC}}(\boldsymbol{\bullet}), \Delta \mathrm{T}_{\mathrm{MI}}(\boldsymbol{\bullet})$ e $\rho_{\text {Máx }}(\boldsymbol{\Delta})$. As linhas pontilhadas estão indicadas para uma melhor visualização dos pontos experimentais.

Figura 3.2.16 - Curvas de resistividade elétrica como função da temperatura para a amostra com $y=0.30$ obtidas com taxa de aquecimento/resfriamento de $6 \mathrm{~K} / \mathrm{min}$ (curvas em preto) e $10 \mathrm{~K} / \mathrm{min}$ (em vermelho).

Figura 3.2.17 - Curvas de resistividade elétrica como função da temperatura para a amostra com $y=0.35$ obtidas com taxa de aquecimento/resfriamento de $6 \mathrm{~K} / \mathrm{min}$ (curvas em preto) e $10 \mathrm{~K} / \mathrm{min}$ (em vermelho).

Figura 3.2.18 - Relaxação da resistência elétrica normalizada como função do tempo para a amostra com $\mathrm{y}=0.30$ para diversas temperaturas.

Figura 3.2.19 - Relaxação da resistência elétrica normalizada como função do tempo para a amostra com $\mathrm{y}=0.35$ para diversas temperaturas.

Figura 3.2.20 - Relaxação da resistência elétrica como função do tempo para correntes de excitação utilizadas de $0.1,2$ e $3 \mathrm{~mA}$ para a amostra com y $=0.35$. 


\section{Lista de Tabelas}

Pág.

Tabela 3.1.1 - Raios iônicos com número de coordenação nove, de acordo com a referência 3.

Tabela 3.2.1 - Posições angulares calculadas das reflexões referentes aos planos (200), (121) e (002) como função de y. $\Delta 2 \theta$ é a distância angular entre duas reflexões vizinhas que ocorrem em posições angulares menores.

Tabela 3.2.2 - Raio iônico médio do sítio $\left.A<r_{A}\right\rangle$, temperatura de Curie $T_{C}$, temperatura de transição de fase metal-isolante $\mathrm{T}_{\mathrm{MI}}$, de ordenamento de carga/orbital $T_{O C}$, resistividade elétrica residual $\rho_{0}(\rho(T=10 \mathrm{~K}))$ e resistividade elétrica em $\mathrm{T}=\mathrm{T}_{\mathrm{MI}}\left(\rho_{\text {Máx }}\right.$ ) como função da concentração y. Os traços na coluna de $T_{O C}$ indicam que a transição de ordenamento de carga não foi observada para os compostos com $\mathrm{y} \leq 0.30$.

Tabela 3.2.3 - Valores de $\mathrm{T}_{\mathrm{MI}}$ obtidos das curvas de $\rho(\mathrm{T})$ em $\mathrm{H}=0$ e $\mathrm{H}=50 \mathrm{kOe}$, em amostras de $\mathrm{La}_{5 / 8-\mathrm{y}} \mathrm{Pr}_{\mathrm{y}} \mathrm{Ca}_{3 / 8} \mathrm{MnO}_{3} . \Delta \mathrm{T}_{\mathrm{MI}}$ é a diferença estimada entre $T_{M I}^{H=0}$ e $T_{M I}^{H=50 k O e}$. 


\section{Capítulo 1}

\subsection{Introdução}

O estudo dos óxidos de manganês, que se cristalizam em uma estrutura cristalina do tipo perovskita e apresentam valência mista, conhecidos como manganitas, teve início com os trabalhos pioneiros de Jonker e Van Santen em 1950, quando os autores apresentaram os primeiros resultados nesses compostos. $^{[1]}$ A fórmula química geral desses materiais foi descrita como $\mathrm{A}_{1-\mathrm{x}} \mathrm{A}_{\mathrm{x}} \mathrm{MnO}_{3}$, onde $\mathrm{A}$ corresponde a íons de terra-rara (com valência $3+$ ou $\mathrm{Bi}^{3+}$ )

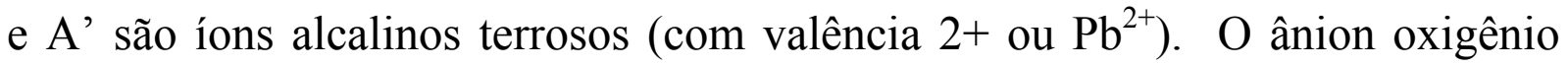
tem valência 2- e as frações relativas de $\mathrm{Mn}^{4+}$ e $\mathrm{Mn}^{3+}$ dependem de $\mathrm{x}$. Em composições com esperada ausência de portadores de carga $(\mathrm{x}=0)$, esses compostos são antiferromagnéticos $\mathrm{AF}^{[2,3]}$ apesar de sua estrutura magnética implicar na existência de interações tanto ferromagnéticas FM quanto AF entre os spins do Mn. A introdução de portadores de carga para a condutividade elétrica é feita via alteração de $\mathrm{Mn}^{3+}$ por $\mathrm{Mn}^{4+}$ e, dependendo da dopagem (x), esses compostos exibem fases $\mathrm{AF}, \mathrm{FM}$ e até mesmo a coexistência dessas fases. É importante notar que os elétrons de condução e os spins locais são devidos ao orbital d do Mn. Uma das propriedades físicas mais importantes destes óxidos, para $\mathrm{x} \sim 0.3$, é a ocorrência de uma transição de fase metal-isolante, caracterizada por um máximo que ocorre em $\mathrm{T}_{\mathrm{MI}}$ na curva de resistividade elétrica como função da temperatura $\rho(T)$. O máximo em $\rho(T)$ também separa duas regiões diferentes: a fase isolante, que ocorre em altas temperaturas $\mathrm{T}>\mathrm{T}_{\mathrm{MI}}$ e a fase metálica em baixas $\mathrm{T}<\mathrm{T}_{\mathrm{MI}}$. Essa transição de fase, em geral, é acompanhada por uma transição magnética a partir de uma fase paramagnética 
em altas $\mathrm{T}$ para uma fase $\mathrm{FM}$ em baixas $\mathrm{T}$, caracterizada pela temperatura de Curie $\mathrm{T}_{\mathrm{C}}$.

$\mathrm{O}$ efeito da magnetorresistência ${ }^{[1]} \mathrm{MR}$ nas manganitas próximo de $\mathrm{T}_{\mathrm{C}} \approx$ $\mathrm{T}_{\mathrm{MI}}$ é conhecido há muito tempo. Em 1969 Searle and Wang ${ }^{[4]}$ publicaram estudos detalhados da resistividade elétrica como função do campo magnético aplicado em monocristais de $\mathrm{La}_{1-\mathrm{x}} \mathrm{Pb}_{\mathrm{x}} \mathrm{MnO}_{3}$. Foi constatada uma magnitude de MR muito grande próximo à $\mathrm{T}_{\mathrm{C}}$. Alguns anos depois, Kubo e Ohata ${ }^{[5]}$ descreveram esse efeito teoricamente usando uma Hamiltoniana de dupla-troca DT que inclui os fatores essenciais do mecanismo de DT elaborado por Zener, ${ }^{[6]}$ Anderson e Hasegawa ${ }^{[7]}$ e de Gennes. ${ }^{[8]}$

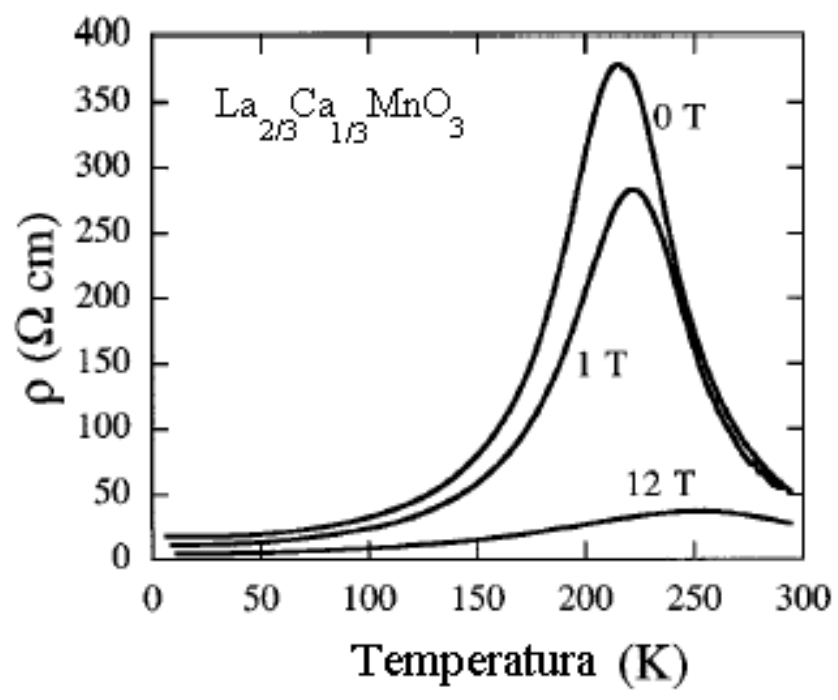

Figura 1.1 - Resistividade elétrica como função da temperatura em campos magnéticos aplicados de 0,1 e 12 Tesla. ${ }^{[9]}$

Um exemplo típico de MR pode ser observado na Fig. 1.1 no composto policristalino $\mathrm{La}_{1-\mathrm{x}} \mathrm{Ca}_{\mathrm{x}} \mathrm{MnO}_{3}(\mathrm{x}=1 / 3) .{ }^{[9]}$ A magnitude da resistividade elétrica $\rho(\mathrm{T})$ decresce com a aplicação do campo magnético aplicado, sendo que o efeito

\footnotetext{
${ }^{1}$ Magnetorresistência é a variação na resistência elétrica induzida pela aplicação de um campo magnético externo. Este fenômeno é observado, basicamente, em metais e semicondutores.
} 
é mais pronunciado para campos de maior magnitude. O decréscimo de $\rho(T)$ na presença de um campo magnético é denotado de MR negativa. $\mathrm{O}$ aparente sucesso da teoria de DT naquela época resultou em um desenvolvimento modesto da área nos anos subseqüentes. Entretanto, houve um renovado interesse por parte da comunidade científica nesses materiais no início dos anos 90, devido à descoberta do efeito de magnetorresistência colossal MRC ${ }^{[10]}$ nos mesmos compostos. Esses materiais tornaram-se de grande interesse pelo seu potencial em aplicações tecnológicas, tais como cabeça de leitura, escrita em mídias magnéticas, sensores e eletrônica de spin polarizado, além de apresentarem um rico diagrama de fases magnéticas e estruturais como função da temperatura, campo magnético aplicado, nível de dopagem, pressão hidrostática e raio iônico médio do sítio $\mathrm{A}\left(<\mathrm{r}_{\mathrm{A}}>\right)$.

(a)

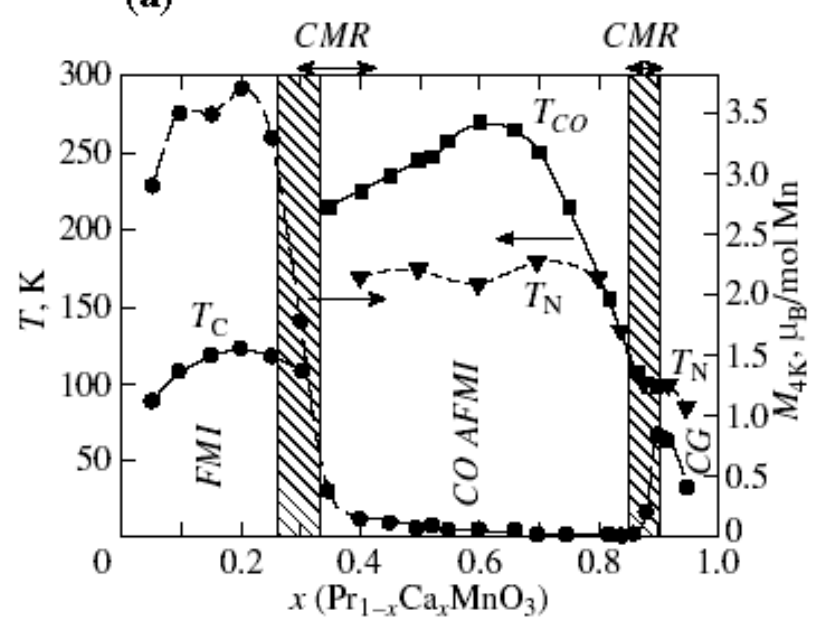

(b)

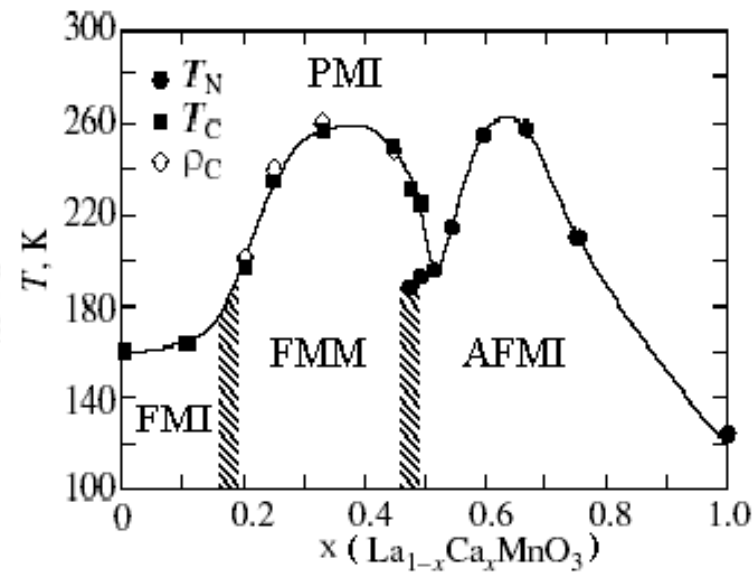

Figura 1.2 - Diagramas de fases como função da concentração x dos compostos cerâmicos de (a) $\operatorname{Pr}_{1-\mathrm{x}} \mathrm{Ca}_{\mathrm{x}} \mathrm{MnO}_{3}{ }^{[11]}$ e (b) $\mathrm{La}_{1-\mathrm{x}} \mathrm{Ca}_{\mathrm{x}} \mathrm{MnO}_{3} \cdot{ }^{[12]}$ As fases presentes são: ferromagnética-isolante (FMI), ferromagnética-metálica (FMM), antiferromagnético-isolante (AFMI), ordenamento de carga (CO), paramagnética-isolante (PMI) e "cluster glass" (CG). Temperaturas de transição: temperatura de Curie $\left(\mathrm{T}_{\mathrm{C}}\right)$, de ordenamento de carga $\left(\mathrm{T}_{\mathrm{CO}}\right)$ e Néel $\left(\mathrm{T}_{\mathrm{N}}\right)$.

Estudos recentes sobre as manganitas revelaram que o modelo de DT, apesar de descrever bem o comportamento metálico da fase FM, não parece ser suficiente para explicar os diversos comportamentos físicos observados nos 
resultados experimentais. $^{[13]}$ O diagrama de fases desses materiais, em baixas temperaturas, contém uma estrutura muito complexa que não é prevista pelo modelo de DT, como as fases isolantes AF (AFI) e de ordenamento de carga $(\mathrm{OCI})$, ordenamento orbital (OO), fases FM isolantes (FMI) e a tendência na formação de configurações não homogêneas de cargas. ${ }^{[14]}$ Dois exemplos de diagrama de fases magnéticas e eletrônicas são mostrados na Fig. 1.2, onde as propriedades físicas diferem quando diferentes íons ocupam o sítio A. No diagrama de fases de Fig. 1.2(a), o sítio A é ocupado pelos íons Pr e Ca, cujos raios iônicos são $1.179 \AA$ e $1.18 \AA$, respectivamente. Observa-se que o estado ferromagnético-metálico FMM não é realizado em toda a concentração de $\mathrm{x}$, mas o estado FMI ocorre em $0<\mathrm{x}<0.30$. Para concentrações maiores, com $\mathrm{x} \geq 0.30$, ocorre um estado de ordenamento de carga/orbital em uma larga de faixa de dopagem $0.3<\mathrm{x}<0.85$. No diagrama de fases 1.2(b) o sítio A é ocupado pelos íons $\mathrm{La}$ e $\mathrm{Ca}$, cujos raios iônicos são $1.216 \AA$ e $1.18 \AA$. Com a concentração de $\mathrm{Ca}$ entre 0.2 e 0.5 , ocorre a transição de fase do estado paramagnético-isolante PMI para o estado FMM com o decréscimo em temperatura. Para concentrações maiores de $\mathrm{Ca}$ com $\mathrm{x} \geq 0.5$, ocorre $\mathrm{o}$ ordenamento de carga e também o ordenamento antiferromagnético AF em baixas temperaturas. Foram citados apenas alguns exemplos de fases existentes nesses materiais, para mais detalhes veja, por exemplo, as Ref. 11 e 12 . O grande volume de trabalhos teóricos e experimentais realizados em manganitas até hoje indica que o efeito de MRC está baseado na competição entre a fase FM e outras presentes nesses materiais.

A seguir são descritas as principais propriedades destes compostos e, em seguida, serão descritos os principais objetivos deste trabalho. Informações mais detalhadas sobre as propriedades físicas das manganitas, com efeito de MRC são descritas e discutidas em várias publicações do tipo "review", citadas nas referências $15-20$. 


\subsection{Revisão bibliográfica}

\subsubsection{Estrutura Tipo Perovskita}

A maioria dos compostos com fórmula geral $\mathrm{ABO}_{3}$ cristaliza-se na estrutura conhecida como perovskita. ${ }^{[21,22]}$ A cela unitária de uma perovskita ideal é mostrada na Fig. 1.3(a), onde A são os íons maiores e ocupam as posições dos vértices do cubo e B são os íons menores, que ocupam as posições octaedrais no centro do cubo. Todos os oxigênios estão localizados nas faces do cubo. Assim, a estrutura resultante é formada por uma rede de octaedros de oxigênio ligados pelo vértice, como mostra a Fig. 1.3(b). No caso das manganitas, o íon A é um elemento terra-rara ou alcalino terroso e o íon B é o manganês. Os octaedros formados pelos íons de oxigênio são conhecidos como octaedros de $\mathrm{MnO}_{6}$.

Goldschmidt ${ }^{[23]}$ mostrou que a perovskita ideal é estável apenas se o fator de tolerância $(\mathrm{t})$, definido por:

$$
t=\frac{\left(r_{A}+r_{O}\right)}{\sqrt{2}\left(r_{B}+r_{O}\right)},
$$

onde t é aproximadamente igual a unidade e $r_{A}, r_{B}$ e $r_{O}$ são, respectivamente, os valores tabelados $^{[24]}$ dos raios iônicos médios dos íons $\mathrm{A}, \mathrm{B}$ e $\mathrm{O}^{2-}$. Para $\mathrm{t} \neq 1$, tensões elásticas tenderão a distorcer a estrutura perovskita ideal, geralmente sob a forma de rotações dos octaedros de oxigênio. Dependendo dos eixos que os octaedros são rotacionados, diferentes variações da estrutura perovskita são geradas. As manganitas dos sistemas $\mathrm{A}_{1-\mathrm{x}} \mathrm{A}_{\mathrm{x}} \mathrm{MnO}_{3}$ cristalizam-se em duas variantes da estrutura perovskita (Fig. 1.3(c) e (d)), sendo a ortorrômbica ( $\mathrm{t}<0.96)$ e a romboédrica $(0.96<\mathrm{t}<1)$, onde o ângulo de ligação Mn-O-Mn, 
nesses casos, é diferente de $180^{\circ}$ (perovskita ideal). É importante salientar que as manganitas também apresentam distorções devido à interação elétron-fônon, além de distorções devidas a efeitos elásticos.

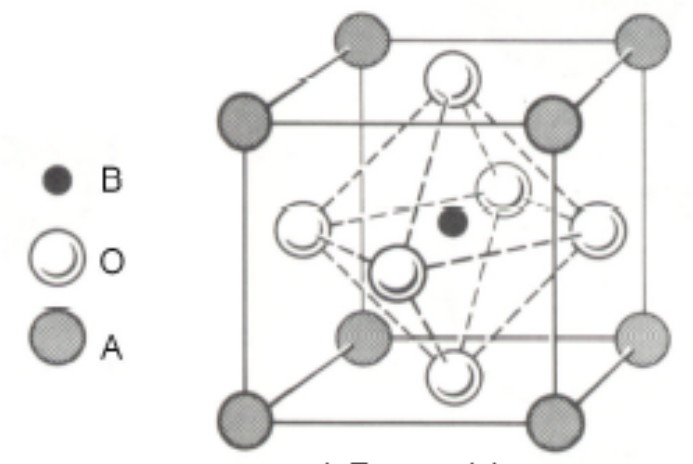

a) Perovskita

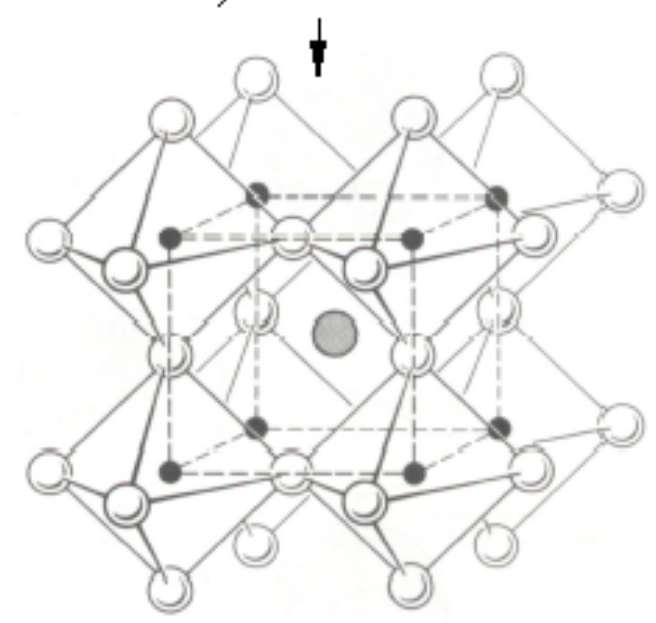

b) Cúbica

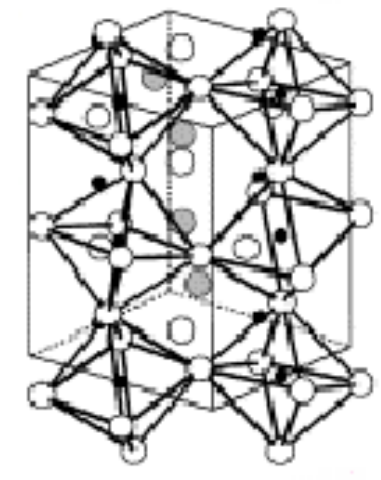

c) Ortorrômbica

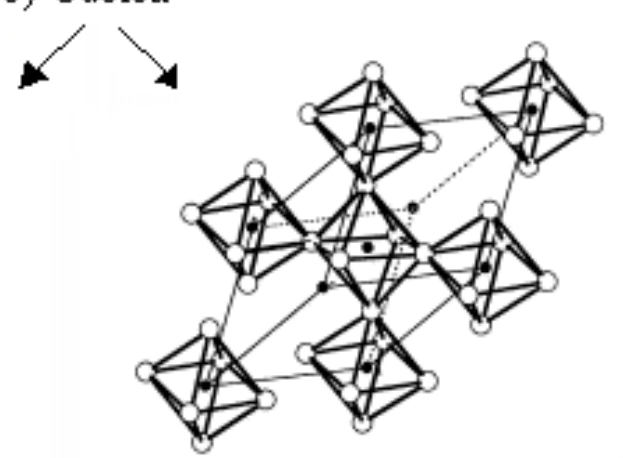

d) Romboédrica

Figura 1.3 - (a) Esquema da estrutura perovskita $\mathrm{ABO}_{3}$ : (b) ideal ou cúbica, (c) ortorrômbica e (d) romboédrica. 


\subsubsection{Orbital 3d}

A Fig. 1.4 mostra o diagrama de níveis eletrônicos do íon $\mathrm{Mn}^{3+}$, cuja configuração é $3 \mathrm{~d}^{4}$. O orbital $3 \mathrm{~d}$ apresenta seus níveis degenerados quando o íon está no estado isolado.

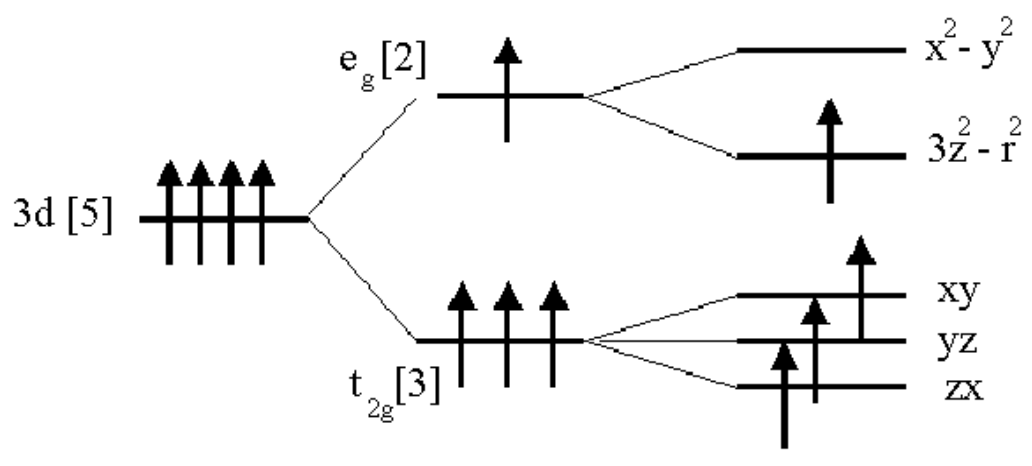

a) esférica

b) octaédrica

c) distorção de Jahn-Teller
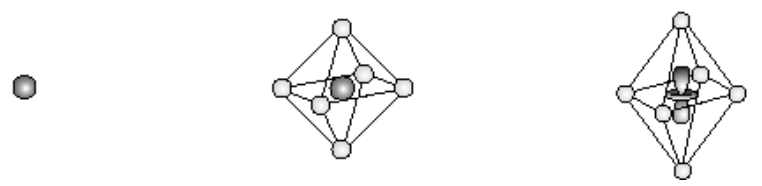

Figura 1.4 - Diagrama de níveis eletrônicos do íon $\mathrm{Mn}^{3+}\left(3 \mathrm{~d}^{4}\right)$ : (a) os níveis são degenerados no caso do íon livre (simetria esférica); (b) íon sujeito a um campo cristalino com simetria octaédrica, levando a uma dupla degenerescência do nível $e_{g}$ e tripla do nível $t_{2 g}$; (c) a degenerescência dos níveis é quebrada pela ação de um campo cristalino de simetria ortorrômbica, devido à distorção do tipo Jahn-Teller.

No caso das manganitas, o íon Mn encontra-se no centro de um octaedro formado pelos íons de oxigênio em seus vértices $\left(\mathrm{MnO}_{6}\right)$, estando, portanto, sob a influência de um campo cristalino de simetria octaédrica. Nessa condição, os níveis desdobram-se em um dubleto (denominado $\mathrm{e}_{\mathrm{g}}$ ) e um tripleto $\left(\mathrm{t}_{2 \mathrm{~g}}\right)$, sendo que o preenchimento desses níveis depende dos efeitos de correlação eletrônica e seguem a regra de Hund. O tripleto $t_{2 g}$ consiste dos orbitais $d_{x y}, d_{y z}$ e $d_{z x}$ e o

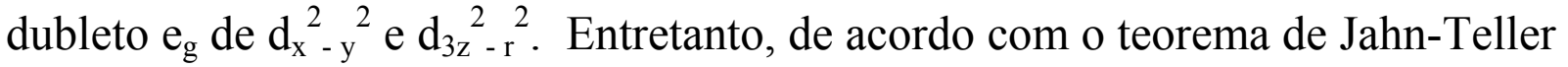
$\mathrm{JT},{ }^{[25]}$ essa configuração de simetria octaédrica ao redor do íon $\mathrm{Mn}^{3+}$ não é estável. A estabilidade é obtida via rotação e distorção interna do octaedro 
formado pelos oxigênios devido às tensões elásticas que ocorrem nesses materiais. A distorção de JT não ocorre independentemente em cada sítio de $\mathrm{Mn}^{3+}$, sendo observado um efeito JT cooperativo. Observa-se pela Fig. 1.4(c) que a distorção do tipo JT do $\mathrm{MnO}_{6}$ resulta na quebra da degenerescência de cada nível, diminuindo a energia total do sistema, gerando assim, uma configuração mais estável.

Nos compostos não dopados, baseados em $\mathrm{Mn}^{3+}$ como o $\mathrm{LaMnO}_{3}$, o sítio do Mn exibe configuração eletrônica $\mathrm{t}_{2 \mathrm{~g}}{ }^{3} \mathrm{e}_{\mathrm{g}}{ }^{1}$ com número de spin total igual a 2 $(\mathrm{S}=2)$. Os elétrons $\mathrm{t}_{2 \mathrm{~g}}{ }^{3}$ são localizados, e o princípio de exclusão de Pauli restringe a um único elétron de cada spin nas regiões de superposição da ligação Mn-O-Mn. Assim, somente o acoplamento antiparalelo de spins é permitido nos extremos das ligações Mn-O-Mn, localizando também os elétrons do nível $\mathrm{e}_{\mathrm{g}}{ }^{1}$. Esse tipo de configuração resulta em uma ordem AF dos momentos magnéticos, acoplamento este chamado de supertroca, leva o material a um comportamento isolante, ou seja, um isolante de Mott. Entretanto, os elétrons e $e_{\mathrm{g}}$ podem ganhar mobilidade e desempenhar papel importante na condutividade elétrica quando buracos são introduzidos nos níveis $\mathrm{e}_{\mathrm{g}}$ do cristal. Os buracos são criados através da substituição parcial do íon de terra-rara por um íon alcalino terroso, como na fórmula citada anteriormente $\mathrm{A}_{1-\mathrm{x}} \mathrm{A}_{\mathrm{x}} \mathrm{MnO}_{3}$. Dessa forma, devido ao balanceamento de carga, promove-se uma mistura de íons $\operatorname{Mn}^{3+}\left(3 \mathrm{~d}^{4}\right)$ e $\mathrm{Mn}^{4+}\left(3 \mathrm{~d}^{3}\right):\left(\mathrm{A}^{3+}{ }_{1-\mathrm{x}} \mathrm{A}^{, 2+}{ }_{\mathrm{x}}\right)\left(\mathrm{Mn}^{3+}{ }_{1-\mathrm{x}} \mathrm{Mn}^{4+}{ }_{\mathrm{x}}\right) \mathrm{O}_{3}$. Com a presença simultânea dos dois íons $\mathrm{Mn}^{3+}$ e $\mathrm{Mn}^{4+}$, ocorre um acoplamento $\mathrm{FM}$ nos extremos da ligação $\mathrm{Mn}^{3+}-\mathrm{O}-\mathrm{Mn}^{4+}$. Esse acoplamento FM entre átomos de valências diferentes pode ocorrer e é chamado de interação de dupla troca (DT), que será comentada brevemente na próxima seção. É essa competição entre supertroca e DT que define a ordem magnética de longo alcance nas manganitas dopadas. Enquanto a 
mobilidade é relacionada aos elétrons $\mathrm{e}_{\mathrm{g}}$, os elétrons $\mathrm{t}_{2 \mathrm{~g}}$ são estabilizados pela ação do campo cristalino e são vistos como sendo localizados pelo forte efeito de correlação, apresentando spin local $(\mathrm{S}=3 / 2)$ mesmo no estado metálico.

\subsubsection{Interação de Dupla Troca}

As propriedades magnéticas das manganitas são governadas pelas interações de troca entre spins dos sítios do Mn. Essas interações são relativamente fortes entre os dois spins de Mn separados por um íon oxigênio e são controlados pela superposição dos orbitais d do Mn e orbitais p do oxigênio. As correspondentes interações de supertroca dependem da configuração orbital que seguem as leis de Goodenough-Kanamori. Geralmente, as interações de $\mathrm{Mn}^{4+}-\mathrm{O}-\mathrm{Mn}^{4+}$ são $\mathrm{AF}$, enquanto que as do tipo $\mathrm{Mn}^{3+}-\mathrm{O}-\mathrm{Mn}^{3+}$ podem ser $\mathrm{AF}$ ou FM. $^{[26]}$

As propriedades eletrônicas e magnéticas dos compostos $\mathrm{A}_{1-\mathrm{x}} \mathrm{A}_{\mathrm{x}}{ }_{\mathrm{XnO}} \mathrm{MnO}_{3}$, no limite de baixas temperaturas têm sido examinadas de acordo com a chamada interação de dupla troca DT. Apesar de muitos autores já concluírem que a interação de DT não seja suficiente para explicar todos os resultados da literatura, essa teoria é a base para o entendimento das propriedades físicas desses materiais. Este tipo de interação considera o acoplamento magnético entre os pares de íons $\mathrm{Mn}^{3+}$ e $\mathrm{Mn}^{4+}$, responsáveis pelo movimento eletrônico entre as duas camadas d parcialmente preenchidas dos íons Mn.

A interação de DT foi explicada, historicamente, de duas formas diferentes. Inicialmente, foi proposto por Zener ${ }^{[6]}$ como um mecanismo que permite a mobilidade de cargas nas manganitas pela geração de um estado de 
spin polarizado. Zener considerou os movimentos dos elétrons escritos esquematicamente ${ }^{[27]}$ por:

$$
\mathrm{Mn}_{1 \uparrow}^{3+} \mathrm{O}_{2 \uparrow, 3 \downarrow} \mathrm{Mn}^{4+} \rightarrow \mathrm{Mn}^{4+} \mathrm{O}_{1 \uparrow, 3 \downarrow} \mathrm{Mn}_{2 \uparrow}^{3+},
$$

onde os índices 1, 2 e 3 são os elétrons pertencentes ao oxigênio localizado entre os íons Mn e ao nível $\mathrm{e}_{\mathrm{g}}$ do íon Mn. Observa-se que neste processo, ilustrado na Fig. 1.5, a transferência dos elétrons 1 e 2 para o sítio do oxigênio e para o Mn à direita, respectivamente, ocorre de forma simultânea (portanto a denominação de interação de dupla-troca). A delocalização dos elétrons do sítio de $\mathrm{Mn}^{4+}$ se deve à degenerescência das configurações $\mathrm{Mn}^{3+}-\mathrm{O}-\mathrm{Mn}^{4+}$ e $\mathrm{Mn}^{4+}-\mathrm{O}-\mathrm{Mn}^{3+}$.

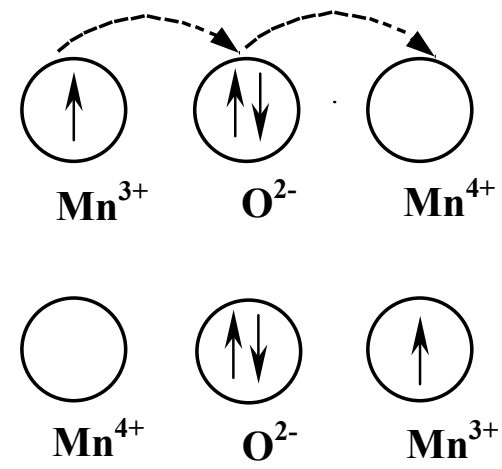

Figura 1.5 - Esquema da interação de dupla-troca elaborado por Zener.

Outra maneira de visualizar o mecanismo de DT foi apresentado por Anderson e Hasegawa, ${ }^{[7]}$ onde os dois estados descritos na Eq. 1.2 são intermediados pelo estado $\mathrm{Mn}_{1 \uparrow}^{3+} \mathrm{O}_{3 \downarrow} M n_{2 \uparrow}^{3+}$, envolvendo um processo de segunda ordem. Nesse contexto, os elétrons $e_{g}$ de condução são tratados quanticamente, enquanto os elétrons $t_{2 g}$ são localizados e considerados classicamente. Considerando $\theta$ o ângulo formado entre os spins $t_{2 g}$ dos íons vizinhos (Fig. 1.6(e)), os autores determinaram que a probabilidade do elétron $\mathrm{e}_{\mathrm{g}}$ ser 
transferido (b) de $\mathrm{Mn}^{3+}$ para o $\mathrm{Mn}^{4+}$ vizinho é $\mathrm{b}_{0} \cos (\theta / 2)$, no caso de forte acoplamento Hund. O processo de transferência resulta na quebra da degenerescência das configurações $\mathrm{Mn}^{3+}-\mathrm{O}-\mathrm{Mn}^{4+}$ e $\mathrm{Mn}^{4+}-\mathrm{O}-\mathrm{Mn}^{3+}$ levando-os a dois níveis de energia $E_{b=0} \pm b_{0} \cos (\theta / 2)$. A energia adquirida com a configuração de spins paralelos, $\theta=0$, que maximiza (b), em relação ao antiparalelo, $\theta=\pi$, revela o caráter FM da interação DT. Observa-se que a dependência angular no mecanismo de DT é $\cos (\theta / 2)$, diferente da interação de supertroca usual que é proporcional a $\cos (\theta)$. Essa diferença na dependência angular, em conjunto com a competição entre FM de DT com AF de supertroca, resulta no complexo diagrama de fases magnéticas dessas manganitas como função, por exemplo, do nível de dopagem x (ver Fig. 1.2). A versão estritamente quântica desse processo foi descrita por Kubo e Ohata em 1972. ${ }^{[5]}$

A Fig. 1.6 mostra esquematicamente como a teoria da DT resulta no aparecimento do estado FM metálico e no efeito de magnetorresistência próximo da temperatura de Curie $\mathrm{T}_{\mathrm{C}}$ nos compostos dopados. $\mathrm{O}$ ordenamento AF é realizado no composto não dopado $\mathrm{LaMnO}_{3}$ (Fig. 1.6(a)), enquanto que o ordenamento FM ocorre em baixas $\mathrm{T}\left(\mathrm{T}<<\mathrm{T}_{\mathrm{C}}\right)$ nos compostos dopados com buracos $\mathrm{La}_{1-\mathrm{x}} \mathrm{Sr}_{\mathrm{x}} \mathrm{MnO}_{3}$ (Fig. 1.6(b)). Nas manganitas dopadas (criação de buracos), o elétron e g $_{\mathrm{g}}$ pode mover-se dependendo da configuração de spins, uma vez que, se os spins do Mn não estiverem alinhados, a probabilidade de transferência do portador diminui consideravelmente (Fig. 1.6(f)). Em baixas T ( $\mathrm{T}<<\mathrm{T}_{\mathrm{C}}$ ), o alinhamento espontâneo dos spins dos Mn delocaliza os elétrons $\mathrm{e}_{\mathrm{g}}$, resultando na baixa resistividade elétrica na fase FM (Fig. 1.6(b)). Se a temperatura do composto está próxima ou acima de $\mathrm{T}_{\mathrm{C}}$, a configuração de spin estará dinamicamente desordenada e, portanto, a amplitude de transferência de carga é reduzida, como mostra a Fig. 1.6(c). Isso leva a um conseqüente 
aumento da resistividade elétrica próximo e acima de $\mathrm{T}_{\mathrm{C}}$. $\mathrm{O}$ alinhamento dos spins pode ser induzido pela aplicação de um campo magnético externo $\mathrm{H}$ no caso de $\mathrm{T} \geq \mathrm{T}_{\mathrm{C}}$ (Fig. 1.6(d)) ou reforçado no caso $\mathrm{T} \leq \mathrm{T}_{\mathrm{C}}$. Assim, uma grande MR nas vizinhanças de $T_{C}$ é esperada, pois os spins locais são relativamente fáceis de serem alinhados via aplicação de um campo magnético externo e a transferência de elétrons e $e_{\mathrm{g}}$ não é esperada ocorrer ocasionalmente.

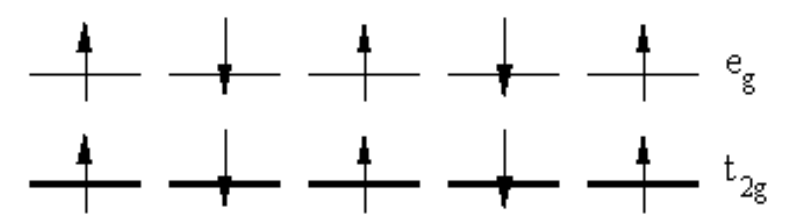

(a) $\mathrm{LaMnO}_{3}$

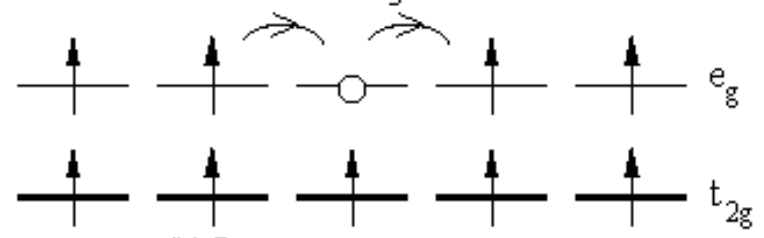

(b) $\mathrm{La}_{1-\mathrm{x}} \mathrm{Sr}_{\mathrm{x}} \mathrm{MnO}_{3}\left(\mathrm{~T}<<\mathrm{T}_{\mathrm{C}}\right)$
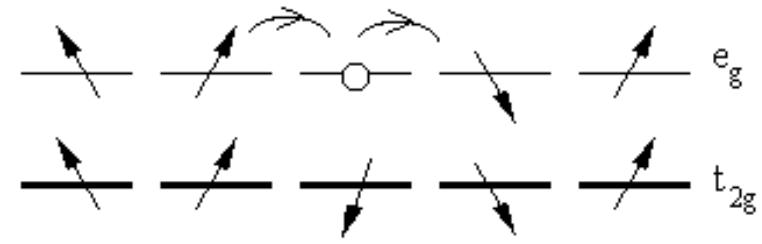

(c) $\mathrm{La}_{1-\mathrm{x}} \mathrm{Sr}_{\mathrm{x}} \mathrm{MnO}_{3}\left(\mathrm{~T} \approx \mathrm{T}_{\mathrm{C}}\right)$

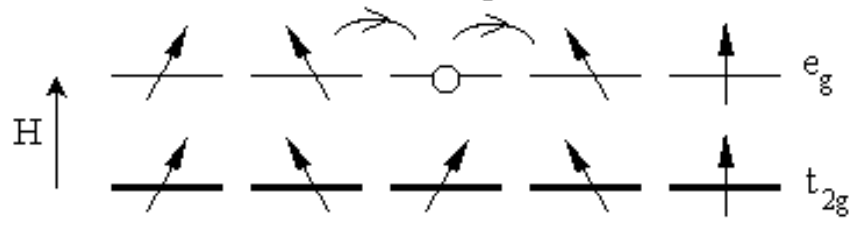

(d) $\mathrm{La}_{1-\mathrm{x}} \mathrm{Sr}_{\mathrm{x}} \mathrm{MnO}_{3}\left(\mathrm{~T} \approx \mathrm{T}_{\mathrm{C}}\right)$ $\mathrm{b}=\mathrm{b}_{0} \cos (\theta / 2)$
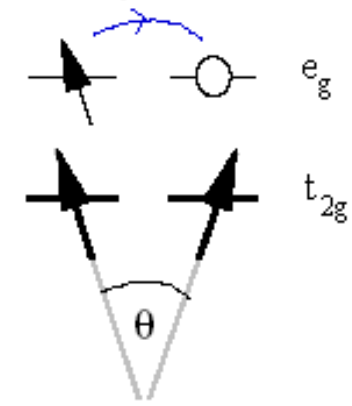

(e)
Ferromag. Paramag.

$$
\mathrm{b}=\mathrm{b}_{0}
$$

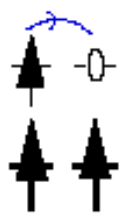

(f) $\mathrm{b} \sim 0.707 \mathrm{~b}_{0}$

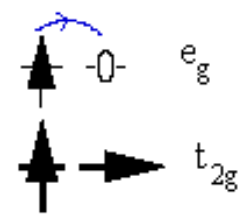

Figura 1.6 - Esquema da interação de dupla troca. (a) Composto não dopado $\mathrm{LaMnO}_{3}$ com ordenamento AF. (b) Ordenamento paralelo dos spins em baixas temperaturas, resultado na interação forte de dupla-troca. (c) Configuração aleatória em $\mathrm{T} \sim \mathrm{T}_{\mathrm{C}}$, resultando em interação fraca de dupla troca. (d) A aplicação de um campo magnético externo favorece o alinhamento dos spins, fortalecendo a interação de dupla-troca em relação ao caso (c). (e, f) Ilustração do conceito de DT - a amplitude de transferência dos elétrons $e_{\mathrm{g}}$ como função do alinhamento dos spins. 


\subsubsection{Magnetorresistência Colossal}

Magnetorresistência MR é a variação na resistência elétrica $\mathrm{R}$ induzida pela aplicação de um campo magnético externo. Este fenômeno é observado, basicamente, em metais e semicondutores. Na literatura, a definição de MR pode ser encontrada de duas formas:

a) Em relação ao campo aplicado:

$$
M R=\frac{R(H=0)-R(H)}{R(H)}
$$

b) Em relação ao campo zero:

$$
M R=\frac{R(H=0)-R(H)}{R(H=0)}
$$

onde H é o campo magnético externo aplicado.

A definição de MR através da Eq. 1.3, geralmente chamada de magnetorresistividade negativa, é utilizada quando ocorre o efeito de MR "colossal" (MRC), ou seja, uma grande variação em R com a aplicação de um campo magnético externo, alcançando valores de várias ordens de magnitude. A MR definida através da Eq. 1.4 alcança valores menores do que $100 \%$. As discussões acerca de MR, neste trabalho são feitas considerando-se a primeira definição, a Eq. 1.3. A propriedade de MRC das manganitas ainda não está completamente entendida. Inicialmente foi proposto que o efeito seria devido ao mecanismo da DT, discutido na seção anterior. Entretanto, esse mecanismo não é suficiente para explicar todos os resultados da literatura. Ainda mais, diversos 
trabalhos desenvolvidos nas manganitas revelaram outras características importantes nas propriedades físicas das manganitas, como a competição entre o estado FM (de DT) e outras instabilidades associadas ao acoplamento elétronrede. ${ }^{[13,29-31]}$ Nesse contexto, Uehara et al. ${ }^{[31]}$ sugeriram que uma instabilidade relevante é a coexistência, em larga escala, da fase de ordenamento de carga OC com a fase FM metálica.

\subsubsection{Efeitos de volume}

As propriedades físicas das manganitas são fortemente influenciadas por uma pressão interna, gerada pela substituição do cátion $\mathrm{A}\left(\mathrm{A}_{1-\mathrm{x}} \mathrm{A}_{\mathrm{x}}{ }_{\mathrm{M}} \mathrm{MnO}_{3}\right)$ por íons de diferentes raios iônicos. ${ }^{[32,33]} \mathrm{O}$ principal efeito da variação do raio iônico médio $<\mathrm{r}_{\mathrm{A}}>$ é o de promover a variação do ângulo de ligação Mn-O-Mn, resultando em um aumento da distorção da estrutura cristalina. De acordo com o discutido na seção 1.2.1, esse ângulo de ligação é esperado ser de $180^{\circ}$ para uma cela cúbica ideal, sendo que a redução $<\mathrm{r}_{\mathrm{A}}>$ e conseqüentemente do fator de tolerância $t$, causa, de forma não sistemática, uma contração na distância de ligação Mn-O-Mn, aumentando a tendência de localização dos portadores de carga. Este efeito resulta em um estreitamento da largura de banda, reduzindo a mobilidade dos elétrons de condução do cristal (transferência ou "hopping" entre os íons de Mn). Este resultado está de acordo com o decréscimo sistemático de $\mathrm{T}_{\mathrm{C}}$, para um decréscimo de $\left\langle\mathrm{r}_{\mathrm{A}}\right\rangle$, resultado observado nesses compostos. ${ }^{[32,34]}$ Entretanto, esses efeitos não são suficientes para uma explicação satisfatória da dependência da magnetorresistência com $\mathrm{T}_{\mathrm{C}}$.

Outro parâmetro relevante e que determina as propriedades físicas das manganitas é a desordem introduzida pelas substituições químicas no sítio A, definida como $\sigma^{2}=\left\langle\mathrm{r}_{\mathrm{A}}^{2}\right\rangle-\left\langle\mathrm{r}_{\mathrm{A}}\right\rangle^{2}$. Os trabalhos de Rodríguez-Martinez e 
Attfield $^{[35]}$ indicaram que $T_{C}$ pode ser reduzido apreciavelmente se $\sigma^{2}$ é modificado mantendo-se $\left\langle\mathrm{r}_{\mathrm{A}}\right\rangle$ constante. Além disso, efeitos de máxima MR também são observados em materiais com valor pequeno de $\sigma^{2}$ e não apenas com baixo valor de $<\mathrm{r}_{\mathrm{A}}>$. Um exemplo é o sistema $\operatorname{Pr}_{1-\mathrm{x}} \mathrm{Ca}_{\mathrm{x}} \mathrm{MnO}_{3}$, no qual os raios iônicos do $\operatorname{Pr}^{3+}$ e do $\mathrm{Ca}^{2+}$ são similares. Essa desordem é um parâmetro muito importante no cenário da separação de fase, descrito na seção 1.2.7.

\subsubsection{Ordenamento de carga e orbital}

As manganitas dopadas exibem uma grande variedade de estados ordenados, como ferromagnéticos FM, de ordenamento de carga OC, incluindo antiferromagnéticos $\mathrm{AF}$ e ordenamento orbital $\mathrm{OO}$, como pode ser visto no diagrama de fases da Fig. 1.2. Nos compostos com proporções adequadas de pares de íons $\mathrm{Mn}^{3+}$ e $\mathrm{Mn}^{4+}(1 / 8,1 / 2$ ou 3/4) os efeitos de ordenamento de carga OC e ordenamento orbital OO são particularmente pronunciados.

A distorção do tipo JT cooperativo do $\mathrm{MnO}_{6}$ (seção 1.2.2), que resulta na estabilização eletrônica do orbital $\mathrm{e}_{\mathrm{g}}$ ocupado, é conhecido mais genericamente como ordenamento orbital. ${ }^{[36]} \mathrm{O}$ ordenamento orbital, em adição ao ordenamento de carga, tem um papel importante na determinação das propriedades físicas do estado fundamental nas manganitas com mistura de valências. A manganita não dopada $\mathrm{LaMnO}_{3}$ é um AF-isolante no seu estado fundamental. Esta apresenta configuração eletrônica $\mathrm{t}_{2 \mathrm{~g}} \mathrm{e}_{\mathrm{g}}{ }_{\mathrm{g}}$, portanto, todos os sítios de Mn apresentam efeito JT cooperativo que podem resultar no ordenamento orbital. O ordenamento orbital nesse composto foi estudado por Murakami et al. ${ }^{[37]}$ Esses estudos indicaram que o parâmetro de ordem do OO decresce acima da temperatura de ordenamento antiferromagnético $\mathrm{T}_{\mathrm{N}} \sim 140 \mathrm{~K} \mathrm{e}$ 
não é mais observado acima de $\sim 780 \mathrm{~K}$, concomitante com a transição de fase estrutural. Uma configuração do OO pode ser vista na Fig. 1.7, juntamente com as configurações para as manganitas dopadas com $x=1 / 2$ e $2 / 3$. Com a introdução de íons dopantes nesse composto, é esperado que o estado de OO seja desestabilizado gradualmente devido à interação fraca desse ordenamento ou ao surgimento de outras interações. ${ }^{[36]}$ Entretanto, a tendência de localização de carga/orbital persiste e pode ser vista nos diagramas de fases das manganitas dopadas (veja Fig. 1.2, por exemplo). As manganitas com $50 \%$ de dopagem, como $\mathrm{A}_{0.5} \mathrm{~A}_{0.5}^{\prime} \mathrm{MnO}_{3}$, têm forte tendência a apresentar o estado de OC que coincide com o ordenamento magnético e OO. É importante destacar que algumas manganitas com outras composições também podem apresentar ordenamento de carga e/ou orbital, dependendo do raio iônico do sítio A. Um exemplo é o composto $\operatorname{Pr}_{0.7} \mathrm{Ca}_{0.3} \mathrm{MnO}_{3}$. Portanto, esse fenômeno não é exclusividade das manganitas com 50\% de dopagem.

As manganitas $\mathrm{A}_{0.5} \mathrm{~A}_{0.5}^{\prime} \mathrm{MnO}_{3}$ com $50 \%$ de dopagem são particularmente interessantes para abordar o tópico desta seção porque elas possuem o mesmo número de íons $\mathrm{Mn}^{3+}$ e $\mathrm{Mn}^{4+}$. Assim, a rede cristalina é composta pelo mesmo número de íons com efeito JT ativo $\left(\mathrm{Mn}^{3+}\right)$ e íons sem efeito JT $\left(\mathrm{Mn}^{4+}\right)$. Magneticamente, esses sistemas formam uma cadeia "ziguezague" alternada de ordenamento FM, mas o resultado geral é um acoplamento AF, como pode ser visto na Fig. 1.8, também denominada de fase magnética do tipo $\mathrm{CE}$, descrito por Wollan e Koehler. ${ }^{[38]}$ Adicionalmente, o estado fundamental é um isolante com ordenamento de carga e orbital. Esse comportamento é observado experimentalmente para várias composições como $\mathrm{Nd}_{0.5} \mathrm{Sr}_{0.5} \mathrm{MnO}_{3},{ }^{[39]}$ $\mathrm{Pr}_{0.5} \mathrm{Sr}_{0.5} \mathrm{MnO}_{3},{ }^{[40]} \mathrm{Pr}_{0.5} \mathrm{Ca}_{0.5} \mathrm{MnO}_{3}{ }^{[41,42]}$ e outros. 


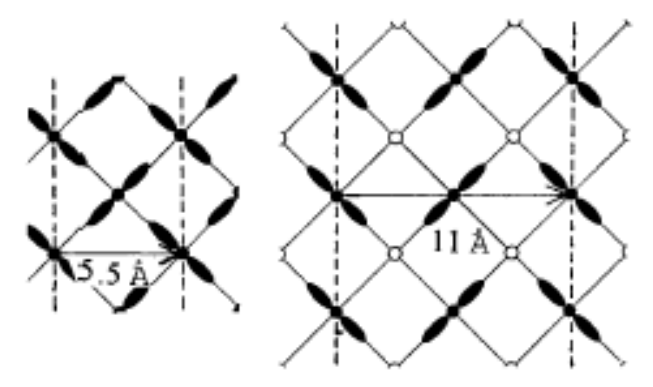

(a) $\mathrm{x}=0$

(b) $x=1 / 2$

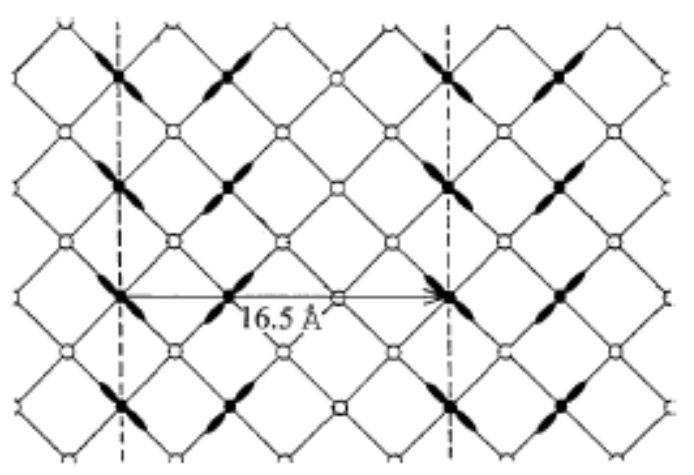

(c)

$x=2 / 3$

Figura 1.7 - Configurações de ordenamento de carga e orbital para $\mathrm{La}_{1-\mathrm{x}} \mathrm{Ca}_{\mathrm{x}} \mathrm{MnO}_{3}$ com: (a) $\mathrm{x}=0$; (b) $\mathrm{x}=1 / 2 \mathrm{e}$ (c) $\mathrm{x}=2 / 3$. Os círculos abertos são os íons $\mathrm{Mn}^{4+}$ e os fechados os íons $\mathrm{Mn}^{3+}$ com ordenamento orbital dos elétrons $\mathrm{e}_{\mathrm{g}}$.

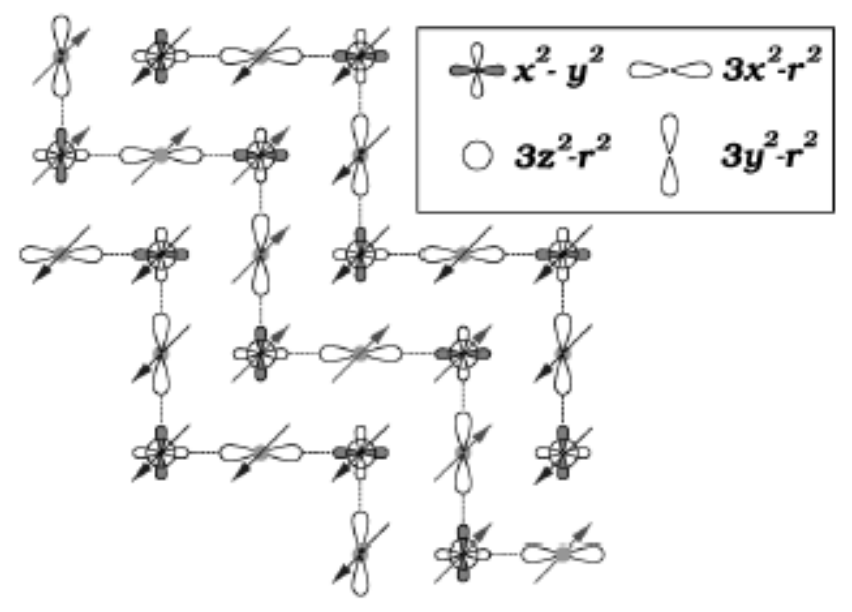

Figura 1.8 - Vista esquemática do plano xy da fase magnética do tipo CE. ${ }^{[43]}$

O OC ocorre como conseqüência da repulsão Coulombiana entre os portadores em $\mathrm{d}_{\mathrm{z}}^{2}$, ou seja, o ordenamento entre um elétron $\mathrm{e}_{\mathrm{g}}$ e um buraco nas sub-redes do $\mathrm{Mn}^{3+} \mathrm{e} \mathrm{Mn}^{4+}$, respectivamente. A primeira evidência para o OC foi mostrado por Chen e Cheong ${ }^{[44]}$ no composto $\mathrm{La}_{0.5} \mathrm{Ca}_{0.5} \mathrm{MnO}_{3}$. As imagens obtidas por Microscopia Eletrônica em baixas temperaturas consistiam de picos alternados de $\mathrm{Mn}^{3+}$ e $\mathrm{Mn}^{4+}$, em concordância com a forte repulsão Coulombiana. O ordenamento magnético observado foi $\mathrm{AF}$ do tipo $\mathrm{CE} .^{[38]}$ 

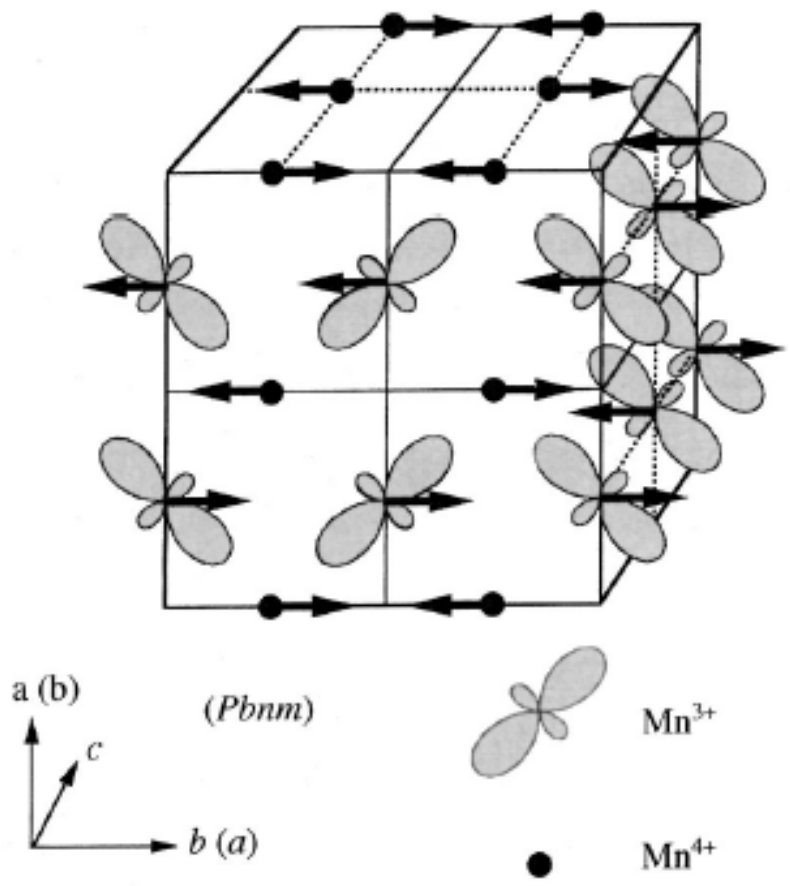

Figura 1.9 - Ordenamento orbital, de carga e de spin do tipo CE (antiferromagnético), muito comum em manganitas com $\mathrm{x} \approx 1 / 2$. Pode-se ver também o ordenamento orbital $\mathrm{e}_{\mathrm{g}}$ dos sítios de $\mathrm{Mn}^{3+}$ e os sítios do $\mathrm{Mn}^{4+}$ que são indicados por círculos fechados. ${ }^{[18]}$

Um esquema do complexo ordenamento orbital, de carga e de spin está mostrado na Fig. 1.9 e foi descrito por Tokura e Tomioka. ${ }^{[18]}$ Observa-se que os spin são ordenados AF enquanto os ordenamentos de carga e orbital ocorrem em planos b e c alternados. Entretanto, essas estruturas de ordenamento sugerem explicações mais complexas do que a simples repulsão Coulombiana. Simulações com método Monte Carlo realizado por Hotta et al. ${ }^{[45]}$ revelaram uma estreita relação entre as várias fases considerando regra de Hund, interação JT e acoplamentos de Heisenberg $\mathrm{J}_{\mathrm{AF}}$. Para um exemplo, considere os diagramas da Fig. 1.2. Para a mesma concentração de $\mathrm{Ca} \sim 0.4$, o estado AF é estável em baixas temperaturas para o composto $\operatorname{Pr}_{1-\mathrm{x}} \mathrm{Ca}_{\mathrm{x}} \mathrm{MnO}_{3}$, mas para o composto $\mathrm{La}_{1-\mathrm{x}} \mathrm{Ca}_{\mathrm{x}} \mathrm{MnO}_{3}$ o estado estável é o FM.

A substituição de La por Pr resulta no estreitamento da largura de banda e desestabiliza o estado ferromagnético. Quando a largura de banda eletrônica é 
comparável à interação Coulombiana, os elétrons móveis tendem a se localizar sobre os íons de Mn que formam uma rede regular. ${ }^{[12,19,46,47]}$ Portanto, a série $\mathrm{Pr}_{1-\mathrm{x}} \mathrm{Ca}_{\mathrm{x}} \mathrm{MnO}_{3}$ exibe ordenamento de carga em temperaturas relativamente altas e em uma larga faixa de dopagem $0.3<\mathrm{x}<0.85$, como mostra o diagrama de fases desse composto na Fig. 1.2.

O estado de ordenamento de carga é caracterizado por um estado isolante, ou seja, há um aumento na resistividade elétrica com o decréscimo da temperatura. Sob a aplicação de um campo magnético, a probabilidade do elétron $\mathrm{e}_{\mathrm{g}}$ ser transferido (b) de $\mathrm{Mn}^{3+}$ para o $\mathrm{Mn}^{4+}$ vizinho aumenta (descrito na seção 1.2.3), resultando em um estado ferromagnético-metálico em campos magnéticos suficientemente fortes. Conseqüentemente, a energia cinética dos portadores de carga supera a interação Coulombiana entre os íons $\mathrm{Mn}^{3+} \mathrm{e} \mathrm{Mn}^{4+}$, que favorecia o estado isolante. Portanto, sob a aplicação de um campo magnético, a fase isolante torna-se metálica, onde a rede de cargas ordenadas é "destruída" (ou "melted") pelo campo magnético. Na literatura o efeito do campo magnético sobre o estado de ordenamento de carga é referido como "melting" da fase OC. Esse efeito resulta na magnetorresistência colossal MRC nas manganitas, pois, com a transformação da fase OC em FMM ocorre um grande decréscimo na resistividade elétrica. Esse é o principal cenário da MRC nas manganitas $\operatorname{Pr}_{1-\mathrm{x}} \mathrm{Ca}_{\mathrm{x}} \mathrm{MnO}_{3}$.

\subsubsection{Separação de fase}

Separação de fases SF significa a coexistência de regiões com mesma densidade de carga, mas com diferentes características, sendo que uma delas é, por exemplo, ferromagnética-metálica e a outra paramagnética-isolante. Aparentemente, a SF parece ser uma característica geral de sistemas fortemente 
correlacionados como é o caso das manganitas $\mathrm{A}_{1-\mathrm{x}} \mathrm{A}_{\mathrm{x}}{ }^{\prime} \mathrm{MnO}_{3}$. A SF como um fator importante no efeito de MRC foi sugerido pioneiramente por Gor'kov em 1998. ${ }^{[48] ~ A ~ S F ~ j a ́ ~ f o i ~ o b s e r v a d a ~ e m ~ v a ́ r i a s ~ s i t u a c ̧ o ̃ e s ~ e x p e r i m e n t a i s ~ e ~ o b t i d a ~}$ teoricamente em compostos com baixa dopagem e com $\mathrm{x} \sim 0.5$. $^{[20,49,50]}$

Estudos teóricos em manganitas (simulações computacionais) revelaram que a separação de fase SF pode ocorrer em uma certa faixa de dopagem de portadores. ${ }^{[51]}$ No caso de manganitas com baixa dopagem, em baixas T, ocorre a separação de fase entre regiões $\mathrm{AF}$ pobres em buracos e regiões FM ricas em buracos, estas últimas sendo energicamente mais favoráveis do que a fase AF "canted" homogênea. A energia dos portadores de carga é minimizada com o ordenamento FM, mas se a densidade não for suficiente para estabilizar este ordenamento, os portadores concentram-se em ilhas ou tiras ("stripes") FM imersas em uma matriz AF isolante. Com o aumento do nível de dopagem, as regiões FM conectam-se entre si e a resistência elétrica do sistema decresce significativamente para concentrações da fase FM acima do limite de percolação.

Quando a transição apresenta características de uma transição de fase de primeira ordem, a separação de fases ocorre em regiões com dimensões micrométricas, já observadas por microscopia eletrônica. ${ }^{[31]}$ Imagens de regiões condutoras e isolantes também foram capturadas por microscopia de tunelamento por Tath et al. ${ }^{[52]}$ Esse estudo indicou a coexistência de regiões isolantes e condutoras com dimensões da ordem de $100 \mathrm{~nm}$. O aumento de regiões metálicas com a aplicação de campo magnético também foi monitorado na região de $\mathrm{T}$ próxima à transição metal-isolante. Adicionalmente, foi mostrado que essas fases possuem a mesma densidade eletrônica. Os estudos realizados por Moreo et al. ${ }^{[53]}$ sugerem que esses grandes "clusters" observados experimentalmente tenham sido originados por desordem. Essa desordem é 
baseada na influência de diferentes raios iônicos de vários elementos que compõem as manganitas, discutida na seção 1.2.5. Dependendo dos íons que compõem o sítio A, a ligação Mn-O-Mn pode ter ângulo igual a $180^{\circ}$ ou pode ser distorcida para ângulos menores do que esse valor. A representação esquemática dessa idéia é mostrada na Fig. 1.10.

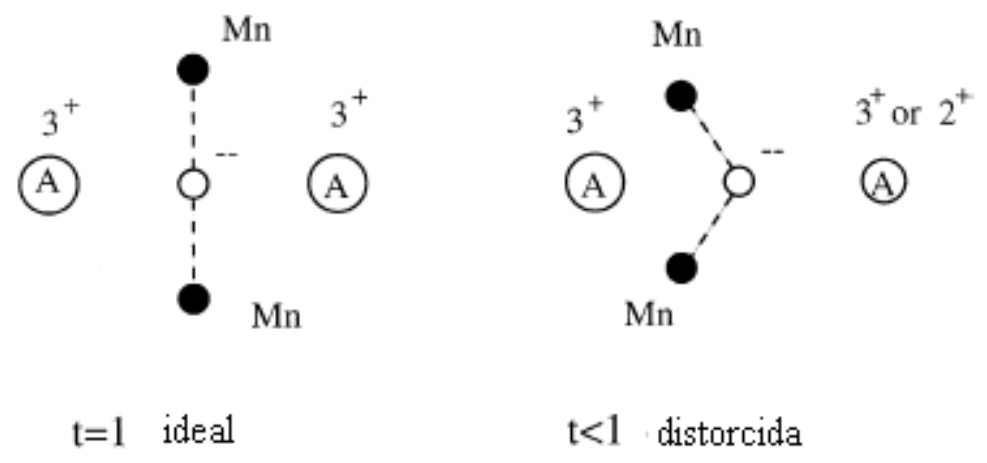

Figura 1.10 - Esquema da influência do tamanho dos íons do sítio A na amplitude de "hopping”entre dois íon de Mn.

A distribuição aleatória dos íons do sítio A na amostra resulta em uma concomitante distribuição aleatória de "hopping" dos portadores entre sítios e dos acoplamentos de Heisenberg $\mathrm{J}_{\mathrm{AF}}$ entre os spins localizados $\mathrm{t}_{2 \mathrm{~g}}$, também influenciados pelo ângulo de ligação Mn-O-Mn. Os resultados de cálculos numéricos e simulações de Monte Carlo realizados por Moreo et al. ${ }^{[53]}$ indicaram que a transição de fase é continua, com "clusters" FM e AF coexistindo em uma região de transição FM-AF. As dimensões dos "clusters" são influenciadas pelo comprimento de desordem, no qual uma pequena desordem resulta em grandes "clusters". 


\subsection{Objetivos do trabalho}

Este trabalho tem como objetivo primário estudar as propriedades físicas das manganitas, especialmente a coexistência de fases, através de medidas de transporte eletrônico e magnetização. Para isso foram produzidas séries dos compostos $\mathrm{La}_{5 / 8 \mathrm{y}} \mathrm{Pr}_{\mathrm{y}} \mathrm{Ca}_{3 / 8} \mathrm{MnO}_{3}$, com $0 \leq \mathrm{y} \leq 0.625$; que foram sinterizados a diversas temperaturas $\left(1250,1300,1350\right.$ e $\left.1400{ }^{\circ} \mathrm{C}\right)$. A concentração de Ca foi fixada em $\mathrm{x}=3 / 8$, pois esse nível de dopagem otimiza $\mathrm{T}_{\mathrm{C}}$ nas manganitas $\mathrm{La}_{1-\mathrm{x}} \mathrm{Ca}_{\mathrm{x}} \mathrm{MnO}_{3} \cdot{ }^{[54]}$ Com a substituição do La pelo Pr, cujo raio iônico é $~ 3 \%$ menor, foi possível observar características interessantes induzidas pela pressão química. Ainda, a coexistência de fases ferromagnética-metálica FMM e de ordenamento de carga-isolante OCI foi observada influenciar de forma marcante as propriedades físicas macroscópicas desses materiais, como o transporte eletrônico, a magnetização e a magnetorresistência. 


\subsection{Referências}

1 G. H. Jonker and J. H. van Santen, Physica 16, 337 (1950).

2 J. B. Elemans, B. Van Laar, K. R. Van Der Veen, and B. O. Loopstra, J. Solid State Chem. 3, 238 (1971).

3 P. Norby, I. G. K. Andersen, E. K. Andersen, and N. H. Andersen, J. Solid State Chem. 119, 191 (1995).

4 C. W. Searle and S. T. Wang, Can. J. Phys. 47, 2023 (1969).

$5 \quad$ K. Kubo and N. Ohata, J. Phys. Soc. Jpn. 33, 21 (1972).

6 C. Zener, Phys. Rev. 82, 403 (1951).

7 P. W. Anderson and H. Hasegawa, Phys. Rev. 100, 67 (1955).

$8 \quad$ P. -G. de Gennes, Phys. Rev. 118, 141 (1960).

9 J. M. De Teresa, M. R. Ibarra, J. Blasco, J. García, C. Marquina, and P. A. Algarabel, Phys. Rev. B 54, 1187 (1996).

10 S. Jin, T. H. Tiefel, M. Mccormack, R. A. Fastnacht, R. Ramesh, and L. H. Chen, Science 264, 413 (1994).

11 C. Martin, A. Maignan, M. Hervieu, and B. Raveau, Phys. Rev. B 60, 12191 (1999).

12 P. Schiffer, A. P. Ramirez, W. Bao, and S. W. Cheong, Phys. Rev. Lett. 75, 3336 (1995).

13 A. J. Millis, P. B. Littlewood, and B. I. Shraiman, Phys. Rev. Lett. 74, 5144 (1995).

14 A. Moreo, S. Yunoki, and E. Dagotto, Science 283, 2034 (1999).

15 A. P. Ramirez, Phys. Condens. Matter 9, 8171 (1999).

16 C. N. R. Rao and A. K. Raychandhuri, Colossal Magnetoresistance, Charge Ordering an Related Properties of Manganese Oxides (ed. C. N. R. Rao and B. Raveau), Singapore: World Scientific (1998). 
17 J. M. D. Coey, M. Viret, and S. von Molnar, Adv. Phys. 48, 167 (1999).

18 Y. Tokura and Y. Tomioka, J. Magn. Magn. Mater. 200, 1 (1999).

19 C. N. R. Rao, A. Arulraj, A. K. Cheetham, and B. Raveau, J. Phys.: Condens. Matter 12, 83 (2000).

20 E. Dagotto, H. Takashi, and A. Moreo, Phys. Reports 344, 1 (2001).

21 S. Francis, Structure, Properties and Preparation of Perovskite-Type Compounds, Galasso, Pergamon Press (1969).

22 R. M. Hazen, Scientific American 258, 52 (1988).

23 V. M. Goldschmidt, Geoch. Vert. Der Elem., VII (1926).

24 R. D. Shannon, Acta Crystallog. Sect. A. 32, 751 (1976).

25 H. A. Jahn and E. Teller, Proc. Roy. Soc. London A 161, 220 (1937).

26 J. B. Goodenough, Phys. Rev. 100, 564 (1955).

27 M. Cieplak, Phys. Rev. B 18, 3470 (1978).

28 J. S. Zhou and J. B. Goodenough, Phys. Rev. Lett. 80, 4012 (1998).

29 V. Laukhin, J. Fontcuberta, J. L. García-Muñoz, and X. Obradors, Phys. Rev. B 56, 10009 (1997).

30 A. J. Millis, B. I. Shraiman, and R. Mueller, Phys. Rev. Lett. 77, 175 (1996).

31 M Uehara, S. Mori, C. H. Chen, and S. W. Cheong, Nature 399, 560 (1999).

32 H. Y. Hwang, S. W. Cheong, N. P. Ong, and B. Batlogg, Phys. Rev. Lett. 77, 2041 (1996).

33 A. Asamitsu, Y. Moritomo, Y. Tomioka, T. Arima, and Y. Tokura, Nature 373, 407 (1995).

34 J. Fontcuberta, B. Martinez, A. Seffar, S. Piñol, J. L. García-Muñoz, and X. Obradors, Phys Rev. Lett. 76, 1122 (1996). 
35 L. M. Rodríguez-Martinez and J. P. Attfield, Phys. Rev. B 54, 15622 (1996).

36 J. F. Mitchell, D. N. Argyriou, and J. D. Jorgensen, in Colossal Magnetoresistive Oxides (ed. Y. Tokura), Ch 6, Gordon and Breach Science Publishers (2000).

37 Y. Murakami, J. Hill, D. Gibbs, M. Blume, I. Koyama, M. Tanaka, H. Kawata, T. Arima, Y. Tokura, K. Hirota, and Y. Endoh, Phys. Rev. Lett. 81, 582 (1998).

38 E. Wollan and K. Koehler, Phys. Rev. 100, 545 (1955).

39 H. Kawano, R. Kajimoto, H. Yoshizawa, Y. Tomioka, H. Kuwahara, and Y. Tokura, Phys. Rev. Lett. 78, 4253 (1997).

40 Y. Tomioka, A. Asamitsu, Y. Moritomo, H. Kuwahara, and Y. Tokura, Phys. Rev. Lett. 74, 5108 (1995).

41 Z. Jirák, S. Krupička, Z. Šimša, M. Dlouhá, and S. Vratislav, J. Magn. Magn. Mater. 53, 153 (1985);

42 Y. Tomioka, Y. Tokura, A. Asamitsu, H. Kuwahara, and Y. Moritomo Phys. Rev. B 53, 1689 (1996).

43 J. van den Brink and G. Khaliullin, Phys. Rev. Lett. 83, 5118 (1999).

44 C. H. Chen and S. W. Cheong, Phys. Rev. B 76, 4042 (1996).

45 T. Hotta, S. Yunoki, M. Mayr, and E. Dagotto, Phys. Rev. B 60, 15009 (1999).

46 H. Kuwahara, Y. Tomioka, A. Asamitsu, Y. Morimoto, and Y. Tokura, Science 270, 961 (1995).

47 Y. Tokura, Y. Tomioka, H. Kuwahara, A. Asamitsu, Y. Morimoto, and M. Kasai, J. Appl. Phys. 79, 5288 (1996).

48 L. P. Gor'kov, Sov. Phys. Usp. 41, 589 (1998).

49 E. L. Nagaev, Phys. Usp. 39, 781 (1996). 
50 D. I. Khomskii, Physica B 280, 325 (2000).

51 S. Yunoki, J. Hu, A. L. Malvezzi, A. Moreo, N. Furukawa, and E. Dagotto, Phys. Rev. Lett. 80, 845 (1998).

52 M. Tath, S. Reisem, A. A. Menovsky, Y. Tomioka, J. Aarts, and J. A. Mydosh, Science 285, 1540 (1999).

53 A. Moreo, M. Mayr, A. Geiguin, S. Yunoki, and E. Dagotto, Phys. Rev. Lett. 84, 5568 (2000).

54 S. W. Cheong and H. Y. Hwang, in Colossal Magnetoresistive Oxides (ed. Y. Tokura), Ch 7, Gordon and Breach Science Publishers (2000). 


\section{Capítulo 2}

\section{Descrição Experimental}

\subsection{Preparação das amostras}

Amostras policristalinas de $\mathrm{La}_{5 / 8-\mathrm{y}} \mathrm{Pr}_{\mathrm{y}} \mathrm{Ca}_{3 / 8} \mathrm{MnO}_{3} ; \mathrm{y}=0,0.10,0.20,0.25$, $0.30,0.35,0.40$ e 0.625 ; foram produzidas por mistura de óxidos a partir de $\mathrm{La}_{2} \mathrm{O}_{3}(99.999 \%), \mathrm{Pr}_{6} \mathrm{O}_{11}(99.9 \%), \mathrm{CaO}(99.9 \%)$ e $\mathrm{MnO}(99 \%)$. Os óxidos foram cuidadosamente pesados em uma balança com precisão de décimos de miligrama e misturados em um almofariz de ágata por aproximadamente 15 minutos. Posteriormente, os pós foram calcinados a $1100{ }^{\circ} \mathrm{C}$ ao ar por 12 horas. A seguir, a mistura foi moída em um almofariz e submetida a outro tratamento térmico a $1200{ }^{\circ} \mathrm{C}$ por $12 \mathrm{~h}$, sendo esta etapa repetida por três vezes. O último tratamento térmico, na forma de pó, foi realizado a $1250{ }^{\circ} \mathrm{C}$ por $12 \mathrm{~h}$. Após os vários tratamentos térmicos descritos acima, as amostras foram moídas por aproximadamente 10 minutos e conformadas na forma de partilhas com diâmetro de $\sim 15 \mathrm{~mm}$ e espessura de $\sim 2 \mathrm{~mm}$ em uma prensa com carga de $1.5 \mathrm{ton} / \mathrm{cm}^{2}$. Essas pastilhas foram sinterizadas a $1250{ }^{\circ} \mathrm{C}$ por 30 horas. As pastilhas foram então cortadas em pequenas barras de aproximadamente $2 \mathrm{~mm}^{2}$ de área de seção transversal. Três conjuntos com amostras representativas tiveram tratamentos térmicos adicionais a 1300,1350 e $1400{ }^{\circ} \mathrm{C}$ por 30 horas cada. 


\subsection{Caracterização por difração de raios-X}

Todas as amostras produzidas foram caracterizadas por difração de raios-X DRX com a finalidade de verificar a formação da fase desejada. Essas medidas foram realizadas no intervalo angular de $20 \leq \theta \leq 80^{\circ}$, passo angular de $0.05^{\circ}$ e tempo de exposição de 5 segundos. O equipamento utilizado foi o Difratômetro Brucker-ASX modelo D8 Advance com filtro de Ni (Projeto FAPESP $n^{0}$. 99/10798-0) pertencente ao IPEN, sendo que a radiação utilizada foi $\mathrm{CuK}_{\alpha}$ com comprimentos de onda $\lambda_{\mathrm{K} \alpha 1}=1.540600 \AA, \lambda_{\mathrm{K} \alpha 2}=1.544390 \AA \mathrm{e}$ $\lambda_{\mathrm{K} \beta}=1.39222 \AA$.

As medidas de DRX para as amostras com $\mathrm{y}=0.30$, submetidas às temperaturas de sinterização de $1250,1300,1350$ e $1400{ }^{\circ} \mathrm{C}$, foram realizadas com passo angular de $0.02^{\circ}$ e tempo de exposição de 10 segundos. Essas medidas foram feitas com a finalidade de verificar o grau de cristalinidade do material como função da temperatura de sinterização.

\subsubsection{Refinamento da estrutura cristalina através do método Rietveld}

Os diagramas de difração de raios- $\mathrm{X}$ foram refinados por um programa denominado Powder Cell 2.4. ${ }^{[1]}$ Assim como os tradicionais programas Rietveld, como LHPM8, ${ }^{[2]}$ PREP/PROF ${ }^{[3]}$ e outros, o Powder Cell 2.4 necessita de um modelo estrutural inicial. O programa contém várias ferramentas de manipulação da estrutura cristalina, mas aqui serão abordadas apenas as utilizadas para a obtenção dos parâmetros de rede $a, b$ e $c$ através do refinamento dos diagramas de DRX obtidos experimentalmente.

Os parâmetros iniciais, necessários para o refinamento, foram baseados nos resultados obtidos no mesmo composto por Collado et al. ${ }^{[4]}$ Os autores 
realizaram caracterização estrutural detalhada para alguns compostos da série através das medidas de difração de raios-X síncrotron e difração de nêutrons. Foi proposto que todos os membros da série $\mathrm{La}_{5 / 8-\mathrm{y}} \mathrm{Pr}_{\mathrm{y}} \mathrm{Ca}_{3 / 8} \mathrm{MnO}_{3}$ apresentam estrutura ortorrômbica e simetria cristalina pertencente ao grupo espacial Pnma na temperatura ambiente.

A partir dos parâmetros iniciais, como o número referente ao grupo espacial (62, para o grupo espacial Pnma), parâmetros de rede $a, b$ e $c$, posição e ocupação de cada átomo, etc, pode-se gerar um difratograma teórico. Esse difratograma pode ser gerado com as condições experimentais desejadas, como por exemplo, o valor inicial e final em $2 \theta$, a radiação utilizada, geometria, passo angular, etc. A seguir o diagrama de DRX de uma amostra é inserido no mesmo plano do diagrama teórico. Finalmente são realizados vários refinamentos com opções de ajuste de vários parâmetros, por exemplo, os próprios parâmetros iniciais, fatores térmicos, etc. $\mathrm{O}$ ajuste foi feito até que a menor diferença entre o diagrama de DRX obtido experimentalmente e o calculado era encontrada. Para isso, o programa fornece os índices de concordância convencionais como em todo refinamento do tipo Rietveld: $\mathrm{R}_{\mathrm{wp}}, \mathrm{R}_{\mathrm{p}}$ e $\mathrm{R}_{\text {exp. }}{ }^{[3]}$ Após o refinamento, obtêmse os parâmetros de rede $a, b$ e $c$ e os índices de Miller $(h k l)$ para todas as reflexões de Bragg. A partir desses dados podem-se obter posições angulares referentes às reflexões dos planos $(h k l)$ através da lei de Bragg:

$$
2 d_{h k l} \operatorname{sen}(\theta)=\lambda,
$$

onde $\lambda$ é o comprimento de onda do feixe de raios-X incidente e $\mathrm{d}_{h k l}$ é o espaçamento entre os planos cristalográficos:

$$
\frac{1}{d_{h k l}^{2}}=\left(\frac{h}{a}\right)^{2}+\left(\frac{k}{b}\right)^{2}+\left(\frac{l}{c}\right)^{2},
$$

onde $a, b$ e $c$ são os parâmetros de rede calculados pelo refinamento. 
O refinamento foi feito para os diagramas de DRX de: (a) amostras com $\mathrm{y}=0.30$ sinterizadas a diversas temperaturas no intervalo de $2 \theta$ de 20 a $80^{\circ}$, com passo angular de $0.02^{\circ}$ e tempo de exposição de $10 \mathrm{~s}$, e (b) amostras com y $=0$, $0.10,0.20,0.25,0.30,0.35,0.40$ e 0.625 sinterizadas a $1400{ }^{\circ} \mathrm{C}$ no intervalo de $2 \theta$ de 20 a $80^{\circ}$, passo angular de $0.05^{\circ}$ e tempo de exposição de $5 \mathrm{~s}$.

\subsection{Medidas de resistividade elétrica}

Medidas de resistividade elétrica como função da temperatura $\rho(T)$ foram realizadas em amostras com diferentes concentrações de $\operatorname{Pr}$ e diversos tratamentos térmicos através do método de quatro pontas de, como mostra o esquema simplificado da Fig. 2.1. Para isto, a superfície de cada barra foi previamente limpa com uma lixa fina e os contatos foram feitos passando-se quatro filetes de um filme de ouro ("bright brushing gold") espaçados seqüencialmente sobre a superfície da amostra e curados a $375{ }^{\circ} \mathrm{C}$ por 10 minutos. A seguir, quatro fios de cobre foram afixados com tinta prata, curada a $170{ }^{\circ} \mathrm{C}$ por 7 minutos, sobre os terminais cobertos com filme de ouro.

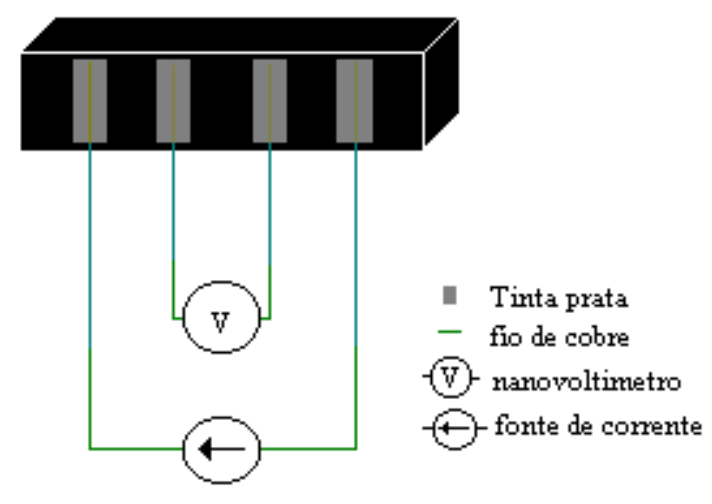

I

Figura 2.1 - Esquema simplificado do arranjo experimental para obtenção de medidas de resistividade elétrica de uma amostra. 
Para a realização das medidas, cada amostra foi conectada a uma fonte de corrente e a um nanovoltímetro e foi inserida no criostato do SQUID (descrito na seção seguinte), onde se obteve o controle sobre a temperatura. A aquisição de dados foi feita por um microcomputador PC, através de uma placa GPIB. Nessas medidas, correntes de excitação de de $1 \mathrm{~mA}$ ou $0.1 \mathrm{~mA}$ foram utilizadas de acordo com a magnitude da queda de tensão medida sobre as amostras e a temperatura foi variada no intervalo de $5 \leq \mathrm{T} \leq 350 \mathrm{~K}$. As medidas de $\rho(\mathrm{T})$ foram realizadas nos processos de aquecimento e de resfriamento das amostras.

A partir desses dados obtém-se a resistência $\mathrm{R}(\mathrm{T})$ das amostras como função da temperatura através da lei de Ohm. Conhecendo-se a geometria das barras, obtém-se também a resistividade elétrica $\rho(T)$ desses materiais:

$$
\begin{gathered}
V(T)=R(T) I \Rightarrow R(T)=\frac{V(T)}{I}, \\
\rho(T)=\frac{R(T) A}{l},
\end{gathered}
$$

onde A é a seção transversal da amostra e 1 o comprimento da amostra, de onde extrai-se a diferença de potencial.

As curvas de $\rho(T)$ obtidas acima apresentam várias indicações de transição de fase, como a transição do tipo metal-isolante $\mathrm{T}_{\mathrm{MI}}$ e de ordenamento de carga $\mathrm{T}_{\mathrm{OC}}$. A transição MI é caracterizada por um máximo que ocorre em $\rho(\mathrm{T}) \mathrm{em}$ uma temperatura denominada $\mathrm{T}_{\mathrm{MI}}$. As medidas de $\rho(\mathrm{T})$ revelam que, além da transição de fase $\mathrm{MI}$, os compostos com $\mathrm{y} \geq 0.35$ apresentam transição de ordenamento de carga, caracterizada por uma inflexão na curva de $\rho(\mathrm{T})$ ao redor de $\mathrm{T}_{\mathrm{OC}} \sim 194 \mathrm{~K}$. A partir das curvas de $\rho(\mathrm{T})$, obtidas no processo de resfriamento, foram determinados os valores $\mathrm{T}_{\mathrm{MI}}$ e $\mathrm{T}_{\mathrm{OC}}$ de todas as amostras. 
Esses dados foram determinados a partir da derivada de $\rho(T)$ como função da temperatura $\mathrm{d} \rho / \mathrm{dT}$. $\mathrm{T}_{\mathrm{MI}}$ e $\mathrm{T}_{\mathrm{OC}}$ foram determinadas pela temperatura na qual as curvas de $\mathrm{d} \rho / \mathrm{dT}$ e $(1 / \rho) \mathrm{d} \rho / \mathrm{dT}$ interceptam o eixo das abscissas, respectivamente. Ainda, outros dados importantes são obtidos a partir das curvas de $\rho(T)$, como a resistividade elétrica residual $\rho_{0}$ e resistividade elétrica em $T_{\text {MI, }} \rho_{\text {Máx. Essas }}$ grandezas são definidas como: $\rho_{0}=\rho(T=10 \mathrm{~K})$ e $\rho_{\text {Máx }}=\rho\left(T=T_{M I}\right)$.

\subsection{Medidas de magnetização}

As curvas de magnetização foram obtidas em um magnetômetro do tipo SQUID, modelo XL-200 da Quantum Design, em campos magnéticos de até 2 kOe e no intervalo de temperatura de $5 \leq \mathrm{T} \leq 350 \mathrm{~K}$. As medidas de magnetização como função da temperatura $\mathrm{M}(\mathrm{T})$ foram realizadas tanto no processo de "zero field cooling" ZFC quanto no de "field cooling" FC. O processo de ZFC consiste em resfriar a amostra até uma temperatura bem abaixo da temperatura de Curie $\mathrm{T}_{\mathrm{C}}$ na ausência do campo magnético, aplicar um campo magnético dc e finalmente medir a magnetização do material durante o processo de aquecimento até temperaturas bem acima de $\mathrm{T}_{\mathrm{C}}$. O processo $\mathrm{FC}$ consiste em se medir a magnetização durante o resfriamento a partir de uma dada temperatura bem acima de $\mathrm{T}_{\mathrm{C}}$ até $\sim 5 \mathrm{~K}$. A partir desses dados obtiveram-se os valores de suscetibilidade magnética $\chi(T)$ das amostras utilizando a expressão abaixo:

$$
\chi(T)=\frac{M(T)}{H \times N_{M}},
$$


onde $\mathrm{H}$ é o campo magnético aplicado e $\mathrm{N}_{\mathrm{M}}$ é o número de moles do composto contido na amostra.

Todas as curvas de $\chi(\mathrm{T})$ apresentaram características de um material paramagnético em altas $\mathrm{T}$ e ferromagnético em baixas $\mathrm{T}$. Portanto, a temperatura de Curie foi definida como sendo a temperatura na qual ocorre a máxima inflexão na curva de $\chi(\mathrm{T})$ obtida no processo de $\mathrm{FC}$. Para a determinação de $T_{C}$, primeiro foi obtida a derivada de $\chi(T)$ e depois a curva de $\mathrm{d} \chi / \mathrm{dT}$ como função da temperatura. A seguir, $\mathrm{T}_{\mathrm{C}}$ foi determinado pelo mínimo local dessa última curva.

\subsection{Magnetorresistência}

A magnetorresistência como função da temperatura $\operatorname{MR}(T)$ foi obtida através das medidas de resistência elétrica como função da temperatura $R(T)$, realizadas em um magnetômetro denominado SQUID, modelo XL-200 da Quantum Design no intervalo de temperatura de $5 \leq \mathrm{T} \leq 350 \mathrm{~K}$. As medidas foram realizadas conforme o procedimento descrito no item 2.3, sendo que a resistência $\mathrm{R}(\mathrm{T}, \mathrm{H}=$ cte) da amostra foi medida primeiramente sem a aplicação de um campo magnético externo $\mathrm{R}(\mathrm{T}, \mathrm{H}=0)$ e em seguida, sob campo magnético aplicado $\mathrm{R}(\mathrm{T}, \mathrm{H}=50 \mathrm{kOe})$. A partir desses dados, obtém-se $\mathrm{MR}(\mathrm{T})$ através da relação abaixo:

$$
M R(T)=\frac{R(T, H=0)-R(T, H=50 k O e)}{R(T, H=50 k O e)} .
$$




\subsection{Relaxação da resistência elétrica}

As medidas de relaxação da resistência elétrica como função do tempo $t$ $\mathrm{R}(\mathrm{t})$ foram realizadas para as amostras com $\mathrm{y}=0.30$ e 0.35 sinterizadas a $1400{ }^{\circ} \mathrm{C}$. O procedimento experimental consistiu em medir a resistência elétrica do material a uma temperatura fixa a cada 1 segundo no primeiro minuto e a cada 8 segundos para o restante do tempo de medida. Nessas medidas, a amostra foi resfriada a partir da temperatura ambiente até a temperatura desejada $\mathrm{T}$ com uma taxa de $\sim 10 \mathrm{~K} / \mathrm{min}$ e sem a aplicação de corrente de excitação. Imediatamente após a estabilização da temperatura do sistema, a corrente de excitação foi aplicada e a queda de tensão sobre as amostras foi medida durante um intervalo de tempo de 300 minutos. Esse procedimento foi adotado em todas as medidas para diferentes T. Nessas medições, correntes de excitação de de $1 \mathrm{~mA}$ e $0.1 \mathrm{~mA}$ foram utilizadas nas amostras com $\mathrm{y}=30$ e 0.35 , respectivamente. A partir desses dados, $\mathrm{R}(\mathrm{t})$ foi obtido através da Eq. 2.3.1. 


\subsection{Referências}

1 http://www.ccp14.ac.uk/main.htm

2 R. J. Hill, J. Appl. Cryst. 25, 589 (1992).

3 H. M. Rietveld, J. Appl. Cryst. 2, 65 (1969).

4 J. A. Collado, C. Frontera, J. L. García-Muñoz, C. Ritter, M. Brunelli, and M.A. G. Aranda, Chem. Matter. 15, 167 (2003). 


\section{Capítulo 3}

\section{Resultados e Discussões}

\subsection{Difração de raios-X}

Os diagramas de difração de raios-X (DRX) foram obtidos para todas as amostras produzidas da série $\mathrm{La}_{5 / 8-\mathrm{y}} \mathrm{Pr}_{\mathrm{y}} \mathrm{Ca}_{3 / 8} \mathrm{MnO}_{3}(0 \leq \mathrm{y} \leq 0.625)$. Entretanto, esses diagramas também foram obtidos após alguns tratamentos térmicos intermediários, durante o processo de sinterização das amostras. Isto possibilitou um monitoramento no sentido da obtenção de materiais com fase única. ${ }^{[1]}$ A Fig. 3.1.1 abaixo ilustra uma situação em que a fase desejada ainda não havia se formado, ou seja, o material era composto de mais de uma fase cristalina após dois tratamentos térmicos: um a 1100 e outro a $1200{ }^{\circ} \mathrm{C}$ por $12 \mathrm{~h}$ cada. A reflexão adicional observada em $2 \theta \sim 28^{\circ}$, indicada pelo asterisco (*) no diagrama de DRX, confirma a presença de uma fase espúria no composto. Ainda, na mesma figura, pode-se notar a formação de fase única para a mesma amostra após dois tratamentos térmicos adicionais efetuados a $1200{ }^{\circ} \mathrm{C}$ por $12 \mathrm{~h}$ cada. Nessas medidas, o $\mathrm{MgO}$ foi utilizado como padrão interno para possíveis correções nas reflexões de Bragg presentes no diagrama de DRX. O mesmo procedimento foi realizado para todas as amostras produzidas, sendo que os diagramas não são mostrados aqui devido ao fato de serem similares aos da Fig. 3.1.1. Comparando os dois diagramas da Fig. 3.1.1, observa-se reflexões mais estreitas e intensas no diagrama de DRX do material com fase única, características consistentes com um aumento do tamanho dos domínios de coerência cristalográfica e um maior grau de cristalinidade do material, respectivamente. $^{[2]}$ Essas propriedades foram desenvolvidas com outros 
tratamentos adicionais, conforme descrito na seção 2.1. Neste trabalho, sinterização e temperatura de sinterização $T_{S}$ referem-se ao último tratamento térmico realizado em uma dada série ou amostra. Todas as amostras foram conformadas na forma de pastilha após a obtenção da fase única.

Após as sinterizações finais, novos diagramas de DRX foram obtidos para todos os conjuntos de amostras submetidas a diferentes $\mathrm{T}_{\mathrm{S}}$. A Fig. 3.1.2 mostra alguns diagramas de DRX de uma amostra representativa, $\mathrm{y}=0.30$, quando submetida a diferentes $T_{S}$. Note que não há diferenças significativas entre os quatro diagramas, considerando a resolução experimental, indicando que a composição química dos materiais não foi alterada com o aumento progressivo de $\mathrm{T}_{\mathrm{S}}$.

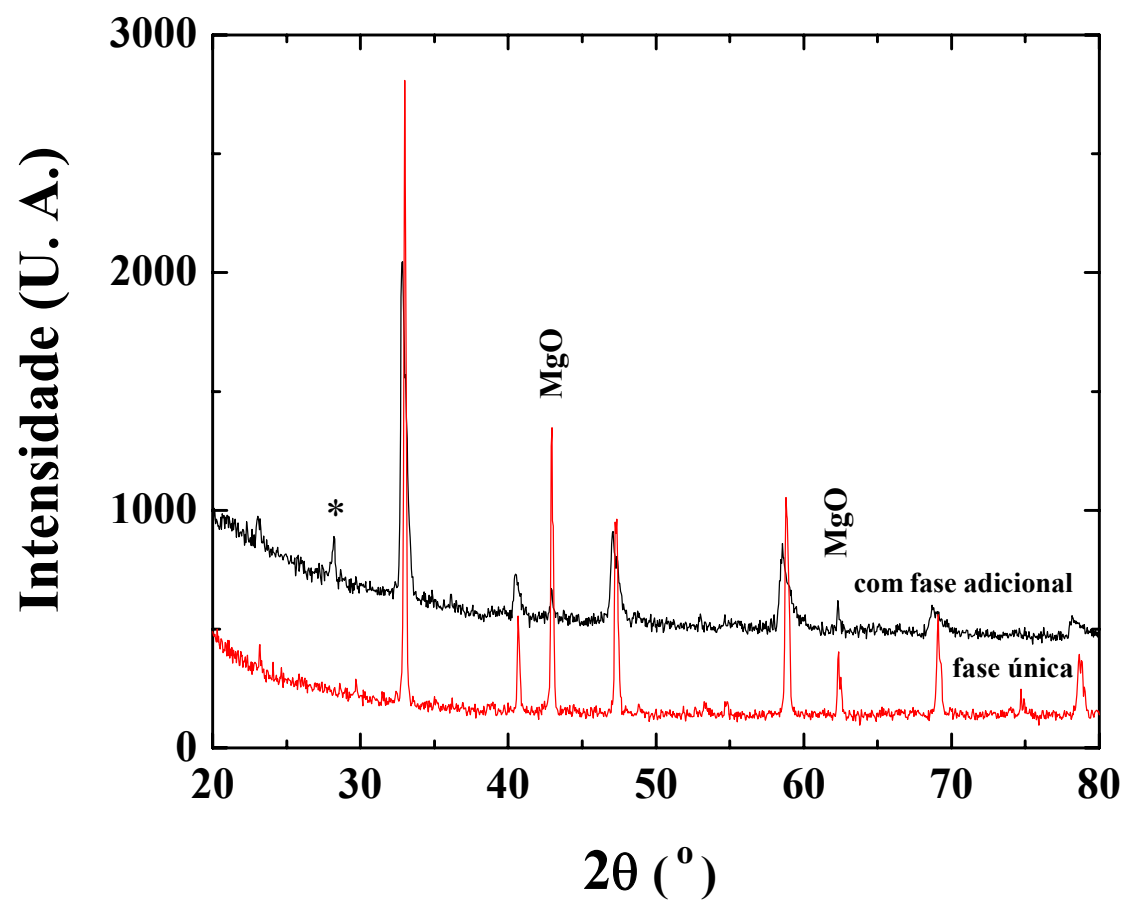

Figura 3.1.1 - Diagramas de difração de raios $\mathrm{X}$ para os compostos $\mathrm{La}_{5 / 8-\mathrm{y}} \mathrm{Pr}_{\mathrm{y}} \mathrm{Ca}_{3 / 8} \mathrm{MnO}_{3}$ com $\mathrm{y}=0.20$ após dois tratamentos térmicos: antes e depois da formação da fase única. $\mathrm{O}$ asterisco indica a presença de uma fase adicional na amostra tratada a $1200{ }^{\circ} \mathrm{C}$, por $12 \mathrm{~h}$. Após três tratamentos térmicos a $1200{ }^{\circ} \mathrm{C}$ por $12 \mathrm{~h}$ cada, observou-se a formação da fase única do composto, representada pelo diagrama em vermelho. 


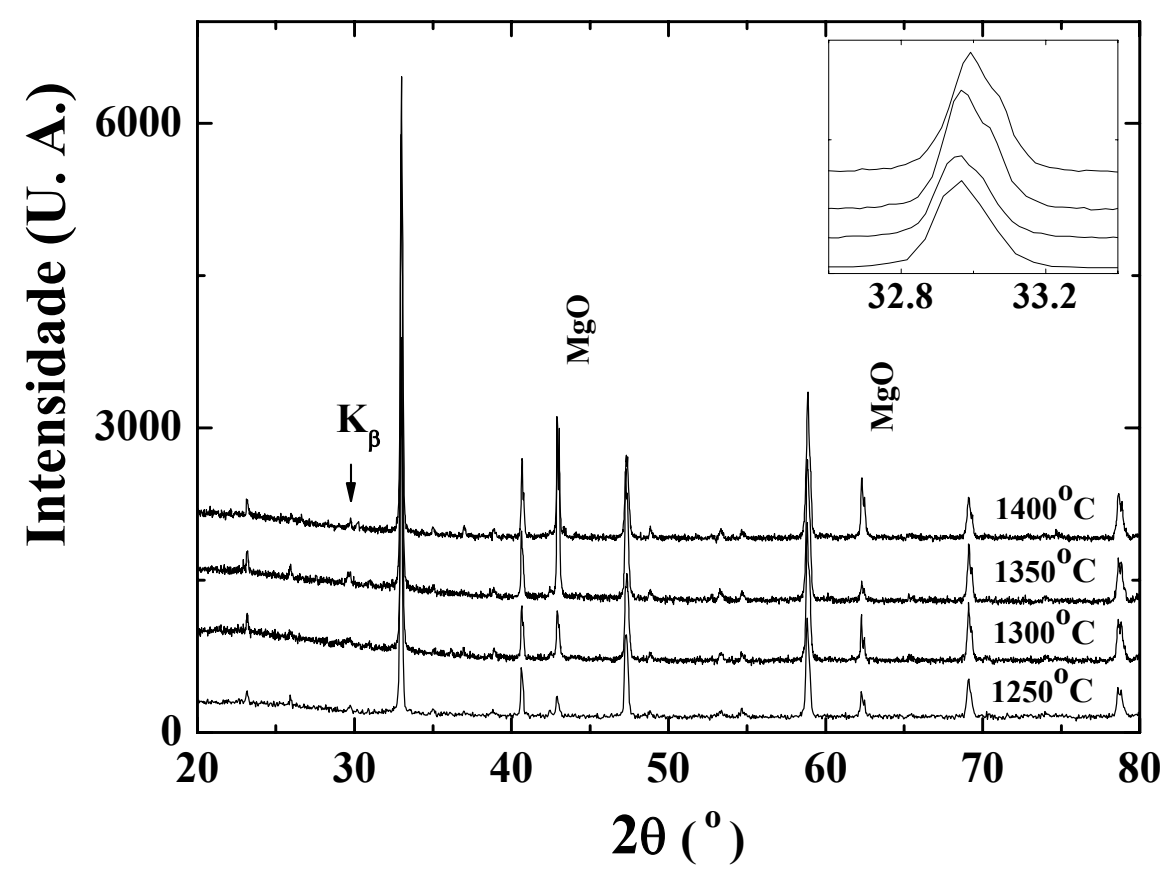

Figura 3.1.2 - Diagramas de difração de raios-X para os compostos $\mathrm{La}_{5 / 8-y} \mathrm{Pr}_{\mathrm{y}} \mathrm{Ca}_{3 / 8} \mathrm{MnO}_{3}$ com $\mathrm{y}=0.30$ submetidos a diferentes temperaturas de sinterização. Reflexões pertencentes à radiação $\mathrm{K}_{\beta}$ foram identificadas e são indicadas pela seta. $\mathrm{O}$ detalhe mostra o deslocamento, para ângulos maiores do pico mais intenso, localizado em $\sim 32.9^{\circ}$, como função crescente da temperatura de sinterização.

Os diagramas de DRX da Fig. 3.1.2 foram obtidos com passo angular de $0.02^{\circ}$ e indicam materiais com alto grau de cristalinidade, através da observação de reflexões pertencentes à radiação $\mathrm{K}_{\beta}$. Porém, uma observação cuidadosa da Fig. 3.1.2 revela pequenas mudanças nos diagramas de DRX que resultam em alterações nos parâmetros de rede $a, b$, e $c$ da estrutura pertencente ao grupo Pnma. O detalhe da figura mostra um sensível deslocamento da reflexão que ocorre na posição angular $2 \theta \sim 32.9^{\circ}$ para ângulos maiores com o aumento de $T_{S}$ (ver detalhe da Fig. 3.1.2). Esse deslocamento indica que o espaçamento entre os planos cristalográficos diminui como aumento de $\mathrm{T}_{\mathrm{S}}$, de acordo com a lei de Bragg (Eq. 2.2.1). Portanto, o volume da cela unitária desses materiais diminui com o aumento de $\mathrm{T}_{\mathrm{S}}$. A Tabela 3.1.1 mostra os raios iônicos dos elementos do sítio A, para o número de coordenação nove, que compõem as manganitas estudadas neste trabalho. 


\begin{tabular}{|c|c|}
\hline Íon & $\mathrm{r}(\AA)$ \\
\hline $\mathrm{La}^{3+}$ & 1.216 \\
\hline $\mathrm{Pr}^{3+}$ & 1.179 \\
\hline $\mathrm{Ca}^{3+}$ & 1.18 \\
\hline
\end{tabular}

Tabela 3.1.1 - Raios iônicos com número de coordenação nove, de acordo com a referência 3.

A redução do volume da cela unitária com o aumento de $\mathrm{T}_{\mathrm{S}}$ sugere que temperaturas de sinterização maiores facilitam a difusão dos íons de $\mathrm{Pr}$, tornando a amostra mais homogênea. Se há maior e melhor difusão do Pr, isso poderia ser observado via uma diminuição do volume da cela unitária. Nesse sentido, os volumes das celas unitárias das quatro amostras com $y=0.30$ foram calculados com os parâmetros de rede $a, b$ e $c$ gerados pelo refinamento dos diagramas de DRX através do programa Powder Cell 2.4. Os detalhes do refinamento estão descritos na seção 2.2.1. Todos os membros da série $\mathrm{La}_{5 / 8-\mathrm{y}} \mathrm{Pr}_{\mathrm{y}} \mathrm{Ca}_{3 / 8} \mathrm{MnO}_{3}$ apresentam estrutura ortorrômbica e simetria cristalina pertencente ao grupo espacial Pnma na temperatura ambiente. ${ }^{[4]}$ Os volumes das celas unitárias das amostras com $\mathrm{y}=0.30$ sinterizadas a diversas temperaturas estão mostrados na Fig. 3.1.3. O volume sofre uma pequena diminuição, mas de forma contínua, com o aumento de $\mathrm{T}_{\mathrm{S}}$, sugerindo que a amostra sinterizada a $1400{ }^{\circ} \mathrm{C}$ foi obtida com elevado grau de cristalinidade devido, provavelmente, a uma distribuição homogênea de Pr em toda a amostra. A difusão de Pr, nesse caso, pode ter sido catalisada pela presença de fase líquida em temperaturas mais altas, que também favorece o crescimento médio dos grãos em amostras policristalinas e aumenta o grau de cristalinidade dos materiais. 


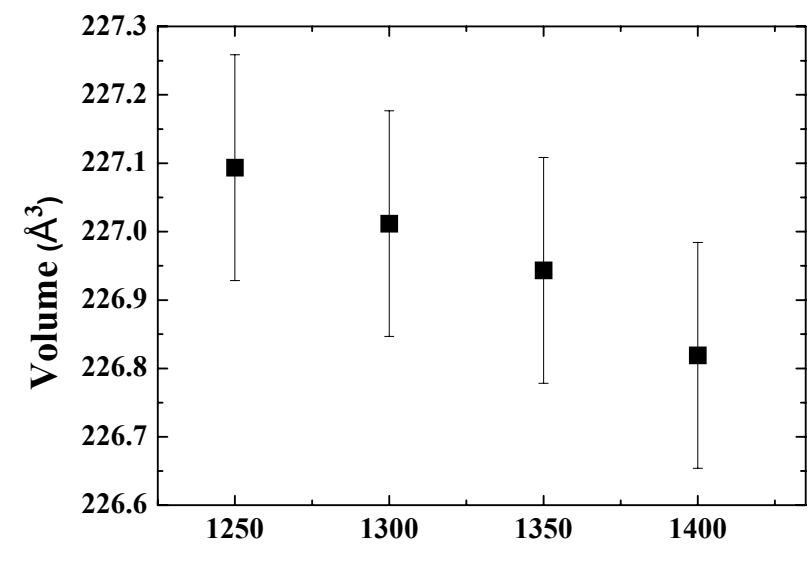

Temperatura de sinterização $\left({ }^{\circ} \mathrm{C}\right)$

Figura 3.1.3 - Volume da cela unitária da amostra com y $=0.30$ como função da temperatura de sinterização.
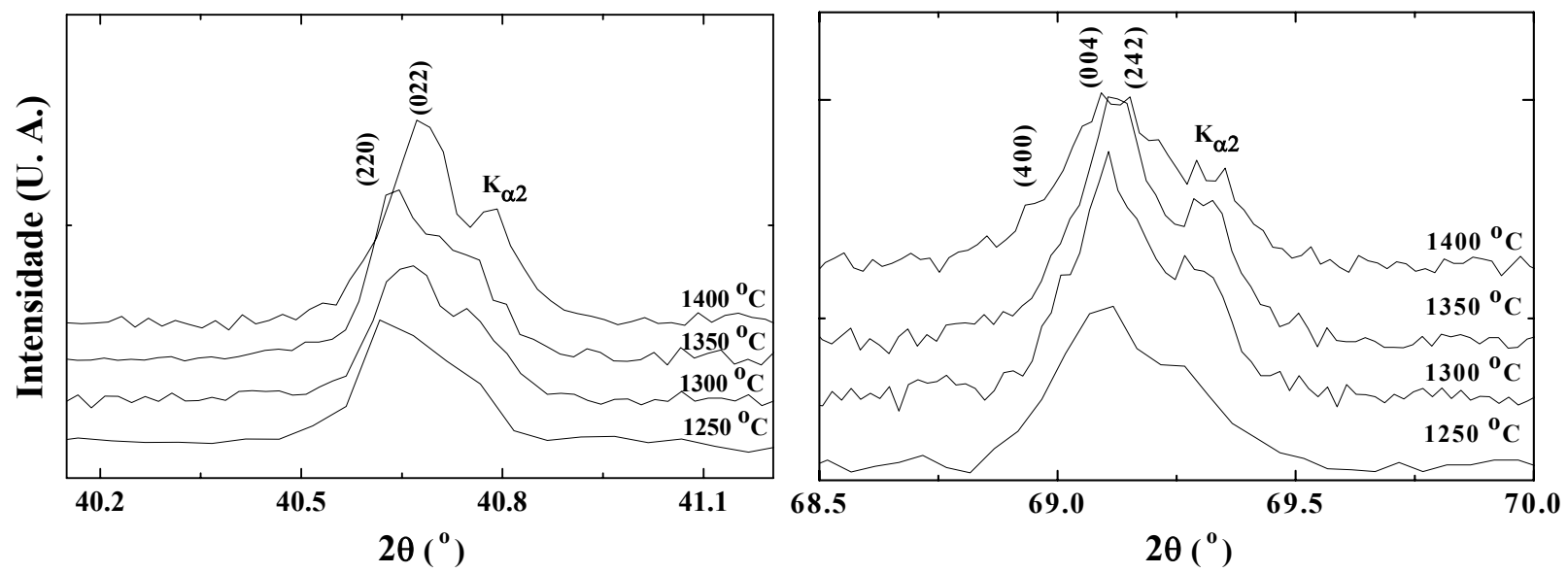

Figura 3.1.4 - Detalhes dos diagramas de difração de raios- $\mathrm{X}$ para os compostos $\mathrm{La}_{5 / 8-y} \mathrm{Pr}_{\mathrm{y}} \mathrm{Ca}_{3 / 8} \mathrm{MnO}_{3}$ com y $=0.30$ submetidos a diferentes temperaturas de sinterização. Reflexões pertencentes à radiação $\mathrm{K}_{\alpha_{2}}$ tornam-se mais definidas para $\mathrm{T}_{\mathrm{S}}$ maiores.

Observam-se ainda pequenas mudanças nos diagramas de DRX que evidenciam o aumento dos domínios com coerência cristalográfica nos materiais submetidos a $T_{S}$ maiores. Nota-se que, na Fig. 3.1.4, as reflexões referentes aos planos (220) e (022), que ocorrem no intervalo de $2 \theta$ entre 40.5 e $40.8^{\circ}$, tornam-se muito mais definidas com o aumento de $\mathrm{T}_{\mathrm{S}}$. $\mathrm{O}$ mesmo se verifica com as reflexões referentes aos planos (400), (004) e (242) que ocorrem no intervalo de $2 \theta$ entre 68.8 e $69.4^{\circ}$. Mesmo que para as amostras sinterizadas a $1400{ }^{\circ} \mathrm{C}$ não seja 
possível uma diferenciação das reflexões que ocorrem muito próximas umas das outras, nota-se que as reflexões referentes à radiação $\mathrm{K}_{\alpha 2}$ tornam-se mais definidas com o aumento de $\mathrm{T}_{\mathrm{S}}$. As observações de reflexões bem definidas e o estreitamento da largura a meia altura (FWHM - Full Width Half Maximun) de algumas reflexões indicam uma melhoria na qualidade cristalográfica da amostra. Aparentemente, a largura dos picos das amostras com $\mathrm{T}_{\mathrm{S}}=1400{ }^{\circ} \mathrm{C}$ é maior. Entretanto, uma observação mais atenta indica que as reflexões pertencentes aos planos (220) e (400), que não eram observadas para as amostras com $\mathrm{T}_{\mathrm{S}} \leq 1350{ }^{\circ} \mathrm{C}$, surgem na forma de um pequeno pico nos diagramas de DRX, aparentemente aumentando a FWHM.

As pequenas diferenças encontradas nos diagramas de DRX das amostras sinterizadas a diversas temperaturas $\mathrm{T}_{\mathrm{S}}$ indicam um maior grau de cristalinidade e uma evolução dos parâmetros estruturais com o aumento de $\mathrm{T}_{\mathrm{S}}$. Isso, de certa forma é refletido de maneira mais clara no comportamento do volume da cela unitária que diminui como função do aumento de $\mathrm{T}_{\mathrm{S}}$, como mostrado na Fig. 3.1.3. Essas mudanças foram refletidas nas propriedades físicas desses materiais como resistividade elétrica $\rho(\mathrm{T})$ e magnetização. Particularmente, nos resultados das medidas de $\rho(T)$, diferenças apreciáveis na magnitude de $\rho(T)$ entre as amostras com diferentes $\mathrm{T}_{\mathrm{S}}$ foram observadas e ainda, na temperatura transição de fase metal-isolante $\mathrm{T}_{\mathrm{MI}}$, que foi vista ocorrer em valores ligeiramente diferentes nas amostras submetidas a diferentes $\mathrm{T}_{\mathrm{S}}$. Esses dados, não apresentados aqui, indicaram que a maior variação na magnitude de $\rho(T)$ ocorre nas amostras com $\mathrm{y}=0$, chegando a uma redução de mais de duas ordens de grandeza entre as amostras submetidas a $\mathrm{T}_{\mathrm{S}}=1250$ e $1400{ }^{\circ} \mathrm{C}$. De acordo com as análises realizadas, as amostras sinterizadas a $1400{ }^{\circ} \mathrm{C}$ mostraram ser mais homogêneas, com maior grau de cristalinidade e com melhores 
propriedades de transporte eletrônico, inferidas via valores de $\mathrm{T}_{\mathrm{MI}}$ e magnitudes de $\rho(\mathrm{T})$. Portanto, a temperatura $\mathrm{T}_{\mathrm{S}}=1400{ }^{\circ} \mathrm{C}$ foi escolhida para a produção dos materiais a serem estudados nesse trabalho.

\subsection{Amostras tratadas a $1400{ }^{\circ} \mathrm{C}$}

Após a análise das amostras através das medidas de difração de raios-X para a escolha das melhores condições de tratamento térmico, constatou-se que as amostras policristalinas de $\mathrm{La}_{5 / 8-\mathrm{y}} \mathrm{Pr}_{\mathrm{y}} \mathrm{Ca}_{3 / 8} \mathrm{MnO}_{3} ; \mathrm{y}=0,0.10,0.20,0.25,0.30$, $0.35,0.40$ e 0.625 ; sinterizadas a $1400{ }^{\circ} \mathrm{C}$ são as mais adequadas para o objetivo deste trabalho.

O composto $\mathrm{La}_{5 / 8-y} \mathrm{Pr}_{\mathrm{y}} \mathrm{Ca}_{3 / 8} \mathrm{MnO}_{3}$ contém uma concentração de $\mathrm{Ca}$ com valência $2+$ constante em $3 / 8$, ou seja, a proporção entre os íons $\mathrm{Mn}^{3+}$ e $\mathrm{Mn}^{4+}$ não varia ao longo da série. $\mathrm{O}$ diagrama de fase $\mathrm{La}_{1-\mathrm{x}} \mathrm{Ca}_{\mathrm{x}} \mathrm{MnO}_{3}$ (veja Fig. 1.2, na pág. 3) indica que a temperatura de Curie é otimizada em $x=3 / 8 .^{[5]}$ Assim, a manganita $\mathrm{La}_{5 / 8} \mathrm{Ca}_{3 / 8} \mathrm{MnO}_{3}$ é um material típico $\mathrm{FM}$, mas a substituição de La por Pr de raio iônico menor induz o estado de ordenamento de carga nesses sistemas. ${ }^{[6]} \mathrm{O}$ efeito da diminuição do raio iônico médio do sítio A é estudado aqui através de medidas de difração de raios-X, resistividade elétrica, susceptibilidade magnética, magnetorresistência e relaxação da resistência elétrica com o tempo. Os resultados obtidos estão, de maneira geral, de acordo com os resultados encontrados na literatura. ${ }^{[7-11]}$ Os parâmetros físicos como as temperaturas de transição de fases, resistividade residual, etc, utilizados nas discussões foram definidos no Capítulo 2. 


\subsubsection{Caracterização através de difração de raios-X}

Os diagramas de difração de raios-X DRX das manganitas $\mathrm{La}_{5 / 8-\mathrm{y}} \mathrm{Pr}_{\mathrm{y}} \mathrm{Ca}_{3 / 8} \mathrm{MnO}_{3} ; 0,0.10,0.20,0.25,0.30,0.35,0.40$ e 0.625 ; sinterizadas a $1400{ }^{\circ} \mathrm{C}$ estão ilustrados na Fig. 3.2.1.

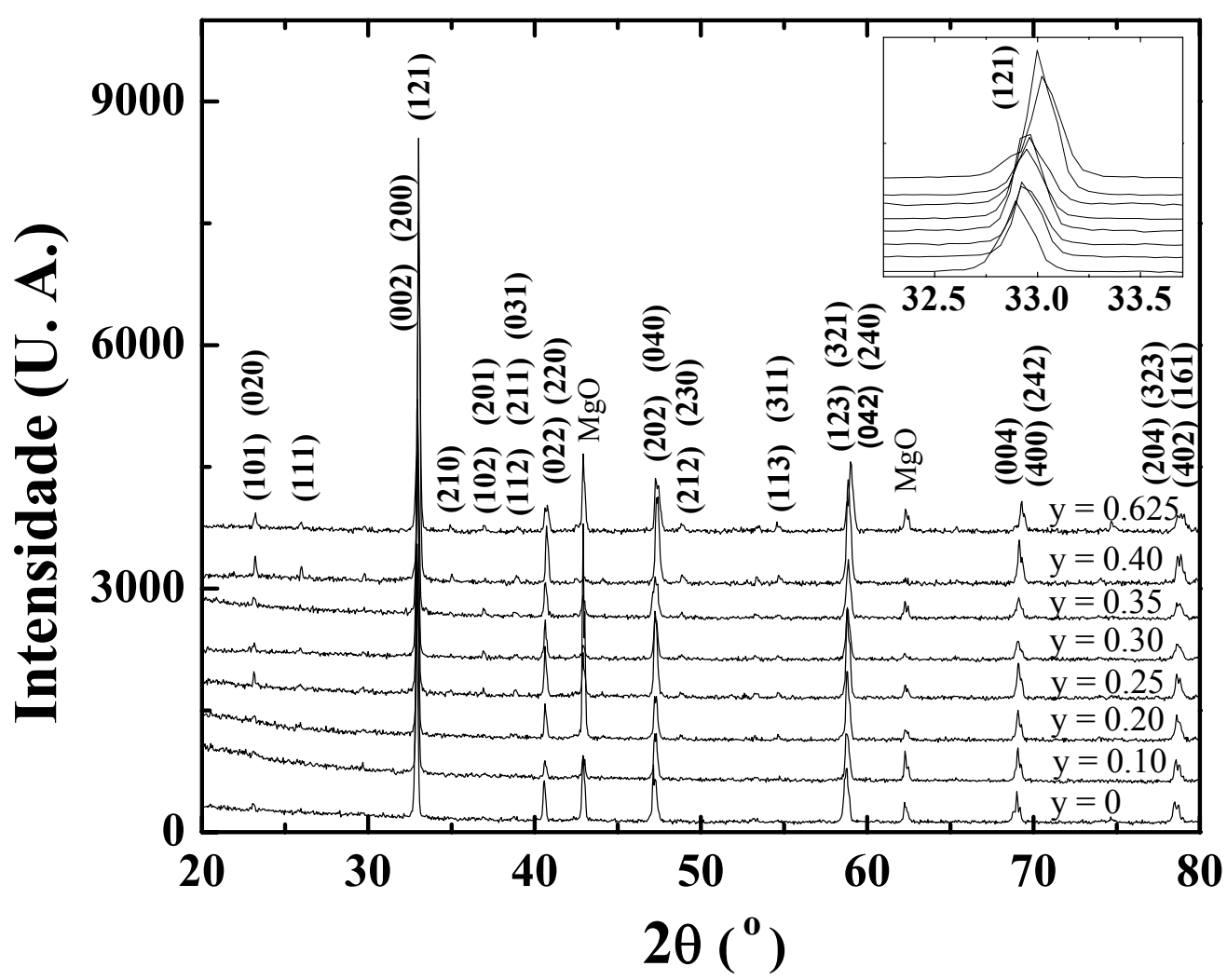

Figura 3.2.1 - Diagramas de difração de raios-X para a série $\mathrm{La}_{5 / 8-\mathrm{y}} \mathrm{Pr}_{\mathrm{y}} \mathrm{Ca}_{3 / 8} \mathrm{MnO}_{3}$ sinterizada a $\mathrm{T}_{\mathrm{S}}=1400{ }^{\circ} \mathrm{C}$.

Os índices de Miller $(h k l)$ foram indexados através do programa Powder Cell 2.4, conforme descrito anteriormente, na seção 2.2.1. Os índices $(h k l)$ indicados nos diagramas de DRX concordam com as reflexões pertencentes ao grupo de simetria Pnma, no intervalo de $20^{\circ}$ a $80^{\circ}$, indicando que todos os compostos são de fase única. As reflexões com intensidades relativas muito baixas não estão identificadas, pois são dificilmente diferenciadas do ruído observado nos dados. As medidas foram obtidas com passo angular de $0.05^{\circ}$, 
portanto resultando em refinamentos estruturais não muito precisos, mas que permitem o monitoramento da evolução estrutural ao longo da série, ou seja, como função da substituição de La por Pr.
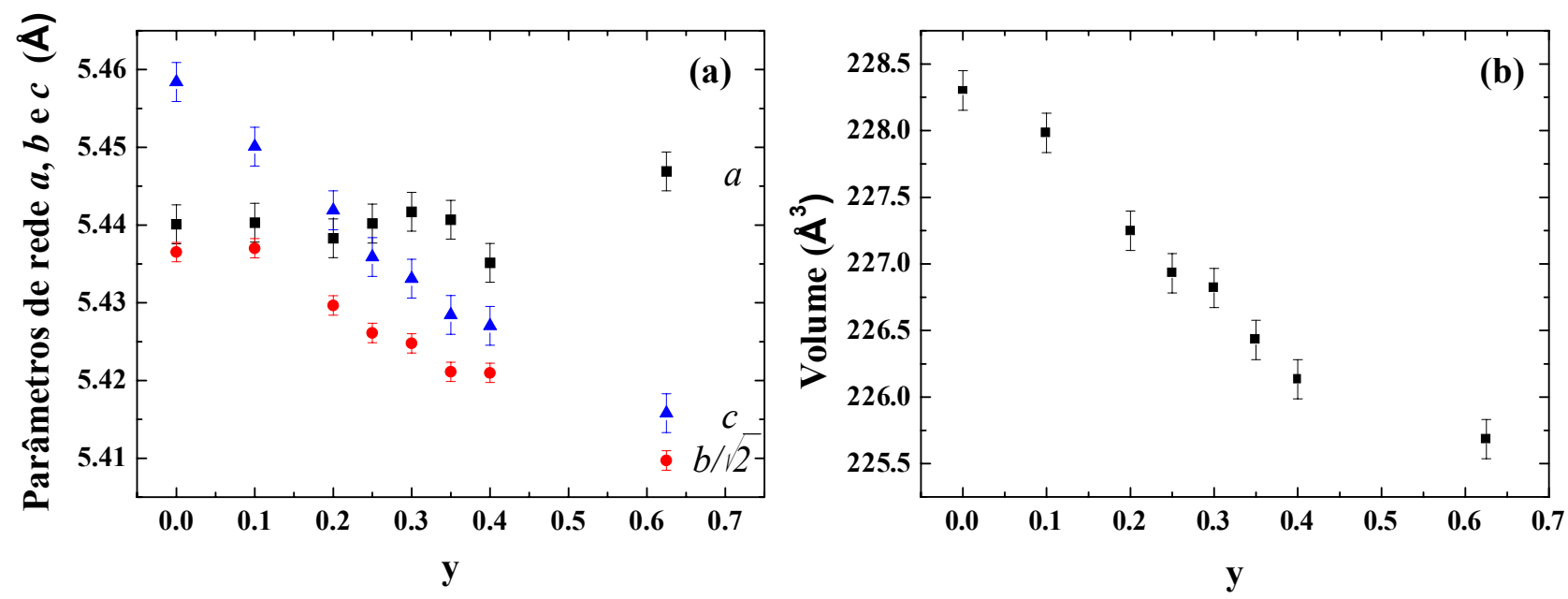

Figura 3.2.2 - (a) Evolução dos parâmetros de rede $a, b$ e $c$ e (b) do volume da cela unitária ao longo da série $\mathrm{La}_{5 / 8} \mathrm{P}_{\mathrm{y}} \mathrm{Pr}_{3 / 8} \mathrm{MnO}_{3}$.

Os parâmetros de rede $a, b$ e $c$ foram calculados para todas as amostras com a finalidade de observar suas evoluções ao longo da série. Esses parâmetros de rede e o volume da cela unitária como função da concentração de Pr estão mostrados na Fig. 3.2.2. O decréscimo observado nos parâmetros de rede $b$ e $c$ com o aumento de $\mathrm{y}$, sendo que o último decresce mais rapidamente, estão de acordo com os resultados obtidos por Collado et al. ${ }^{[4]}$ O parâmetro de rede $a$ foi observado não variar muito ao longo da série, quando comparado aos outros $b \mathrm{e}$ c. Devido aos resultados do refinamento não serem muito precisos, a observação do padrão de evolução do parâmetro de rede $a$ obtido pelos autores da Ref. 4 não foi inteiramente verificada. Nesta referência foi observado que o parâmetro de rede $a$ decresce lentamente na região de concentração $0 \leq \mathrm{y} \leq 0.25$ e aumenta de forma suave no intervalo $0.35 \leq \mathrm{y} \leq 0.625$. Ainda, na Fig. 3.2.2, observa-se um decréscimo no volume da cela unitária ao longo da série. Este resultado está 
de acordo com o esperado da substituição, pois o La, de raio iônico maior (ver Tabela 3.1.1, na pág. 39), é substituído gradualmente pelo Pr, de raio iônico menor, ao longo da série. A diminuição do volume implica na redução das distâncias interplanares, que está relacionada com a posição das reflexões em $2 \theta$, de acordo com a lei de Bragg (Eq. 2.2.1). Portanto, o deslocamento da reflexão referente ao plano (121), por exemplo, para valores de $2 \theta$ maiores, mostrado no detalhe da Fig. 3.2.1, está de acordo com esse decréscimo no volume da cela unitária ao longo da série. Esses resultados indicam que houve uma real substituição de La por Pr no composto $\mathrm{La}_{5 / 8 \text {-y }} \operatorname{Pr}_{\mathrm{y}} \mathrm{Ca}_{3 / 8} \mathrm{MnO}_{3}$. A evolução dos parâmetros de rede $a, b$ e $c$ pode ainda ser identificada no perfil das reflexões referentes aos planos (200), (121) e (002) que ocorrem em $2 \theta \sim 32.9^{\circ}$, por exemplo. A posição angular de uma reflexão referente a um plano $(h k l)$ pode ser obtida através da distância interplanar $\mathrm{d}_{h k l}$, na Eq. 2.2.2 e pela lei de Bragg na Eq. 2.2.1. A Tabela 3.2.1 mostra as posições angulares calculadas das reflexões referentes aos planos (200), (121) e (002) para cada membro da série.

\begin{tabular}{|c|c|c|c|c|c|c|}
\hline $\mathbf{y}$ & $2 \theta_{(002)}\left({ }^{0}\right)$ & $2 \theta_{(121)}\left({ }^{0}\right)$ & $2 \theta_{(200)}\left({ }^{0}\right)$ & $\Delta 2 \theta_{(002,121)}\left({ }^{0}\right)$ & $\Delta 2 \theta_{(002,200)}\left({ }^{0}\right)$ & $\Delta 2 \theta_{(121,200)}\left({ }^{0}\right)$ \\
\hline $\mathbf{0}$ & 32.788 & 32.885 & 32.902 & 0.097 & - & - \\
\hline 0.10 & 32.840 & 32.896 & 32.900 & 0.056 & - & - \\
\hline 0.20 & 32.891 & 32.934 & 32.913 & - & 0.022 & - \\
\hline 0.25 & 32.928 & 32.952 & 32.901 & - & 0.027 & - \\
\hline 0.30 & 32.945 & 32.958 & 32.892 & - & 0.053 & - \\
\hline 0.35 & 32.975 & 32.978 & 32.898 & - & 0.077 & - \\
\hline 0.40 & 32.983 & 32.990 & 32.933 & - & 0.050 & - \\
\hline 0.625 & 33.054 & 33.024 & 32.859 & - & - & 0.165 \\
\hline
\end{tabular}

Tabela 3.2.1 - Posições angulares calculadas das reflexões referentes aos planos (200), (121) e (002) como função de y. $\Delta 2 \theta$ é a distância angular entre duas reflexões vizinhas que ocorrem em posições angulares menores. 


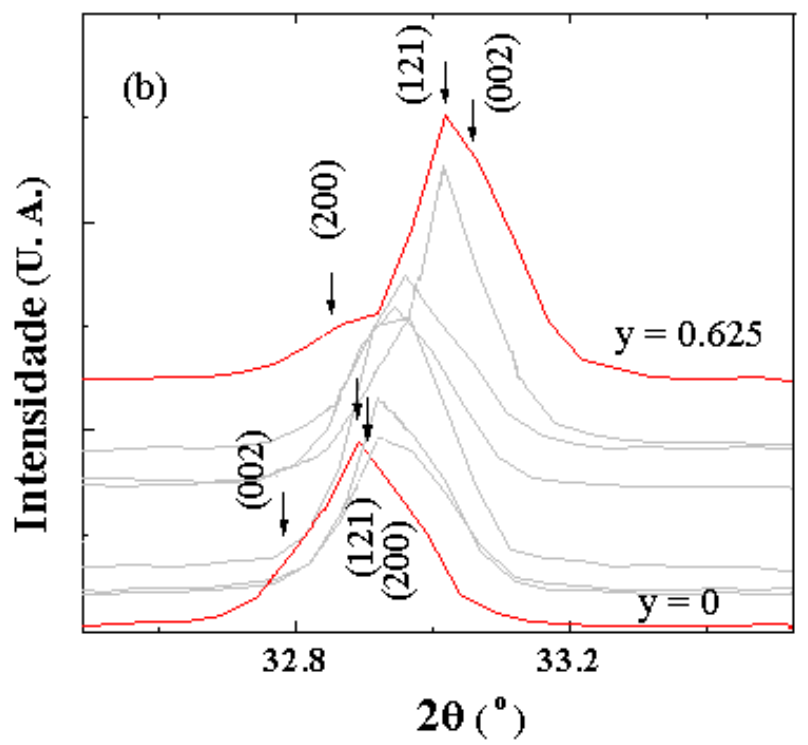

Figura 3.2.3 - Detalhes dos diagramas de DRX indicam as reflexões dos planos (200), (121) e (002). As setas indicam as posições calculadas das reflexões dos planos para a amostra com $y=0$ e 0.625 . Essas duas amostras foram escolhidas por apresentarem maior distância angular entre duas reflexões, veja Tabela 3.2.1.

O detalhe do diagrama de DRX indicado na Fig. 3.2.3 e os dados da Tabela 3.2.1 evidenciam alterações nos valores dos parâmetros de rede $a, b$ e $c$ destes materiais. Na Fig. 3.2.3 os diagramas de DRX para as amostras com y $=0$ e 0.625 são destacados dos demais, por apresentarem distância angular maior entre as reflexões que ocorrem em $2 \theta \sim 32.9^{\circ}$. Nesses dois compostos, a distância angular entre duas reflexões vizinhas é mais pronunciada, sendo $\sim 0.1^{\circ} \mathrm{e} \sim 0.16^{\circ}$ para amostras com y $=0$ e 0.625 , respectivamente. Como pode ser visualizada na Fig. 3.2.3, para a amostra com $\mathrm{y}=0.625$, a reflexão pertencente ao plano (200) é identificada via um pico que ocorre em uma posição angular menor em relação às reflexões referentes aos planos (121) e (002). Para a amostra com $\mathrm{y}=0$, as três reflexões não são diferenciadas, apesar da distância angular entre as reflexões referentes aos planos $(002)$ e (121) ser de $\sim 0.1^{\circ}$. Para outras composições, as reflexões referentes a esses três planos ocorrem muito próximas umas das outras, sendo que no diagrama de DRX as três reflexões são 
observadas a ocorrer em uma única reflexão. Pequenas mudanças nos perfis de outros conjuntos de reflexões podem ser observadas, mas uma análise cuidadosa é difícil de ser realizada devido ao grande número de reflexões que ocorre próximo em uma certa faixa de $2 \theta$ e do passo angular de $0.05^{\circ}$ utilizado nas medidas. Além disso, as reflexões que ocorrem em altos ângulos apresentam contribuições referentes à radiação $\mathrm{K}_{\alpha 2}$.

O principal objetivo desta seção foi estudar a evolução dos parâmetros de rede com a substituição de $\operatorname{Pr}$ no composto $\mathrm{La}_{5 / 8-\mathrm{y}} \mathrm{Pr}_{\mathrm{y}} \mathrm{Ca}_{3 / 8} \mathrm{MnO}_{3}$. Através da análise das reflexões pertencentes aos diagramas de DRX conclui-se que todos os compostos da série são de fase única. Os cálculos dos parâmetros de rede $a, b$ e $c$ e dos volumes das celas unitárias dos membros da série indicaram que houve uma real substituição de La por Pr. As evoluções dos parâmetros de rede $a, b$ e $c$ foram evidenciadas via pequenas alterações dos diagramas de DRX. A alteração nos parâmetros de rede pode ser comparada a uma pressão química, que altera a largura de banda $\mathrm{W}$, ou seja, modifica os parâmetros cristalográficos como a distância de ligação Mn-O e ângulo de ligação Mn-O-Mn, além de influenciar na separação de fase nesses materiais. Esses fatores são refletidos nas medidas de resistividade elétrica e magnetização, que são discutidas a seguir.

\subsubsection{Compostos $\mathrm{La}_{5 / 8} \mathrm{Ca}_{3 / 8} \mathrm{MnO}_{3}$ e $\mathrm{Pr}_{5 / 8} \mathrm{Ca}_{3 / 8} \mathrm{MnO}_{3}$}

Os compostos $\mathrm{La}_{5 / 8} \mathrm{Ca}_{3 / 8} \mathrm{MnO}_{3}$ (LCMO) e $\operatorname{Pr}_{5 / 8} \mathrm{Ca}_{3 / 8} \mathrm{MnO}_{3}$ (PCMO) correspondem aos dois "extremos" da série $\mathrm{La}_{5 / 8-\mathrm{y}} \mathrm{Pr}_{\mathrm{y}} \mathrm{Ca}_{3 / 8} \mathrm{MnO}_{3}$, portanto foram selecionados aqui para serem discutidos preliminarmente. As manganitas $\mathrm{La}_{1-\mathrm{x}} \mathrm{Ca}_{\mathrm{x}} \mathrm{MnO}_{3}$ e $\operatorname{Pr}_{1-\mathrm{x}} \mathrm{Ca}_{\mathrm{x}} \mathrm{MnO}_{3}$ são amplamente estudadas, especialmente aquelas com nível de dopagem $\mathrm{x} \sim 0.33$ : o primeiro por apresentar temperatura de Curie $\mathrm{T}_{\mathrm{C}}$ em alta temperatura e o segundo por apresentar ordenamento de carga e 
orbital. $^{[12,13]}$ Nesse contexto, são discutidos os resultados das medidas de resistividade elétrica $\rho(\mathrm{T})$ e de susceptibilidade magnética $\chi(T)$ obtidas para as amostras de LCMO e PCMO. As curvas de $\rho(\mathrm{T})$ foram obtidas no processo de aquecimento e resfriamento das amostras, no intervalo de temperatura de 5 a $350 \mathrm{~K}$ e na ausência de campo magnético externo. As curvas de $\chi(\mathrm{T})$ foram obtidas no processo de ZFC e FC, no intervalo de medida de 5 a $350 \mathrm{~K}$ e sob campo magnético externo de $2 \mathrm{kOe}$, cuja magnitude é suficiente para alinhar os domínios magnéticos, sem alterar as propriedades da fase isolante de ordenamento de carga OC. ${ }^{[14]}$ A definição e determinação das temperaturas de transição de fase ( $\mathrm{T}_{\mathrm{MI}}, \mathrm{T}_{\mathrm{C}}, \mathrm{T}_{\mathrm{OC}}$, etc) relevantes para a discussão das propriedades físicas desses materiais estão apresentadas nas seções 2.3 e 2.4 e também ao longo do texto.

As curvas de $\chi(T)$ e $\rho(T)$ para a amostra LCMO são mostradas nas Figs. 3.2.4(a) e (b). Observa-se que não há diferenças significativas entre as curvas obtidas nos processos de resfriamento e de aquecimento da amostra. Observa-se também que nas curvas mostradas na Fig. 3.2.4(a), com o decréscimo da temperatura, há a ocorrência de uma transição do estado paramagnético PM para o estado ferromagnético $\mathrm{FM}$ em $\mathrm{T}_{\mathrm{C}} \sim 261 \mathrm{~K}$. Essa transição magnética tem sua assinatura nas curvas de $\rho(T)$, caracterizada por uma transição de fase do tipo metal-isolante MI, definida por um máximo na magnitude de $\rho(T)$, que ocorre em $\mathrm{T}_{\mathrm{MI}} \sim 264 \mathrm{~K}$. Acima de $\mathrm{T}_{\mathrm{MI}}$, esses compostos apresentam um comportamento isolante e abaixo desta um comportamento metálico (a magnitude de $\rho(\mathrm{T})$ decresce com o decréscimo da temperatura). Esse composto é, portanto, caracterizado pela presença de uma fase paramagnética-isolante PMI em altas T e outra ferromagnética-metálica FMM em baixas T. Para a amostra LCMO, a variação máxima na magnitude de $\rho(\mathrm{T})$ em toda a faixa de T medida é 
$\sim 3$ vezes, sendo que a resistividade residual $\rho_{0}\left(\rho_{0}=\rho(T=10 \mathrm{~K})\right)$ é $9 \times 10^{-3} \Omega \mathrm{cm}$ e a resistividade máxima $\rho_{\text {Máx }}\left(\rho_{\text {Máx }}=\rho\left(\mathrm{T}=\mathrm{T}_{\mathrm{MI}}\right)\right)$ é $2.7 \times 10^{-2} \Omega \mathrm{cm}$.
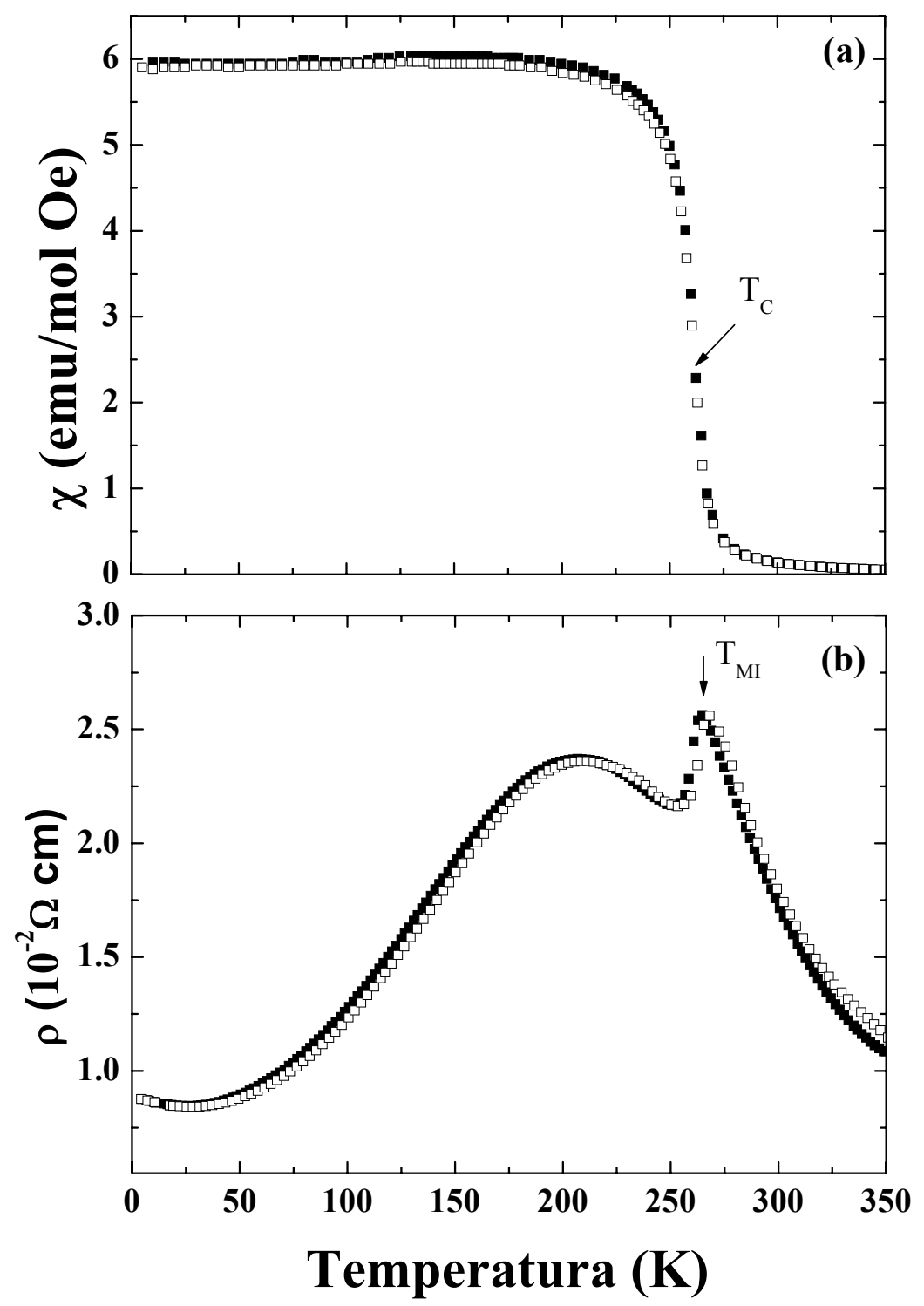

Figura 3.2.4 - (a) Curvas de susceptibilidade magnética obtidas no processo de ZFC (símbolo aberto) e de FC (símbolo fechado). (b) Curvas de resistividade elétrica como função da temperatura, obtidas nos processos de aquecimento (símbolo aberto) e de resfriamento (símbolo fechado) para a amostra LCMO. As temperaturas de transição indicadas pelas setas são: $\mathrm{T}_{\mathrm{MI}}$ (metal-isolante) e $\mathrm{T}_{\mathrm{C}}$ (temperatura de Curie). 
O comportamento de $\rho(\mathrm{T})$ em altas $\mathrm{T}$ foi abordado de diversas maneiras na literatura (condução via polarons, ${ }^{[15]}$ ativação térmica, ${ }^{[16]}$ VRH-"Mott variablerange-hopping,",[17] etc), mas não será tratado aqui devido à dificuldade de diferenciar os resultados apresentados por esses modelos em uma faixa restrita de T. ${ }^{[18]}$ Em baixas T, o alinhamento espontâneo dos spins dos íons de Mn, abaixo de $T_{C}$, permite a delocalização dos elétrons $e_{g}$, resultando na redução da magnitude de $\rho(T)$ para $T \leq T_{C}$. Esse modelo é baseado na interação de duplatroca, discutido na seção 1.2.3. Na Fig. 3.2.4(a), observa-se a magnetização de saturação $\mathrm{M}_{\mathrm{S}}$ com um valor relativamente alto de $\sim 6 \mathrm{emu} / \mathrm{mol} \mathrm{Oe}$, consistente com o baixo valor de $\rho_{0}$ observado nas curvas da Fig. 3.2.4(b). $\mathrm{M}_{\mathrm{S}}$ aqui é definida como sendo o valor constante de $\chi(\mathrm{T})$ no limite de baixas $\mathrm{T}$ sob campo magnético $\mathrm{H}=2 \mathrm{kOe}$.

As curvas de $\chi(T)$ e $\rho(T)$ para a amostra PCMO são mostradas nas Figs. 3.2.5 (a) e (b). Os compostos PCMO e LCMO contêm a mesma densidade de portadores de carga (razão entre os íons $\mathrm{Mn}^{3+}$ e $\mathrm{Mn}^{4+}$ ), mas o valor de $\mathrm{T}_{\mathrm{MI}}$ para os dois compostos varia consideravelmente, sendo $\mathrm{T}_{\mathrm{MI}} \sim 63 \mathrm{~K}$ na amostra PCMO. Outra característica marcante é a variação na magnitude de $\rho_{\text {Máx. }}$ Enquanto que a variação para a amostra LCMO foi de apenas 2.5 vezes em relação à magnitude de $\rho(\mathrm{T}=350 \mathrm{~K})$, para a amostra $\mathrm{PCMO}$, $\rho_{\text {Máx }}$ foi observado variar sete ordens de grandeza. Vale ressaltar que a magnitude de $\rho(T=350 \mathrm{~K})$ para as duas amostras é essencialmente a mesma, ou seja, $\sim 10^{-2} \Omega \mathrm{cm}$. A fração volumétrica das regiões FM também foi alterada com a substituição de La por $\operatorname{Pr}$, como pode ser inferido da comparação entre os valores de $\mathrm{M}_{\mathrm{S}}$ das curvas de $\chi(T)$ para as duas amostras. Nota-se que ocorre uma redução significativa no valor de $\mathrm{M}_{\mathrm{S}}$ de $\sim 6 \mathrm{emu} / \mathrm{mol}$ Oe (Fig. 3.2.4(a)) para $\sim 0.6 \mathrm{emu} / \mathrm{mol}$ Oe (Fig. 3.2.5(a)) para as amostras LCMO e PCMO, respectivamente. 
Adicionalmente, o composto PCMO exibe uma transição de fase para o estado de ordenamento de carga $\mathrm{OC}$ dos íons $\mathrm{Mn}^{3+}$ e $\mathrm{Mn}^{4+}$ que pode ser visualizada na curva de $\rho(\mathrm{T})$ pelo ponto de inflexão que ocorre quando a taxa de crescimento de $\rho(\mathrm{T})$ varia nesse ponto.
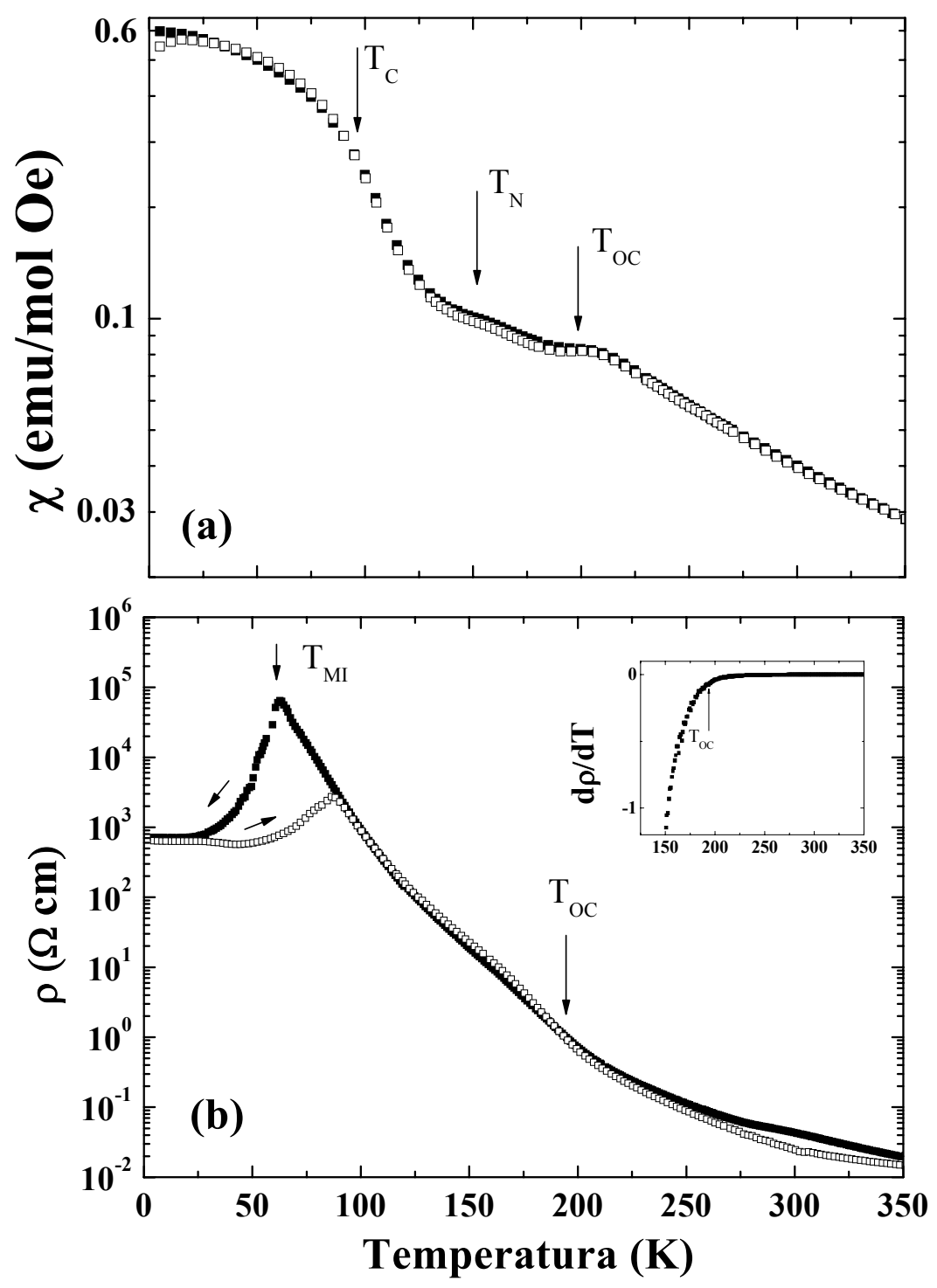

Figura 3.2.5 - a) Curvas de susceptibilidade magnética obtidas no processo de ZFC (símbolo aberto) e de FC (símbolo fechado). (b) Curvas de resistividade elétrica como função da temperatura, obtidas nos processos de aquecimento (símbolo aberto) e de resfriamento (símbolo fechado) para a amostra PCMO. As temperaturas de transição indicadas são: $\mathrm{T}_{\mathrm{MI}}$ (metal-isolante), $\mathrm{T}_{\mathrm{C}}$ (temperatura de Curie), $\mathrm{T}_{\mathrm{OC}}$ (ordenamento de carga/orbital) e $\mathrm{T}_{\mathrm{N}}$ (temperatura de ordenamento antiferromagnética). $\mathrm{O}$ detalhe mostra a derivada de $\rho(\mathrm{T})$ como função da temperatura. 
Em geral, compostos com pequeno raio iônico médio do sítio $\mathrm{A}\left\langle\mathrm{r}_{\mathrm{A}}\right\rangle$, caso da amostra PCMO, apresentam distorções acentuadas dos octaedros $\mathrm{MnO}_{6} \mathrm{e}$, como conseqüência, ocorre a redução da largura de banda devido ao fator de tolerância. O estreitamento da largura de banda resulta no estado de localização de cargas com a simultânea estabilização da estrutura antiferromagnética AF. Uehara et al. ${ }^{[7]}$ mostraram que o OC que ocorre na amostra PCMO é do mesmo tipo que ocorre na manganita $\mathrm{La}_{0.5} \mathrm{Ca}_{0.5} \mathrm{MnO}_{3}$, ou seja, com $\mathrm{Mn}^{3+} / \mathrm{Mn}^{4+}=1$, sendo que os excessos de cargas poderiam se acomodar como defeitos nos domínios de OC. ${ }^{[19]}$ Devido ao fato dos portadores de carga ficarem localizados, ocorre um grande aumento na magnitude de $\rho(T)$. Como pode ser visto no detalhe da Fig. 3.2.5(b), os valores de $\mathrm{d} \rho / \mathrm{dT}$ acima de $\mathrm{T}_{\mathrm{OC}} \sim 194 \mathrm{~K}$ são constantes. Isso indica que não há variação no processo (ou mecanismo) de transporte eletrônico entre $\sim 194$ e $350 \mathrm{~K}$. Porém, na temperatura $\mathrm{T}_{\mathrm{OC}} \sim 194 \mathrm{~K}$, a curva apresenta uma mudança de comportamento, a partir da qual d $\rho / \mathrm{dT}$ inicia um decréscimo acentuado, indicando que a taxa de variação de $\rho(T)$, com o decréscimo de $\mathrm{T}$, é muito maior abaixo de $\mathrm{T}_{\mathrm{OC}}$. Isso sugere uma alteração no mecanismo de condução e pode ser atribuído ao ordenamento de carga.

As medidas de $\chi(\mathrm{T})$ também indicam uma certa correspondência com os dados de $\rho(\mathrm{T})$ nas amostras PCMO. Observa-se que, com o decréscimo em T, há ocorrência de um máximo local em $\sim 197 \mathrm{~K}$, atribuído a $\mathrm{T}_{\mathrm{OC}}$, seguido da temperatura de ordenamento $\mathrm{AF}$ em $\mathrm{T}_{\mathrm{N}} \sim 148 \mathrm{~K} \mathrm{e}$, mais abaixo, em $\mathrm{T}_{\mathrm{C}} \sim 95 \mathrm{~K}$, correspondendo ao ordenamento FM. As temperaturas de transição, mostradas por setas na Fig. 3.2.5(a), foram definidas baseando-se nos estudos de difração de raios-X e de nêutrons realizados para o $\operatorname{Pr}_{1-\mathrm{x}} \mathrm{Ca}_{\mathrm{x}} \mathrm{MnO}_{3},{ }^{[20]}$ no qual foram determinadas as seguintes temperaturas de transição: $\mathrm{T}_{\mathrm{OC}}$ entre 200 e $250 \mathrm{~K}, \mathrm{~T}_{\mathrm{N}}$ (ordenamento AF) $\sim 130 \mathrm{~K}$ e $\mathrm{T}_{\mathrm{C}} \sim 110 \mathrm{~K}$. Na Fig. 3.2.5(b), observa-se que as 
curvas de $\rho(T)$, obtidas nos processos de resfriamento e de aquecimento, apresentam irreversibilidade térmica na faixa de temperatura $25 \lesssim \mathrm{T} \lesssim 90 \mathrm{~K}$. A presença de histerese térmica sugere que a transição de fase MI seja de primeira ordem, indicando a coexistência de fases ferromagnética-metálica FMM e de ordenamento de carga-isolante OCI nessa faixa de $\mathrm{T}$. Trabalhos teóricos e experimentais sugeriram evidências de coexistência e competição entre duas fases no sistema. ${ }^{[21-26]}$ Esses trabalhos ainda evidenciam um alto grau de desordem abaixo da transição OC, devido a quase-degenerescência em energia dos estados FM e de OC-AF. Nessa situação espera-se que a instabilidade da fase FM seja facilmente removida pela aplicação de um campo magnético relativamente baixo, resultando na transição MI com caráter percolativo. A fase metálica também pode ser induzida por aplicação de pressão hidrostática, ${ }^{[27]}$ irradiação por raios- $X,{ }^{[28]} \mathrm{luz}^{[29,30]}$ ou campo elétrico. ${ }^{[29]}$

Os trabalhos de Okamoto et al. ${ }^{[31]}$ indicam que muitas características da transição de fase nas manganitas são atribuídas ao grau de liberdade orbital. Adicionalmente, os trabalhos experimentais de Zimmermann et al. ${ }^{[32]}$ indicam que os compostos $\operatorname{Pr}_{1-\mathrm{x}} \mathrm{Ca}_{\mathrm{x}} \mathrm{MnO}_{3}(\mathrm{x}=0.4$ e 0.5$)$ apresentam transição de ordenamento de carga e orbital em $\mathrm{T}_{\mathrm{OC} / \mathrm{OO}}$ e em seguida ordenamento $\mathrm{AFM}$ do tipo CE (descrito por Wollan e Koehler ${ }^{[33]}$ ) com o decréscimo de T. Logo, será considerado que na amostra PCMO também ocorre o ordenamento OC e OO na mesma temperatura. Abaixo de $\mathrm{T}_{\mathrm{OC} / \mathrm{OO}}$ ocorre o ordenamento de carga com coerência de longo alcance, mas o ordenamento orbital com coerência de longo alcance não é estabelecido em qualquer T. Portanto, isso resulta em um complexo diagrama de fases nesses materiais, sendo que os trabalhos de Hotta e Dagotto $^{[21]}$ indicaram competição entre a fase FM e os estados OC com vários tipos de ordenamentos $\mathrm{CE}$ nesses mesmos materiais. Além disso, foram 
propostas diferentes polarizações dos orbitais, dependendo dos diversos tipos de ordenamento. $^{[21]}$ Logo, a amostra PCMO apresenta várias transições de fase indicadas pelas setas na Fig. 3.2.5 devido, provavelmente, a esses graus de liberdade de carga, orbital e spin, que competem para a determinação dos ordenamentos magnéticos como função da temperatura. Assim, baseado nessas referências, para a amostra $\mathrm{PCMO}$ é inferido que abaixo de $\mathrm{T}_{\mathrm{OC} / \mathrm{OO}} \sim 194 \mathrm{~K}$ é estabelecido o ordenamento de carga de longo alcance até $T_{\mathrm{N}} \sim 148 \mathrm{~K}$. Entre $\mathrm{T}_{\mathrm{N}}$ e $\mathrm{T}_{\mathrm{C}} \sim 95 \mathrm{~K}$ os spins de $\mathrm{Mn}$ da região OC ordenam-se AF em uma estrutura do tipo CE e, abaixo de $\mathrm{T}_{\mathrm{C}}$, os "clusters" $\mathrm{FM}$ tornam-se correlacionados e ocorre o ordenamento FM. ${ }^{[27]}$

Os resultados da literatura indicam que as manganitas $\operatorname{Pr}_{1-\mathrm{x}} \mathrm{Ca}_{\mathrm{x}} \mathrm{MnO}_{3}$ exibem comportamento isolante em todo o intervalo de dopagem $\mathrm{x}$, mesmo naquelas que apresentam fase FM. Portanto, é difícil encontrar correspondências claras entre os resultados das medidas de $\rho(\mathrm{T})$ e $\chi(\mathrm{T})$. Entretanto, há correspondências entre os dados apresentados aqui e ainda, observa-se uma transição MI nas curvas de $\rho(T)$ na ausência de campo magnético, resultado dificilmente observado na literatura (ver fig. 3.2.5). Esse fato pode estar relacionado com a temperatura e/ou tempo de sinterização das amostras. A alta temperatura de sinterização $\mathrm{T}_{\mathrm{S}}=1400{ }^{\circ} \mathrm{C}$, a qual a amostra PCMO foi submetida, pode ter provocado uma maior estabilidade da fase FM em baixas $\mathrm{T}$ e, assim, possibilitando a ocorrência da transição MI. Portanto, $\mathrm{T}_{\mathrm{S}}$ também poderia estar exercendo um papel na estabilização da fase metálica, possibilitando a ocorrência da transição MI mesmo na ausência de campo magnético externo. De fato, as amostras com $\mathrm{y}=0.625$ sinterizadas a $1350{ }^{\circ} \mathrm{C}$ não apresentaram transição $\mathrm{MI}$ em toda a faixa de $\mathrm{T}$ medida, como pode ser inferido das curvas da Fig. 3.2.6. Vale destacar que a transição de fase MI nesta amostra não foi observada devido à magnitude da queda de tensão sobre a 
amostra exceder a escala do voltímetro utilizado. Assim, o método de preparação dessas amostras parece influenciar bastante as propriedades físicas desses materiais que possuem forte competição entre os graus de liberdade da rede, de spin e de carga.

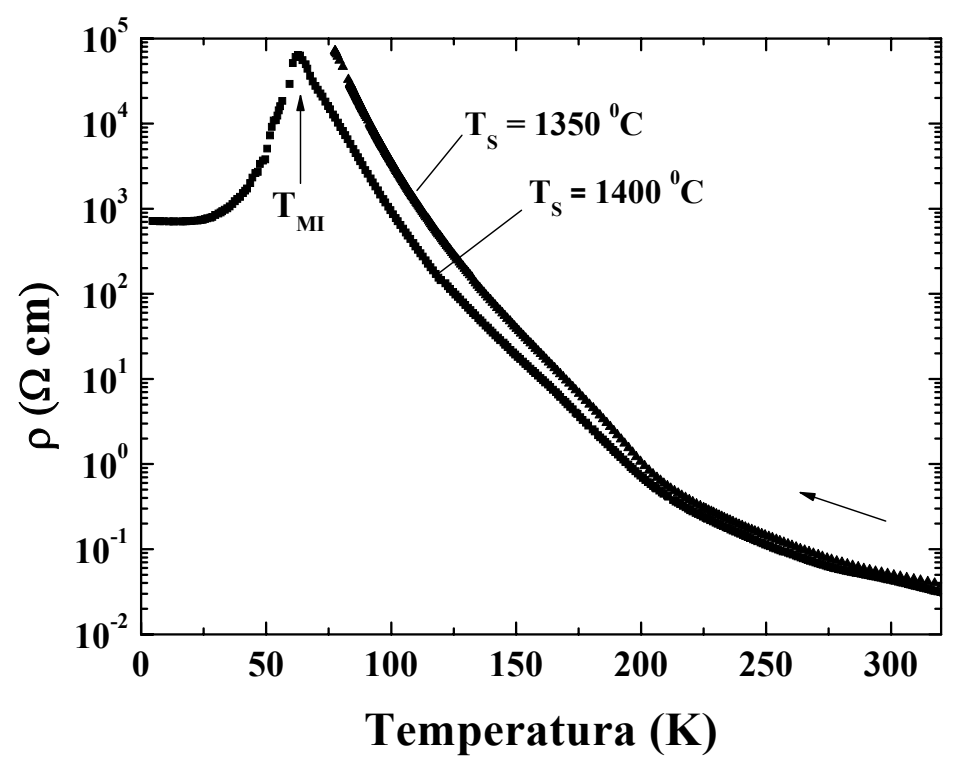

Figura 3.2.6 - Curvas de resistividade elétrica como função da temperatura obtidas no processo de resfriamento para as amostras com $\mathrm{y}=0.625$ sinterizadas a 1350 e $1400{ }^{\circ} \mathrm{C}$.

Comparando-se os resultados experimentais de $\rho(\mathrm{T})$ e $\chi(\mathrm{T})$ das amostras LCMO e PCMO nota-se que a substituição total de La por Pr resulta em uma mudança drástica nas propriedades físicas nesses compostos. ${ }^{[34]}$ As medidas de $\rho(\mathrm{T})$ e $\chi(\mathrm{T})$ indicaram também que um dos extremos da série, o composto $\mathrm{La}_{5 / 8} \mathrm{Ca}_{3 / 8} \mathrm{MnO}_{3}$, é basicamente FMM abaixo de $\sim 261 \mathrm{~K}$ e o outro extremo, o composto $\operatorname{Pr}_{5 / 8} \mathrm{Ca}_{3 / 8} \mathrm{MnO}_{3}$, é OCI abaixo de $\sim 194 \mathrm{~K}$. Apesar de conter o mesmo número de pares de íons $\mathrm{Mn}^{3+}$ e $\mathrm{Mn}^{4+}$, um dos parâmetros físicos relevante no efeito de DT, o composto LCMO é um material típico FM de DT e o composto PCMO é um isolante com $\mathrm{OC} / \mathrm{OO}$, exibindo característica metálica apenas em baixas T. Devido ao caráter percolativo das propriedades de transporte eletrônico nesses materiais, pode-se concluir que as frações relativas das fases coexistentes variam com a temperatura e certamente com a substituição de La 
por Pr. Ao comparar essas duas amostras, nota-se que quando a energia cinética dos portadores de carga é dominante sobre a Coulombiana, encontra-se um estado fundamental metálico e com ordenamento ferromagnético, que é o caso do LCMO. Quando os efeitos de localização tornam-se dominantes, o estado fundamental é isolante, com ordenamento de carga/orbital e fortes distorções na rede cristalina (efeito JT), sendo este o caso do PCMO. A seguir são estudados, juntamente com estes, os outros membros da série $\mathrm{La}_{5 / 8-\mathrm{y}} \mathrm{Pr}_{\mathrm{y}} \mathrm{Ca}_{3 / 8} \mathrm{MnO}_{3}$ com a finalidade de verificar as propriedades físicas da série como função da substituição gradual de La por Pr. Especial atenção será dada à coexistência de fases e como estas fases competem entre si como função de $<\mathrm{r}_{\mathrm{A}}{ }$.

\subsubsection{Caracterização através de medidas de resistividade elétrica e de magnetização}

Curvas de susceptibilidade magnética $\chi(T)$ e de resistividade elétrica $\rho(T)$ são mostradas nas Figs. 3.2.7(a) e (b), respectivamente, para as amostras policristalinas de $\mathrm{La}_{5 / 8-\mathrm{y}} \mathrm{Pr}_{\mathrm{y}} \mathrm{Ca}_{3 / 8} \mathrm{MnO}_{3} ; \mathrm{y}=0,0.10,0.20,0.25,0.30,0.35,0.40 \mathrm{e}$ 0.625 ; sinterizadas a $1400^{\circ} \mathrm{C}$. As medidas de $\rho(\mathrm{T})$ foram obtidas nos processos de aquecimento e resfriamento, no intervalo de temperatura de 5 a $350 \mathrm{~K}$ e na ausência de campo magnético externo. As curvas de $\chi(\mathrm{T})$ foram obtidas no processo de ZFC e FC e sob um campo magnético externo de 2 kOe. ${ }^{[14]}$

$\mathrm{O}$ detalhe da Fig. 3.2.7(a) mostra algumas das curvas de $\mathrm{d}(\chi(\mathrm{T})) / \mathrm{dT}$ como função da temperatura, onde a temperatura de Curie $T_{C}$ é determinada pelo mínimo local dessa derivada. As curvas utilizadas para a determinação de $\mathrm{T}_{\mathrm{C}}$ foram aquelas obtidas no processo de $\mathrm{FC}$. A partir das derivadas das curvas de $\rho(T)$, obtidas no processo de resfriamento, foram determinados os 
valores $\mathrm{T}_{\mathrm{MI}}$ e $\mathrm{T}_{\mathrm{OC}}$ de todos os compostos. As Figs. 3.2.8 (a) e (b) mostram, como exemplo, algumas curvas de $\mathrm{d} \rho / \mathrm{dT}$ como função da temperatura utilizadas na determinação de $\mathrm{T}_{\mathrm{MI}}$ e $\mathrm{T}_{\mathrm{OC}}$. Os resultados das medidas de $\chi(\mathrm{T}) \mathrm{e}$ $\rho(T)$ apresentados nesta seção estão, de um modo geral, de acordo com os obtidos nos mesmos compostos, por Uehara et al. ${ }^{[7]}$, Kim et al. ${ }^{[8]}$ e Collado et al. ${ }^{[4]}$

Na primeira parte desta seção serão apresentados os aspectos gerais das medidas de $\chi(T)$ e $\rho(T)$, abrangendo todas as amostras da série. A seguir são apresentadas discussões mais detalhadas dessas caracterizações, separando as amostras em três grupos. O primeiro grupo corresponde às amostras com $\mathrm{y} \leq 0.25$ (pobres em Pr), o segundo às amostras com $\mathrm{y} \geq 0.40$ (ricas em Pr) e o terceiro às amostras com $0.30 \leq \mathrm{y} \leq 0.40$.

Os resultados mostrados na Fig. 3.2.7 indicam que todos os compostos da série apresentam uma transição de fase do tipo metal-isolante MI, sugerindo a presença de fase FM em todos eles. Os resultados dessas medidas também indicam que as propriedades de transporte eletrônico e de magnetização estão estreitamente relacionadas. A Tabela 3.2.2 lista valores de grandezas importantes obtidos das curvas de $\rho(\mathrm{T})$, mostradas na Fig. 3.2.7(a), para a discussão das propriedades de transporte eletrônico como função de $<\mathrm{r}_{\mathrm{A}}>, \mathrm{T}_{\mathrm{MI}}$, $\mathrm{T}_{\mathrm{OC}}$, resistividade elétrica residual $\rho_{0}$ (definida como $\rho(10 \mathrm{~K})$ ) e resistividade elétrica máxima $\rho_{\text {Máx }}\left(\right.$ definida como $\rho\left(T=T_{M I}\right)$ ). A tabela também lista os valores de $\mathrm{T}_{\mathrm{C}}$, obtidos das curvas de $\chi(\mathrm{T})$ mostradas na Fig. 3.2.7(b). $\quad<\mathrm{r}_{\mathrm{A}}>$ foi calculado pela expressão: 


$$
\left\langle r_{A}\right\rangle=\left(\frac{5}{8}-y\right) r_{L a}+y r_{\mathrm{Pr}}+\left(\frac{3}{8}\right) r_{C a}
$$

onde y é a concentração de $\operatorname{Pr}$ e $r_{\mathrm{La}}, \mathrm{r}_{\mathrm{Pr}}$ e $\mathrm{r}_{\mathrm{Ca}}$ são os raios iônicos para a coordenação nove mostrados na Tabela 3.1 .1 (ver pág. 39). Os valores de $\left\langle\mathrm{r}_{\mathrm{A}}\right\rangle$ da Tabela 3.2.2 são os calculados teoricamente, mas as medidas de DRX da seção 3.2.1 sugeriram que houve, de fato, uma substituição efetiva de La por Pr ao longo da série.

\begin{tabular}{|c|c|c|c|c|c|c|}
\hline $\mathrm{y}$ & $<\mathrm{r}_{\mathrm{A}}>(\AA)$ & $\mathrm{T}_{\mathrm{C}}(\mathrm{K})$ & $\mathrm{T}_{\mathrm{MI}}(\mathrm{K})$ & $\mathrm{T}_{\mathrm{OC}}(\mathrm{K})$ & $\rho_{0}(\Omega \mathrm{cm})$ & $\rho_{\text {Máx }}(\Omega \mathrm{cm})$ \\
\hline 0 & 1.2025 & 261 & 264 & - & $9 \times 10^{-3}$ & $2.7 \times 10^{-2}$ \\
\hline 0.10 & 1.1988 & 238 & 247 & - & $3 \times 10^{-3}$ & $3.6 \times 10^{-2}$ \\
\hline 0.20 & 1.1951 & 206 & 228 & - & $7 \times 10^{-3}$ & $1.4 \times 10^{-1}$ \\
\hline 0.25 & 1.1933 & 193 & 212 & - & $2.3 \times 10^{-2}$ & $5.9 \times 10^{-1}$ \\
\hline 0.30 & 1.1914 & 179 & 190 & - & $1.7 \times 10^{-2}$ & $6.1 \times 10^{0}$ \\
\hline 0.35 & 1.1896 & 93 & 95 & 194 & $3.2 \times 10^{0}$ & $4.2 \times 10^{2}$ \\
\hline 0.40 & 1.1877 & 91 & 73 & 194 & $5.6 \times 10^{2}$ & $1.3 \times 10^{4}$ \\
\hline 0.625 & 1.1794 & 95 & 63 & 194 & $7.9 \times 10^{2}$ & $6.4 \times 10^{4}$ \\
\hline
\end{tabular}

Tabela 3.2.2 - Raio iônico médio do sítio $\mathrm{A}\left\langle\mathrm{r}_{\mathrm{A}}\right\rangle$, temperatura de Curie $\mathrm{T}_{\mathrm{C}}$, temperatura de transição de fase metal-isolante $\mathrm{T}_{\mathrm{MI}}$, de ordenamento de carga/orbital $\mathrm{T}_{\mathrm{OC}}$, resistividade elétrica residual $\rho_{0}(\rho(T=10 K))$ e resistividade elétrica em $T=T_{M I}$ ( $\rho_{\text {Máx }}$ ) como função da concentração y. Os traços na coluna de $\mathrm{T}_{\mathrm{OC}}$ indicam que a transição de ordenamento de carga não foi observada para os compostos com $\mathrm{y} \leq 0.30$. 

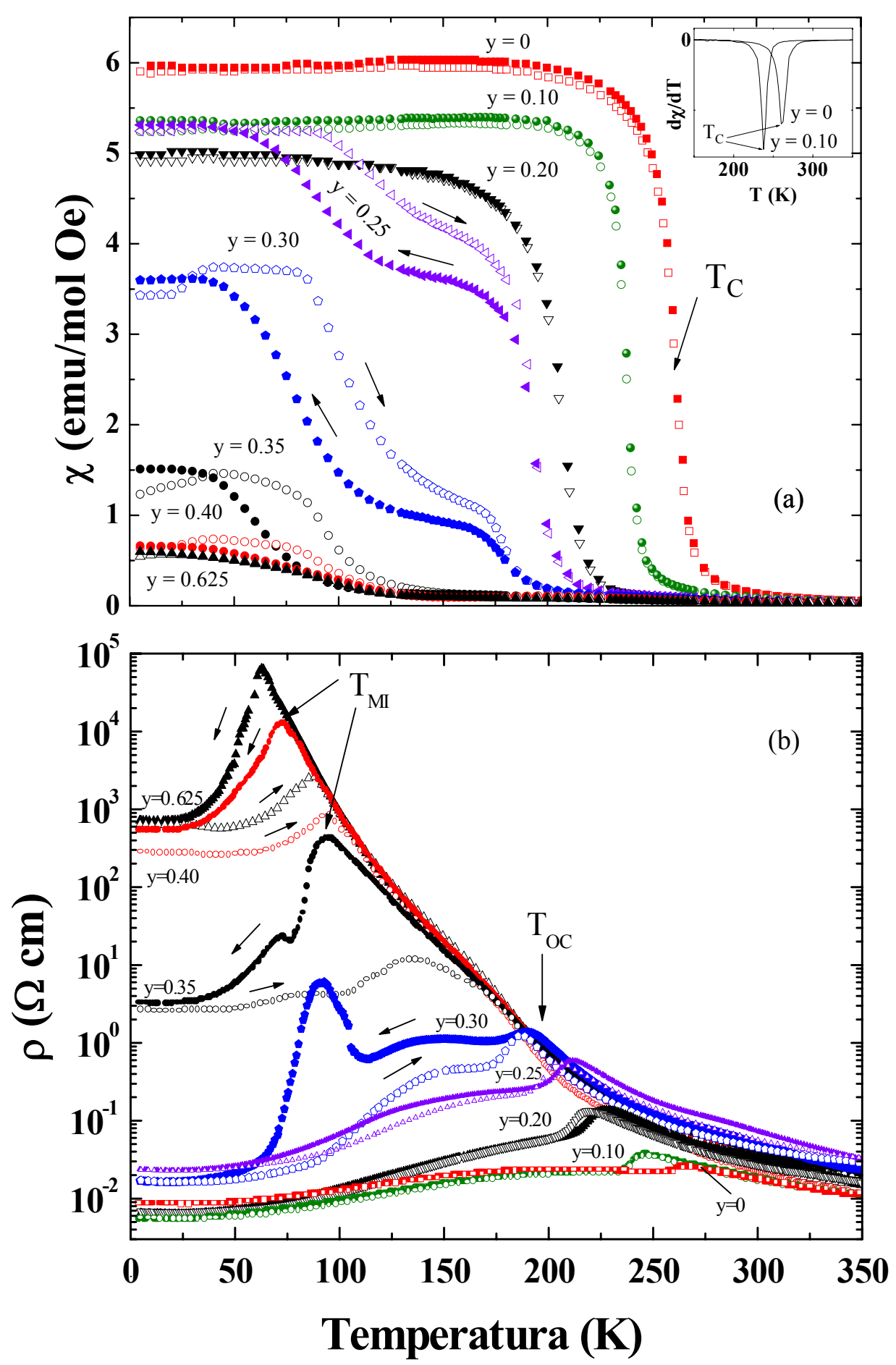

Figura - 3.2.7 Curvas de (a) susceptibilidade magnética e (b) resistividade elétrica como função da temperatura para a série $\mathrm{La}_{5 / 8-\mathrm{y}} \mathrm{Pr}_{\mathrm{y}} \mathrm{Ca}_{3 / 8} \mathrm{MnO}_{3}$. As curvas mostradas com símbolos abertos foram obtidas no processo de ZFC ou de aquecimento da amostra e os fechados no processo de $\mathrm{FC}$ ou de resfriamento. Esses processos térmicos estão indicados por setas. As temperaturas $\mathrm{T}_{\mathrm{C}}, \mathrm{T}_{\mathrm{MI}}$ e $\mathrm{T}_{\mathrm{OC}}$ para algumas amostras também estão indicadas por setas. 

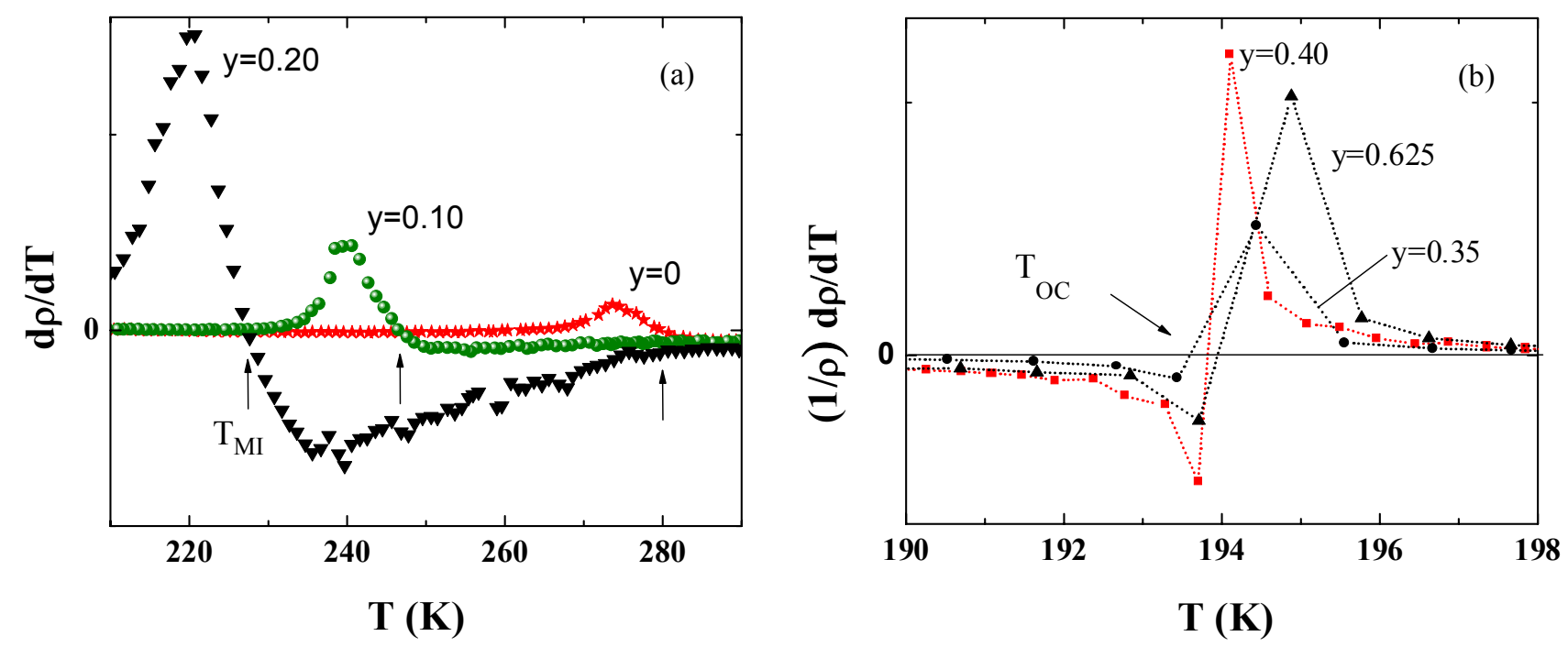

Figura 3.2.8 - Derivada d $/$ dT como função da temperatura para a determinação de: (a) temperaturas de transição de fase metal-isolante, indicadas por setas verticais, nas amostras representativas com y $=0,0.10$ e 0.20 ; (b) temperatura de ordenamento de carga para as amostras com y $=0.35,0.40$ e 0.625 . As linhas pontilhadas estão indicadas para melhor visualização dos pontos experimentais.

Uma característica que pode ser observada imediatamente na Fig. 3.2.7(b) e na Tabela 3.2.2 é que o decréscimo em $<\mathrm{r}_{\mathrm{A}}>$ resulta em um decréscimo de $\mathrm{T}_{\mathrm{MI}}$ e $\mathrm{T}_{\mathrm{C}}$ e no aumento da magnitude de $\rho_{\text {Máx }}$. Esses resultados estão de acordo com os estudos efetuados acerca dos efeitos da pressão química mostrados na literatura. ${ }^{[7-9]}$ Nesses compostos, a pressão química, devido à redução de $<\mathrm{r}_{\mathrm{A}}>$, resulta na alteração de parâmetros estruturais como a distância de ligação Mn-O e o ângulo de ligação Mn-O-Mn, que influenciam a transferência de portadores de carga entre os sítios de Mn. A redução do ângulo de ligação Mn-O-Mn, devido às distorções da estrutura cristalográfica, diminui a interação FM de DT e tende a aumentar a tendência de localização de carga. ${ }^{[6,30]}$ Portanto, o transporte eletrônico está fortemente relacionado com detalhes da estrutura cristalina desses materiais. ${ }^{[6]}$ As medidas de $\rho(\mathrm{T})$ também indicam que, além da transição de fase MI, os compostos com alta concentração de $\operatorname{Pr}$ apresentam transição de ordenamento de carga e orbital OC/OO (baseado na discussão da seção 3.2.2 
para a amostra PCMO) e, por simplicidade, a temperatura de transição para o estado OC/OO será indicada como $\mathrm{T}_{\mathrm{OC}}$. Observa-se que irreversibilidades ou histereses são evidentes entre as curvas de $\rho(T)$ obtidas durante os processo de resfriamento e aquecimento das amostras, ocorrendo em uma larga faixa de temperatura e marcadamente em amostras com $y \geq 0.25$. A presença de histerese térmica sugere que a transição de fase MI é de primeira ordem, ou seja, há a coexistência de regiões metálicas e isolantes no intervalo de $\mathrm{T}$ onde a histerese ocorre. Este aspecto sugere também a ocorrência de condução do tipo percolativa através de regiões metálicas imersas em regiões isolantes. Acerca deste ponto, os resultados experimentais obtidos por Uehara et al. ${ }^{[7]}$ indicam a coexistência, em escala micrométrica, de domínios FMM e de ordenamento de OCI nas manganitas $\mathrm{La}_{5 / 8-\mathrm{y}} \mathrm{Pr}_{\mathrm{y}} \mathrm{Ca}_{3 / 8} \mathrm{MnO}_{3}$. Adicionalmente, Kim et al. ${ }^{[8]}$ obtiveram resultados consistentes com a transição MI do tipo percolativa em sistemas de mistura de fases FM-OC nos mesmos compostos.

Nesses materiais, as regiões metálicas estão diretamente relacionadas com o ferromagnetismo. Sendo assim, é esperado que a fração volumétrica dos domínios FMM aumente com o decréscimo de $\mathrm{T}$ devido à magnetização espontânea do material. Baseado nisso, a condutividade elétrica do material aumenta no regime de baixas T, como pode ser observado nas curvas de $\rho(T)$ da Fig. 3.2.7(b). Adicionalmente, as curvas de $\chi(\mathrm{T})$ mostradas na Fig. 3.2.7(a) indicam que a magnetização de saturação $\mathrm{M}_{\mathrm{S}}$ diminui apreciavelmente com $\mathrm{o}$ aumento de $\mathrm{y}$, sendo que $\mathrm{M}_{\mathrm{S}}$ é assumido aqui como o valor de $\chi(\mathrm{T})$ no limite de baixas $\mathrm{T} . \mathrm{M}_{\mathrm{S}}$ é reduzido ao longo da série de $\sim 6 \mathrm{emu} / \mathrm{mol}$ Oe para a amostra com $\mathrm{y}=0$ para $0.6 \mathrm{emu} / \mathrm{mol}$ Oe na amostra com $\mathrm{y}=0.625$. Essa diminuição sugere que a fração volumétrica de domínios FM diminui com o aumento da concentração de Pr. Portanto, os dados combinados de $\rho(\mathrm{T})$ e $\chi(\mathrm{T})$ indicam uma 
redução do volume relativo de domínios FMM com o aumento de y. Esse resultado pode ser inferido também via valores de resistividade elétrica residual. Como pode ser visto na Tabela 3.2.2, obteve-se $\rho_{0} \sim 9 \times 10^{-3} \Omega \mathrm{cm}$ para a amostra com y $=0$ e $\rho_{0} \sim 7.9 \times 10^{2} \Omega$ cm para a amostra com $y=0.625$, ou seja, houve uma variação de $\sim 5$ ordens de grandeza neste valor, indicando que as amostras com altas concentrações de Pr, apesar de metálicas em baixas T, apresentam uma fração volumétrica apreciável de fase isolante. Uma variação robusta como essa

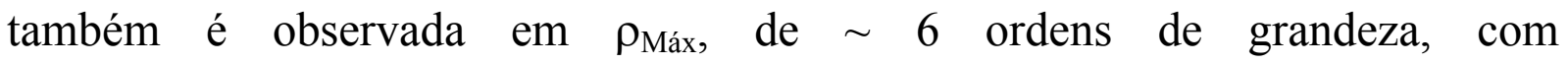
$\rho_{\text {Máx }} \sim 2.7 \times 10^{-2} \Omega \mathrm{cm}$ para a amostra com $\mathrm{y}=0$ e $\rho_{\text {Máx }} \sim 6.4 \times 10^{4} \Omega \mathrm{cm}$ para a amostra com $\mathrm{y}=0.625$. O decréscimo em $\mathrm{M}_{\mathrm{S}}$ ao longo da série também é outro indicativo de que a fase $\mathrm{OC} / \mathrm{OO}$ está presente até mesmo em baixas T. Esses dados estão consistentes com os da Ref. 35, que além da coexistência de fases FMM e OCI em $20 \mathrm{~K}$, foi observado que a fração volumétrica de domínios OC nesta mesma temperatura crescia rapidamente com y nos compostos $\mathrm{La}_{5 / 8-\mathrm{y}} \mathrm{Pr}_{\mathrm{y}} \mathrm{Ca}_{3 / 8} \mathrm{MnO}_{3}$.

Na Fig. 3.2.7(b), observa-se também que $\rho(T)$ em altas $T$ não varia de modo significativo com o aumento de $\mathrm{y}$, sugerindo que o mecanismo de transporte eletrônico na região não metálica é o mesmo para todas as amostras. ${ }^{[9]}$ As "irreversibilidades" observadas em $\rho(\mathrm{T})$ também ocorrem em $\chi(\mathrm{T})$ e também podem estar associadas à coexistência de fases FMM e de OCI. Conforme discutido, um dos extremos da série, a amostra com y $=0$ é basicamente FMM abaixo de $\sim 261 \mathrm{~K}$ e o outro extremo, a amostra com y $=0.625$, é OCI abaixo de $\sim 194 \mathrm{~K}$. As características das curvas de $\chi(\mathrm{T})$ e $\rho(\mathrm{T})$ para as outras composições de y parecem estar distribuídas entre esses dois extremos da série, sendo que a fração volumétrica das regiões metálicas parece decrescer com o 
aumento da concentração de Pr. Isso pode ser inferido observando-se as curvas de $\chi(T)$ e $\rho(T)$ na Fig. 3.2.7, onde $M_{S}$ diminui e $\rho_{\text {Máx }}$ aumenta significativamente com o aumento de y. Esses dados indicam que a alta concentração de Pr diminui o volume relativo de domínios FM, mas as amostras apresentam volume ou "clusters" suficientes para uma contribuição magnética apreciável e a ocorrência do ordenamento ferromagnético abaixo de $\mathrm{T}_{\mathrm{C}}$.

Até aqui foi apresentado um quadro geral do efeito de substituição de La por Pr ao longo da série. Com a finalidade de analisar as propriedades de transporte eletrônico com mais detalhes, as curvas de $\rho(T)$ serão apresentadas novamente em três partes para melhor visualização.

\subsection{3.a Propriedades das amostras com $y \leq 0.25$}

No cenário da separação de fases as amostras com pequenas concentrações de $\operatorname{Pr}$ no composto $\mathrm{La}_{5 / 8-\mathrm{y}} \mathrm{Pr}_{\mathrm{y}} \mathrm{Ca}_{3 / 8} \mathrm{MnO}_{3}$ apresentam frações volumétricas da fase FMM maior do que a fase isolante. Nesses compostos, o decréscimo de T favorece a fase FM de forma que as frações existentes crescem em diversas regiões aumentando seu volume relativo no material. Portanto, o volume de domínios FM necessários para que estes se conectem e ocorra a condução do tipo percolativa ocorre em $\mathrm{T}$ relativamente altas. As curvas de $\rho(\mathrm{T})$ das amostras com y $\leq 0.25$ estão mostradas na Fig. 3.2.9.

Para as amostras com $\mathrm{y} \leq 0.25, \mathrm{~T}_{\mathrm{MI}}$ desloca-se de forma suave para baixas $\mathrm{T}$ com o aumento de $\mathrm{y}$, sendo $\sim 264 \mathrm{~K} \mathrm{e} \sim 212 \mathrm{~K}$ nas amostras com $\mathrm{y}=0$ e 0.25 , respectivamente (veja Tabela 3.2.2, pág. 58). A resistividade elétrica máxima $\rho_{\text {Máx }}$ de cada amostra, $\rho\left(T=T_{M I}\right)$, varia aproximadamente uma ordem de magnitude com o aumento de y, sendo $2.7 \times 10^{-2} \Omega \mathrm{cm}$ para a amostra com y $=0 \mathrm{e}$ 
$5.9 \times 10^{-1} \Omega \mathrm{cm}$ na amostra com $y=0.25$. A resistividade residual $\rho_{0}$ nesses compostos é relativamente baixa, menor que $2.3 \times 10^{-2} \Omega \mathrm{cm}$, formando $\mathrm{o}$ conjunto de materiais basicamente metálicos da série. Ainda, a variação na magnitude de $\rho(T)$ em toda a faixa de T medida foi observada não variar mais do que uma ordem de grandeza. Todas essas características indicam que o estado fundamental dessas amostras é heterogêneo, mas composto de uma grande fração volumétrica da fase FMM. Essa fração é esperada decrescer com o aumento de y, com indicado, por exemplo, pelo aumento de $\rho_{0}$.

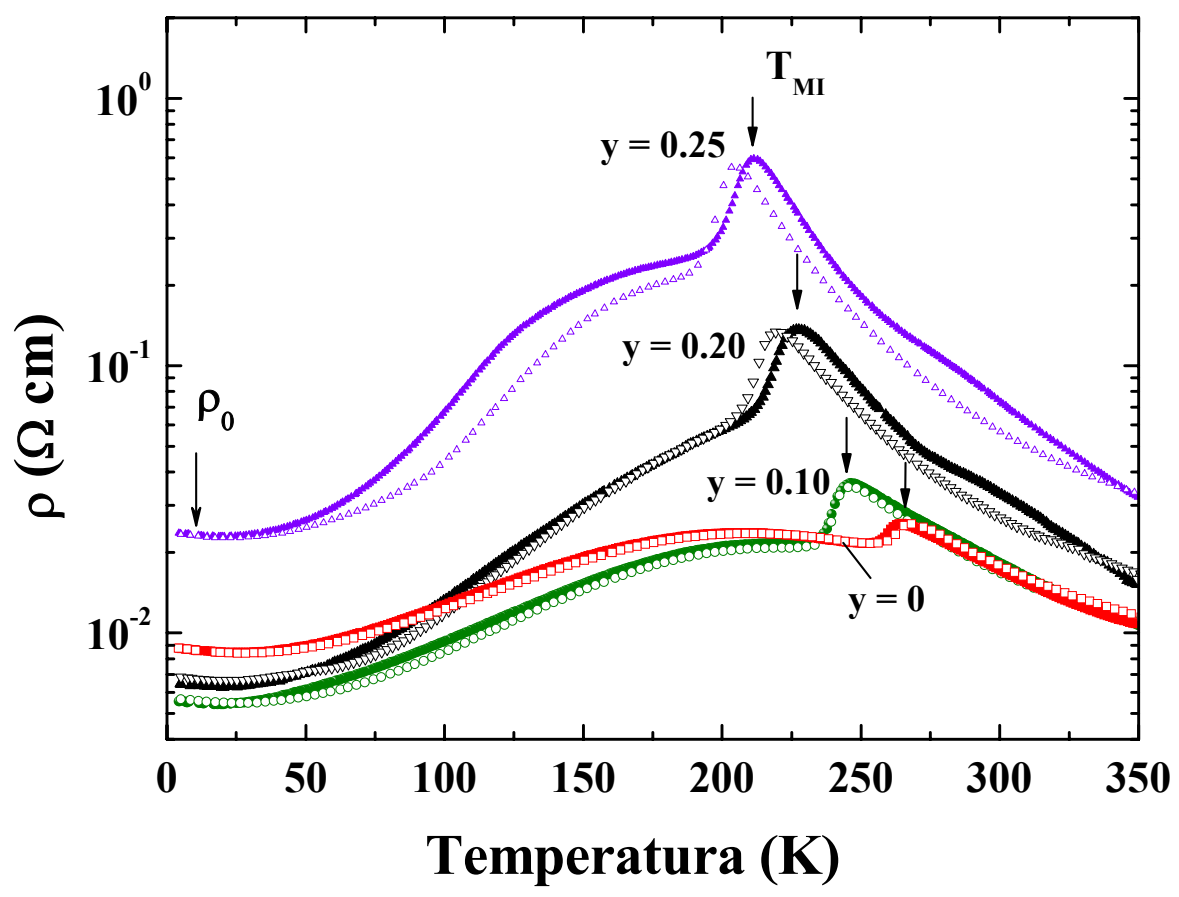

Figura 3.2.9 - Curvas de resistividade elétrica como função da temperatura para as amostras com $\mathrm{y}=0,0.10,0.20$ e 0.25 . As curvas mostradas com símbolos abertos foram obtidas no processo de aquecimento da amostra e os fechados no processo de resfriamento. $\mathrm{T}_{\mathrm{MI}}$ e $\rho_{0}$ estão indicadas por setas.

A irreversibilidade térmica nas curvas de $\rho(T)$ ocorre nas amostras com $\mathrm{y}=0.20$ e 0.25 , mas é mais marcante na última. A faixa de temperatura em que ocorre a histerese térmica é difícil de ser definida precisamente nesse conjunto 
de amostras. Provavelmente, em altas T, as irreversibilidades observadas devem estar relacionadas com as incertezas experimentais. A qualidade dos contatos das quatro pontas (descrita na seção 2.3) pode ter influenciado nas medidas, pois a magnitude da queda de tensão medida sobre essas amostras era muito pequena. Outra fonte de incerteza nas irreversibilidades reside nas taxas de aquecimento/resfriamento das amostras durante o processo de medida. Como esses materiais, em geral, apresentam relaxação eletrônica, pequenas alterações nessas taxas podem ser responsáveis pelos comportamentos observados. Entretanto, é possível afirmar que a histerese térmica realmente existe, pois $\rho_{\text {Máx }}$ ocorre em $\mathrm{T}$ significativamente diferentes para curvas obtidas nos processos de resfriamento e de aquecimento. Esse fato indica que a competição entre as fases começa a se pronunciar nas propriedades físicas macroscópicas mesmo em sistemas pobres em Pr, como a amostra com y $=0.20$. Portanto, essas amostras são sensíveis aos processos térmicos, mais especificamente, se o sistema foi aquecido ou resfriado, se esses processos foram feitos de forma lenta ou rápida, etc.

Os dados de $\chi(\mathrm{T})$ mostrados na Fig. 3.2.7(a) sugerem uma transição do estado PM, em altas T, para o FM, em baixas T. Tal transição ocorre em uma temperatura denominada $T_{C}$. Para as amostras nessa faixa de concentração de $\operatorname{Pr}, M_{S}$ decresce apenas ligeiramente como função do aumento de Pr em relação à magnetização de saturação da amostra com y $=0$. Esse resultado concorda com os dados de $\rho(T)$, ou seja, essas amostras são as que apresentam as maiores frações volumétricas da fase FMM de toda a série. Portanto, as amostras com $\mathrm{y} \leq 0.25$ são compostas de fase FMM dominante, mas a competição com a fase isolante já é anunciada via observação de histereses térmicas que ocorrem tanto em $\rho(T)$ como em $\chi(T)$ e o acréscimo em $\rho_{0}$ com o aumento de $y$. 


\subsection{3.b Propriedades das amostras com $y \geq 0.40$}

A seguir são descritos os comportamentos de $\rho(\mathrm{T})$ e $\chi(\mathrm{T})$ das amostras com $y=0.40$ e 0.625 . As curvas de $\rho(T)$ para essas amostras são mostradas na Fig. 3.2.10(b).

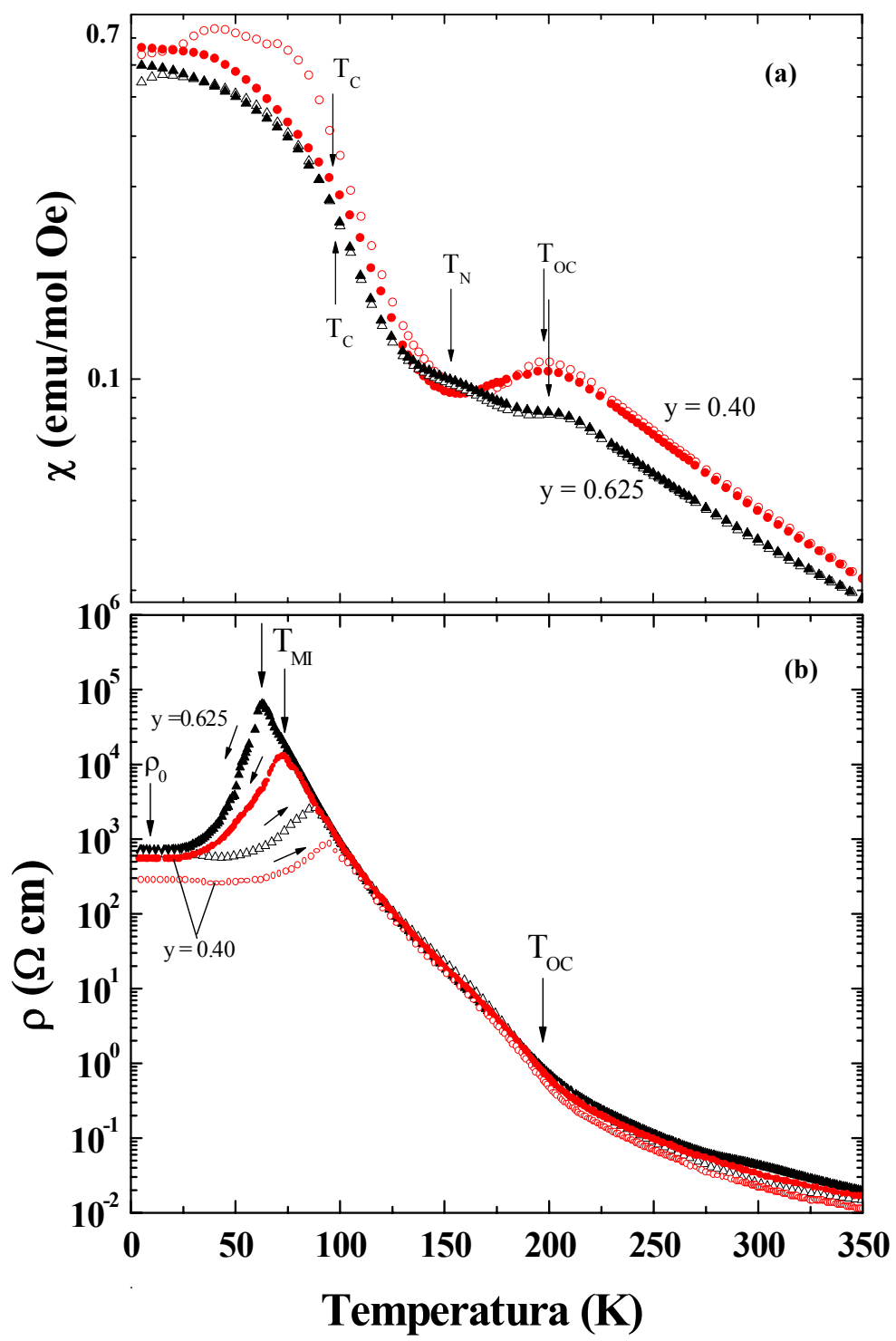

Figura 3.2.10 - (a) Curvas de $\chi(\mathrm{T})$ obtidas no processo de ZFC (símbolo aberto) e FC (símbolo fechado) para as amostras com y $=0.40$ e 0.625 . As temperaturas de ordenamento de carga $\mathrm{T}_{\mathrm{OC}}$ são indicadas por setas. (b) Curvas de $\rho(\mathrm{T})$ para as amostras com y $=0.40$ e 0.625 . As curvas mostradas com símbolos abertos foram obtidas no processo de aquecimento da amostra e os fechados no processo de resfriamento. $T_{M I}, T_{O C}$ e $\rho_{0}$ estão indicadas por setas verticais. 
Em contraste com os materiais com baixa concentração de Pr, as amostras com $y \geq 0.40$ apresentam variações significativas na magnitude de $\rho(T)$. Observa-se que $\rho(\mathrm{T})$ aumenta $\sim 6$ e 7 ordens de grandeza a partir de $350 \mathrm{~K}$ até $\mathrm{T}_{\mathrm{MI}}(\sim 73 \mathrm{e} \sim 63 \mathrm{~K})$ para as amostras com $\mathrm{y}=0.40$ e 0.625 , respectivamente, como pode ser visto nos dados da Tabela 3.2 .2 (pág. 58). A alta concentração de Pr resulta no ordenamento de carga dos íons de $\mathrm{Mn}$, devido à diminuição do raio iônico médio do sítio A. Concomitante ao ordenamento de carga, ocorre o ordenamento orbital nesses sistemas. No estado de OC/OO os portadores de carga estão localizados, aumentando a resistividade elétrica do sistema. Portanto, abaixo de $\mathrm{T}_{\mathrm{OC}} \sim 194 \mathrm{~K}$ a taxa de variação de $\rho(\mathrm{T})$ é ainda maior do que as observadas em altas T. O OC/OO ocorre na mesma temperatura para as duas amostras, como pode ser visto na Fig. 3.2.10(b) e na Tabela 3.2.2 (pág. 58).

As características das curvas de $\rho(T)$ para as amostras são muito semelhantes. Observa-se uma variação gradual nos valores de $\mathrm{T}_{\mathrm{MI}}$, de 73 para $63 \mathrm{~K}$ e elas apresentam resistividade residual $\rho_{0}$ essencialmente com a mesma magnitude, da ordem de $\sim 10^{2} \Omega \mathrm{cm}$. Nota-se também que $\rho_{\text {Máx }}$ apresenta a mesma ordem de grandeza, sendo de $\sim 10^{4} \Omega \mathrm{cm}$ para os dois compostos. As medidas de $\chi(T)$, de certa forma, refletem os resultados observados em $\rho(T)$. Observa-se uma redução robusta de $\mathrm{M}_{\mathrm{S}}$ para as amostras com $\mathrm{y} \geq 0.40 \mathrm{em}$ relação à da amostra com y $=0$, mas a transição para o estado FM ainda é observada. $\quad \mathrm{M}_{\mathrm{S}}$ é reduzido de $\sim 6 \mathrm{emu} / \mathrm{mol}$ Oe para $0.6 \mathrm{emu} / \mathrm{mol}$ Oe para as amostras com y $=0$ e y $=0.625$, respectivamente. A transição de fase para o estado de OC também tem sua assinatura nas curvas de $\chi(T)$, identificada como uma descontinuidade que ocorre em $\mathrm{T}_{\mathrm{OC}} \sim 197 \mathrm{~K}$ nas curvas mostradas na Fig. 3.2.10(a) para as amostras com $y=0.40$ e 0.625 . Adicionalmente, observase que a transição MI ocorre abaixo da temperatura de ordenamento 
ferromagnético do sistema para as amostras com y $=0.40$ e 0.625 . Comparando os valores, tem-se $\mathrm{T}_{\mathrm{MI}} \sim 73$ e $63 \mathrm{~K}$ e $\mathrm{T}_{\mathrm{C}} \sim 91$ e $95 \mathrm{~K}$ para as amostras com $\mathrm{y}=0.40$ e 0.625 , respectivamente. Portanto, apesar de ocorrer o ordenamento FM, a fração volumétrica de regiões FMM necessária para que ocorra a percolação é obtida apenas em $\mathrm{T}$ mais baixas, indicando que o volume relativo de regiões OCI é apreciável para as amostras com $\mathrm{y} \geq 0.40$. Portanto, a diminuição de $\mathrm{M}_{\mathrm{S}}$ para amostras com alta concentração de y parece estar relacionada com o incompleto alinhamento ferromagnético dos momentos dos íons de Mn e a maior formação de regiões não ferromagnéticas, ou seja, de OCI em baixas T. Isso dificulta a conexão entre os domínios FMM e, conseqüentemente, de ocorrer a condução do tipo percolativa nesses sistemas. Esse fato pode ser confirmado através da resistividade residual muito grande observada nesses dois compostos, da ordem de $\sim 10^{2} \Omega \mathrm{cm}$, mesmo em baixas $\mathrm{T}$, onde os compostos ainda exibem comportamento dito metálico. A histerese térmica é observada tanto nas curvas de $\rho(\mathrm{T})$ como de $\chi(\mathrm{T})$, mas para a amostra com y $=0.625$ ela é quase imperceptível, como indica os dados da Fig. 3.2.10(a). A temperatura de ordenamento AF também é indicada na Fig. 3.2.10(a) e ocorre logo abaixo de $\mathrm{T}_{\mathrm{OC}}$. Baseado nos comentários da seção 3.2.3.b, essas características devem-se, provavelmente, ao grau de liberdade orbital que compete com a fase FM com o decréscimo de T.

As amostras com y $=0.40$ e 0.625 são os compostos da série com menor $<\mathrm{r}_{\mathrm{A}}>$, indicando que a redução desse parâmetro é fundamental no aparecimento do estado de OCI nesses compostos. Nas amostras ricas em Pr o estado de ordenamento de carga/orbital isolante é dominante, sendo observado um comportamento isolante até temperaturas muito baixas como $73 \mathrm{~K}$ e $63 \mathrm{~K}$, temperaturas nas quais ocorrem a transição de fase MI nas amostras com $\mathrm{y}=0.40$ e 0.625 , respectivamente. 


\subsection{3.c Propriedades das amostras com $0.30 \leq \mathrm{y} \leq 0.40$}

Até o momento foram analisados os resultados de $\rho(\mathrm{T})$ e $\chi(\mathrm{T})$ das amostras tipicamente mais resistivas, com alta concentração de $\operatorname{Pr}(\mathrm{y} \geq 0.40)$, e as ditas metálicas, com pequenas concentrações de $\operatorname{Pr}(\mathrm{y} \leq 0.25)$. A variação na concentração de $\operatorname{Pr}$ nessas duas regiões de y indicou que as propriedades de transporte e magnéticas são alteradas através da substituição de La por Pr. Entretanto, essas alterações ocorreram de forma suave. Assim, foram definidas duas regiões na qual uma é predominantemente FMM $(\mathrm{y} \leq 0.25)$ e outra predominantemente OCI $(\mathrm{y} \geq 0.40)$. A seguir, a região de $0.30 \leq \mathrm{y} \leq 0.40$ será analisada através das curvas de $\chi(\mathrm{T})$ e $\rho(\mathrm{T})$ mostradas nas Figs. 3.2.11(a) e (b).

Observa-se nas curvas de $\rho(\mathrm{T})$ para a amostra com y $=0.35$ uma transição de ordenamento de carga/orbital em $\mathrm{T}_{\mathrm{OC}} \sim 194 \mathrm{~K}$. Tal transição ocorre na mesma $\mathrm{T}$ para as amostras com $\mathrm{y}=0.40$ e 0.625 . Portanto, $\mathrm{T}_{\mathrm{OC}}$ parece ser insensível à concentração y nessa faixa e é observada apenas em compostos com $y \geq 0.35$. Portanto, nas amostras com $y \geq 0.35$ ocorrem duas transições de fase com o decréscimo de $\mathrm{T}$ : a primeira para o estado de ordenamento de carga/orbital isolante e a segunda na forma de uma transição de fase MI em baixas T. Ao observar a Fig. 3.2.11, nota-se que esta região de concentração y é distinta das demais e discutidas acima. Além da observação de histereses térmicas mais pronunciadas e que ocorrem em uma larga faixa de $\mathrm{T}$, as curvas de $\chi(T)$ e $\rho(T)$ são alteradas significativamente com uma pequena variação de $y$. 


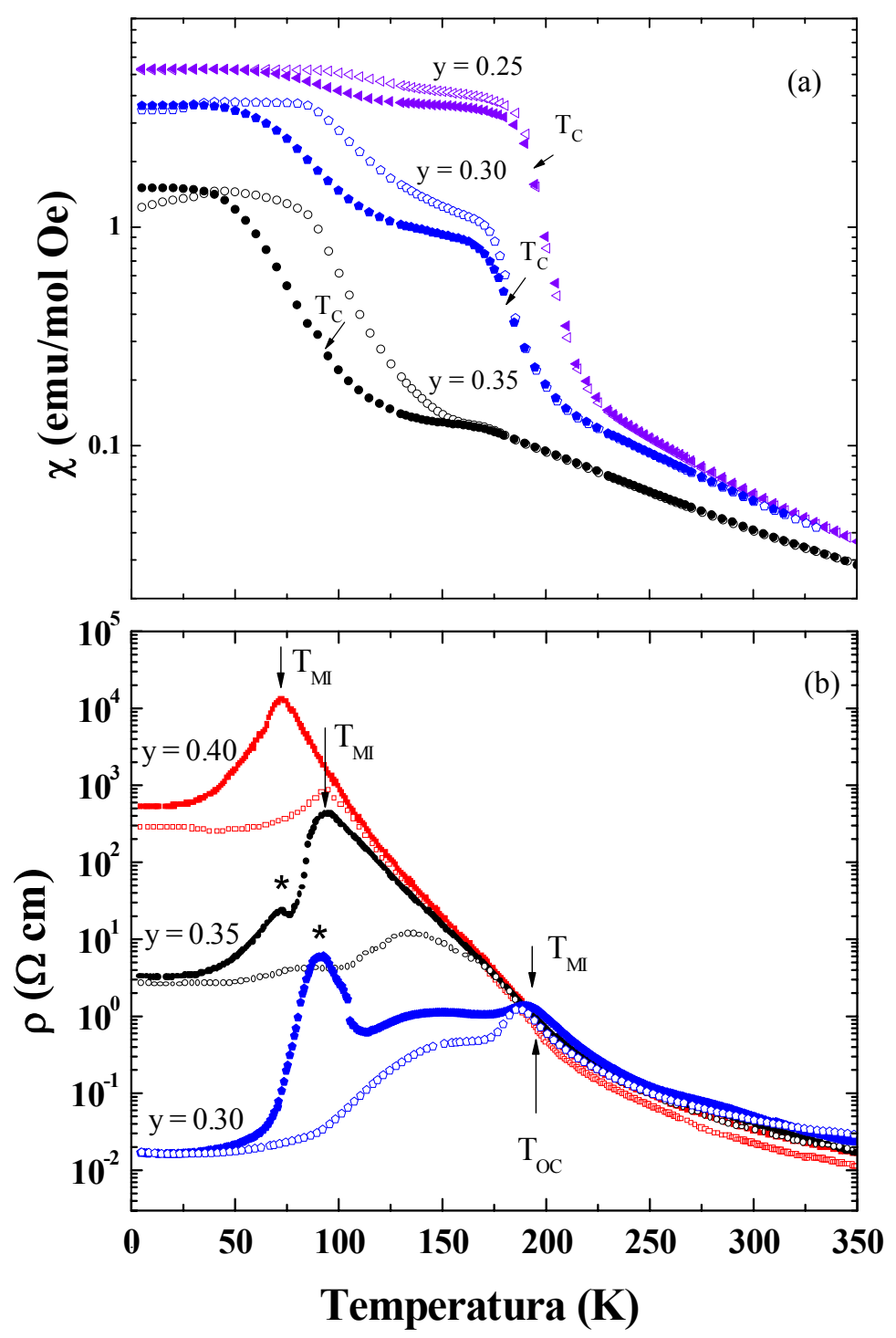

Figura 3.2.11 - (a) Curvas de $\chi(\mathrm{T})$ obtidas no processo ZFC (símbolo aberto) e FC (símbolo fechado) para as amostras com $y=0.25,0.30$ e 0.35 . (b) Curvas de $\rho(\mathrm{T})$ obtidas no processo de aquecimento (símbolo aberto) e resfriamento (símbolo fechado) das amostras com y $=0.30$, 0.35 e 0.40 . $\mathrm{T}_{\mathrm{MI}}$ e $\mathrm{T}_{\mathrm{OC}}$ são indicadas por setas. Os asteriscos indicam anomalias que ocorrem abaixo de $\mathrm{T}_{\mathrm{MI}}$ nas curvas de $\rho(\mathrm{T})$.

Enquanto que a variação em $\mathrm{T}_{\mathrm{MI}}$ foi observada ser suave com o aumento de y nas regiões $\mathrm{y} \leq 0.25$ e $\mathrm{y} \geq 0.40$, esta varia de modo abrupto na região $0.30 \geq \mathrm{y} \geq 0.40$. Isso é mais pronunciado entre as amostras com $\mathrm{y}=0.30$ e 0.35 , nas quais o valor de $\mathrm{T}_{\mathrm{MI}}$ é reduzido de $190 \mathrm{~K}$ para $95 \mathrm{~K}$, respectivamente. Essas variações robustas também ocorrem para outros parâmetros analisados, como $\rho_{0}$ 
e $\rho_{\text {Máx. }}$ Observa-se que a variação em $\rho_{0}$ e $\rho_{\text {Máx }}$ entre amostras com y $=0.30$, 0.35 e 0.40 é de duas ordens de grandeza, como pode ser visto na Tabela 3.2.2 (pág. 58). Um variação significativa em $\mathrm{M}_{\mathrm{S}}$ também pode ser observada nas curvas de $\chi(\mathrm{T})$ entre as amostras com $\mathrm{y}=0.30$ e 0.35 , sendo de $\sim 3.5 \mathrm{emu} / \mathrm{mol}$ Oe para $\sim 1.5 \mathrm{emu} / \mathrm{mol} \mathrm{Oe}$, respectivamente. Ainda, nas curvas de $\chi(T)$, observa-se que ao mesmo tempo em que as histereses térmicas tornamse mais pronunciadas, a forma geral das curvas de $\chi(\mathrm{T})$ parece variar com a concentração y. Para as amostras com $\mathrm{y}=0.25$ e 0.30 a magnitude de $\chi(\mathrm{T})$ volta a crescer com o decréscimo de $\mathrm{T}$ abaixo de $\mathrm{T}_{\mathrm{C}}$ e para a amostra com $\mathrm{y}=0.35$, um máximo local é observado abaixo de $\mathrm{T}_{\mathrm{C}}$. Essas características podem estar associadas ao ordenamento ferromagnético de duas regiões distintas e que coexistem abaixo de $\mathrm{T}_{\mathrm{OC}}{ }^{[8]}$ A natureza desses ordenamentos não é bem relatada na literatura.

Entretanto, como foi observado nas amostras com y $\geq 0.40$, as diversas transições de fases (magnéticas ou estruturais) devido à competição entre a fase FM e outras instabilidades como, por exemplo, o grau de liberdade orbital, carga e rede são refletidas nas curvas de $\chi(\mathrm{T})$. Portanto, as características observadas nas curvas de $\chi(T)$ para as amostras com $0.25 \leq \mathrm{y} \leq 0.35$ podem ter a mesma origem, mas manifesta-se de maneira diversa devido à menor fração volumétrica de regiões $\mathrm{OC} / \mathrm{OO}$. Adicionalmente a todas essas características que diferenciam a região $0.30 \geq y \geq 0.40$, surgem algumas anomalias nas curvas de $\rho(T)$ abaixo de $\mathrm{T}_{\mathrm{MI}}$. Essas anomalias são indicadas por asteriscos $\left(^{*}\right)$ na curvas de $\rho(\mathrm{T})$ mostradas na Fig. 3.2.11(b). A ocorrência de um segundo pico em $\rho(T)$, em baixas T é, no mínimo, intrigante, pois a resistividade elétrica aumenta na região de temperatura abaixo da transição de fase MI, onde o composto já exibe 
característica metálica. $\mathrm{Na}$ amostra com y $=0.35$ essa anomalia é vista como um pequeno máximo local em $\rho(\mathrm{T})$, que ocorre em $\sim 72 \mathrm{~K}$, mas para a amostra com $\mathrm{y}=0.30$, um aumento em $\rho(\mathrm{T})$ em $\sim 90 \mathrm{~K}$, que supera a magnitude de $\rho_{\text {Máx }}$, é observado. Através de uma observação mais cuidadosa, pode-se notar que os aumentos em $\chi(T)$ abaixo de $T_{C}$ e as anomalias observadas em $\rho(T)$ ocorrem na mesma região de temperatura e, por conseguinte, podem estar relacionadas.

Todas essas características discutidas sugerem que as propriedades físicas desses materiais não são influenciadas apenas pelas alterações esperadas na estrutura cristalográfica, mas também pela forte competição e coexistência de fases FMM e OCI. ${ }^{[7]}$ Um volume relativo maior de uma dessas fases controla essencialmente as propriedades de transporte eletrônico, ou seja, o material pode apresentar características metálicas ou de um isolante via pequenas alterações nos volumes das fases FMM e OCI. Entretanto, na região de concentração $0.30 \geq \mathrm{y} \geq 0.40$ a fração relativa dessas fases não influencia as propriedades físicas discutidas de maneira simples. Há vários aspectos dos resultados experimentais indicando que a competição entre as duas fases é que define as propriedades físicas macroscópicas. Especialmente nas amostras na região de concentração $0.30 \geq \mathrm{y} \geq 0.40$, a competição entre essas fases é marcante, conforme observado nas medidas $\rho(\mathrm{T})$ e $\chi(\mathrm{T})$ para as amostras dessa região.

Baseados nas discussões realizadas até o momento, seguem os resultados das medidas de magnetorresistência realizadas em todas as amostras da série. Se a competição entre as fases FMM e OCI é que define as propriedades físicas macroscópicas, então perturbações no sistema como, por exemplo, a aplicação de um campo magnético externo deveria influenciar essas propriedades. Isso é discutido a seguir. 


\subsubsection{Magnetorresistência}

Medidas de resistividade elétrica como função da temperatura na presença de campo magnético externo $\mathrm{H}, \rho(\mathrm{T}, \mathrm{H}=$ cte $) ; 0 \leq \mathrm{T} \leq 350 \mathrm{~K}$; foram realizadas nas amostras da série $\mathrm{La}_{5 / 8-\mathrm{y}} \mathrm{Pr}_{\mathrm{y}} \mathrm{Ca}_{3 / 8} \mathrm{MnO}_{3}$ sinterizadas a $1400^{\circ} \mathrm{C}$. A Fig. 3.2.12 mostra as curvas de $\rho(T, H=0)$ e $\rho(T, H=50 \mathrm{kOe})$ para todas as amostras da série. As temperaturas de transição de fase $\mathrm{MI}$ obtidas das curvas de $\rho(T, H=0)$ e $\rho(\mathrm{T}, \mathrm{H}=50 \mathrm{kOe})$ são denominadas de $T_{M I}^{H=0}$ e $T_{M I}^{H=50 k O e}$, respectivamente, e estão mostradas na Tabela 3.2.3.

De maneira geral, observa-se na Fig. 3.2.12 que a magnitude da resistividade elétrica decresce com a aplicação de $\mathrm{H}=50 \mathrm{kOe}$ em toda a série. $\mathrm{O}$ maior decréscimo ocorre ao redor da temperatura de transição de fase MI devido ao deslocamento de $\mathrm{T}_{\mathrm{MI}}$ para altas $\mathrm{T}$ com a aplicação de $\mathrm{H}$. Esse deslocamento pode ser visualizado melhor na Tabela 3.2.3, onde $T_{M I}^{H=0}$ e $T_{M I}^{H=50 k O e}$ podem ser facilmente comparados.

\begin{tabular}{|c|c|c|c|}
\hline $\mathrm{y}$ & $T_{M I}^{H=0}(\mathrm{~K})$ & $T_{M I}^{H=50 k O e}(\mathrm{~K})$ & $\Delta \mathrm{T}_{\mathrm{MI}}(\mathrm{K})$ \\
\hline 0 & 264 & 292 & 28 \\
\hline 0.10 & 244 & 288 & 44 \\
\hline 0.20 & 216 & 257 & 41 \\
\hline 0.25 & 200 & 248 & 48 \\
\hline 0.30 & 177 & 234 & 57 \\
\hline 0.35 & 86 & 211 & 125 \\
\hline 0.40 & 83 & 199 & 116 \\
\hline 0.625 & 63 & 196 & 133 \\
\hline
\end{tabular}

Tabela 3.2.3 - Valores de $\mathrm{T}_{\mathrm{MI}}$ obtidos das curvas de $\rho(\mathrm{T})$ em $\mathrm{H}=0$ e $\mathrm{H}=50 \mathrm{kOe}$, em amostras de $\mathrm{La}_{5 / 8-\mathrm{y}} \mathrm{Pr}_{\mathrm{y}} \mathrm{Ca}_{3 / 8} \mathrm{MnO}_{3} . \Delta \mathrm{T}_{\mathrm{MI}}$ é a diferença estimada entre $T_{M I}^{H=0}$ e $T_{M I}^{H=50 k O e}$. 

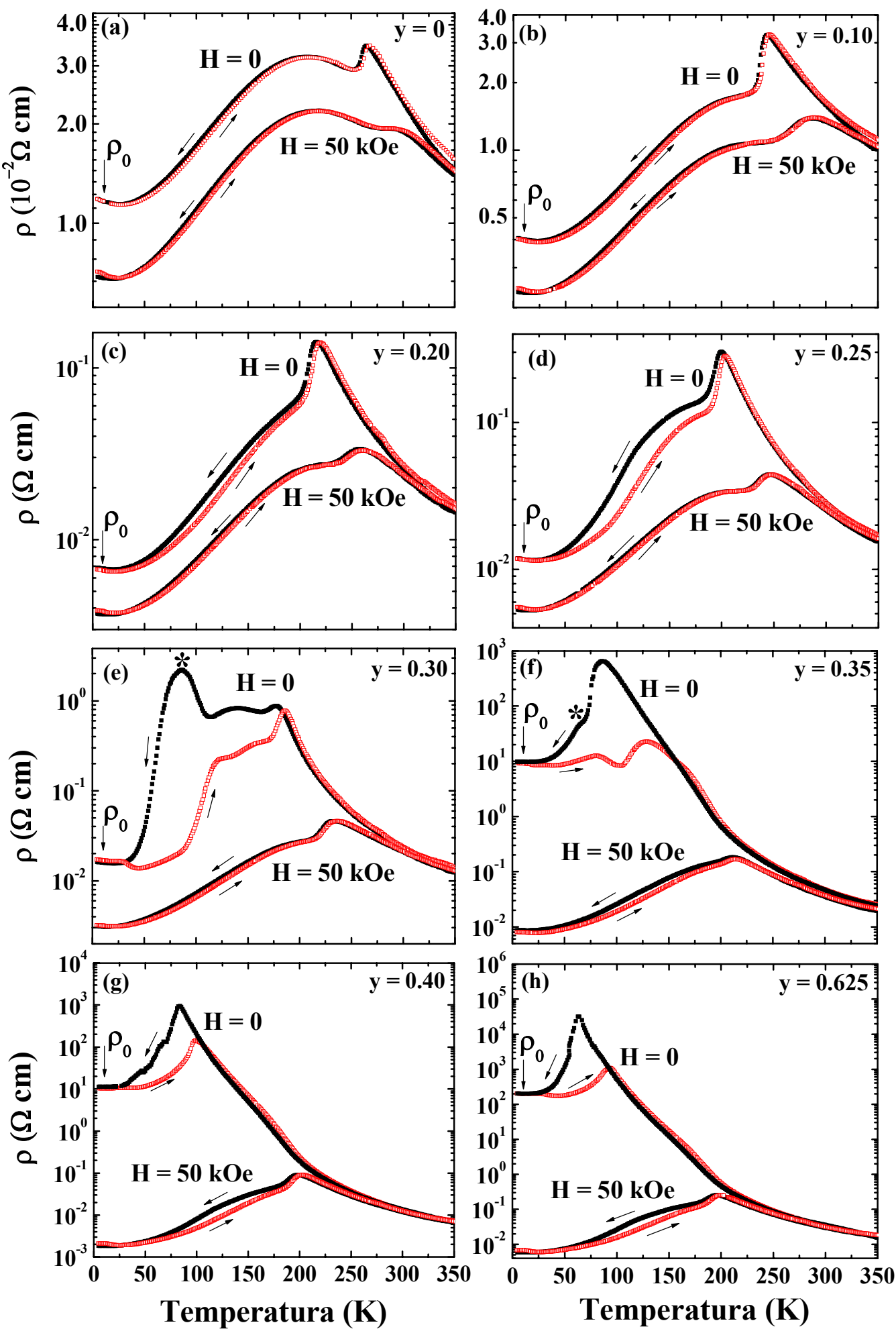

Figura 3.2.12 - Curvas de resistividade elétrica como função da temperatura, obtidas nos processos de aquecimento (curva em vermelho) e resfriamento (preto) nas amostras sob um campo magnético externo aplicado $\mathrm{H}$, indicado na figura, para a série $\mathrm{La}_{5 / 8-\mathrm{y}} \mathrm{Pr}_{\mathrm{y}} \mathrm{Ca}_{3 / 8} \mathrm{MnO}_{3}$. Os processos térmicos estão indicados por setas. As setas verticais indicam a resistividade elétrica residual $\rho_{0}$, definida como $\rho(\mathrm{T}=10 \mathrm{~K})$. 
Os resultados indicam que decréscimo da resistividade elétrica em altas $\mathrm{T}$ é muito menos pronunciado que aquele ao redor de $\mathrm{T}_{\mathrm{MI}} \mathrm{e}$ chega a ser essencialmente zero em uma faixa de $\mathrm{T}$ acima de $T_{M I}^{H=50 \mathrm{kO} e}$, como pode ser observado nas Figs. 3.2.12(a)-(h). Através desses gráficos nota-se que a aplicação de um campo magnético externo de $50 \mathrm{kOe}$ foi suficiente para deslocar $\mathrm{T}_{\mathrm{MI}}$ de todas as amostras para temperaturas mais altas $(\mathrm{T}>196 \mathrm{~K})$ e reduzir a resistividade residual $\left(\rho_{0}=\rho(10 \mathrm{~K})\right)$ para valores da ordem de $10^{-3} \Omega \mathrm{cm}$. Um fato importante a ser evidenciado é que o deslocamento de $\mathrm{T}_{\mathrm{MI}}$ para $\mathrm{T}$ mais elevadas é, particularmente, de interesse em toda a série. Nota-se que nas amostras com alta fração volumétrica da fase FM $(\mathrm{y} \leq 0.30)$ o aumento de $\mathrm{T}_{\mathrm{MI}}$ reflete o alinhamento maior dos domínios $\mathrm{FM}$ devido a aplicação de $\mathrm{H}$. $\mathrm{Na}$ verdade, isso pode estar relacionado ao mecanismo mostrado na Fig. 1.6 (pág. 12), onde a aplicação de $\mathrm{H}$ nas vizinhanças de $\mathrm{T}_{\mathrm{MI}}$ induz o ordenamento ferromagnético em $\mathrm{T}$ ligeiramente maiores que $T_{M I}^{H=0}$. Os spins dos íons $\mathrm{Mn}$ em temperaturas próximas de $\mathrm{T}_{\mathrm{C}}$ são relativamente fáceis de serem alinhados e a probabilidade de transferência do portador de carga entre íons Mn aumenta, resultando na redução da resistividade elétrica e, conseqüentemente, do efeito de MRC próximo a $\mathrm{T}_{\mathrm{C}}$.

Observa-se que, nas Figs. 3.2.12(f) - (h), correspondentes às amostras com $\mathrm{y} \geq 0.35$ o decréscimo em $\rho(\mathrm{T})$ é evidentemente maior quando comparados com os das amostras com y $\leq 0.30$. Adicionalmente ao mecanismo mostrado na Fig. 1.6 (pág. 12), o efeito "colossal” de MR está diretamente relacionado com a coexistência e variação volumétrica das fases OCI e FMM, observadas por Cheong et al. ${ }^{[35]}$ nos mesmos compostos. Nesse contexto, a aplicação de $\mathrm{H}$ favorece o aumento relativo da região $F M$ e as regiões isolantes podem transformar-se em FM se $\mathrm{H}$ for suficientemente intenso. Esse processo é 
denominado de "melting" da fase OC e ocorre também quando outro parâmetro termodinâmico, como pressão hidrostática, é aplicada aos materiais. ${ }^{[12]}$ Observando os valores na Tab. 3.2.3, nota-se que, para as amostras com y $\leq 0.30$, o valor de $\Delta \mathrm{T}_{\mathrm{MI}}$ é de algumas dezenas, mas quando a concentração de Pr é maior que 0.35 , o deslocamento de $\mathrm{T}_{\mathrm{MI}}$ supera $100 \mathrm{~K}$ e valores de $T_{M I}^{H=50 k O e}$ são observados em temperaturas ligeiramente maiores a $\mathrm{T}_{\mathrm{OC}}(\sim 194 \mathrm{~K})$. De fato, para $\mathrm{H}=50 \mathrm{kOe}$ espera-se a ocorrência de um "melting" da fase OCI. Anane et al. ${ }^{[36]}$ estudaram o monocristal $\operatorname{Pr}_{0.67} \mathrm{Ca}_{0.33} \mathrm{MnO}_{3}$, um composto similar a um dos extremos da série estudado aqui. Os autores obtiveram um diagrama de fases magnéticas onde se verifica que, ao redor de $100 \mathrm{~K}$, a ocorrência uma transição da fase OCI para o estado FMM sob aplicação de $\mathrm{H}=50 \mathrm{kOe}$. A magnitude do campo magnético necessário ou suficiente para que essa transição ocorra (ou colapso da fase $\mathrm{OCI}$ ) depende de fatores como $<\mathrm{r}_{\mathrm{A}}>$ e o quanto a concentração $\mathrm{x}$ está afastada de $0.5\left(\mathrm{~A}_{1-\mathrm{x}} \mathrm{A}_{\mathrm{x}}{ } \mathrm{MnO}_{3}\right)$. Esses fatores estão relacionados com a estabilização da fase $\mathrm{OC}$, que é maximizada para $\left\langle\mathrm{r}_{\mathrm{A}}>\right.$ menores e $\mathrm{x}=0.5$. $\mathrm{O}$ aumento de $\left\langle\mathrm{r}_{\mathrm{A}}>\right.$ e o decréscimo de $\mathrm{x}$ a partir de 0.5 torna o estado OC menos estável e, portanto, a aplicação de um determinado $\mathrm{H}$ resulta em um maior decréscimo na magnitude da resistividade elétrica. Esse efeito de MRC ainda pode estar relacionado com os resultados discutidos na Ref. 21. Foi sugerido que a diferença entre as energias do estado fundamental das fases OC/OO e FM no composto $\operatorname{Pr}_{1-\mathrm{x}} \mathrm{Ca}_{\mathrm{x}} \mathrm{MnO}_{3}(\mathrm{x}=0,1 / 4,3 / 8$ e 1/2) é muito pequena. Portanto, um campo magnético de intensidade relativamente baixa poderia induzir a transição OC - FM. Para a manganita $\operatorname{Pr}_{1 / 2} \mathrm{Ca}_{1 / 2} \mathrm{MnO}_{3}$, em $100 \mathrm{~K}$, o campo magnético crítico para colapsar completamente a fase de ordenamento de carga e orbital foi estimado ser de $230 \mathrm{kOe}$ e para o $\mathrm{Nd}_{1 / 2} \mathrm{Sr}_{1 / 2} \mathrm{MnO}_{3}$ (com $<\mathrm{r}_{\mathrm{A}}>$ maior) foi medido em $\sim 60$ kOe. $^{[37]}$ Os estudos da Ref. 38 indicaram que a fase OCI é 
completamente suprimida para $\mathrm{H}>87 \mathrm{kOe}$ no monocristal $\operatorname{Pr}_{0.63} \mathrm{Ca}_{0.37} \mathrm{MnO}_{3}$. Baseado nesses dados, as nossas amostras com $\mathrm{y} \geq 0.35$ podem conter ainda uma pequena fração volumétrica de fase OCI, com campo aplicado de $50 \mathrm{kOe}$. Entretanto, observando os dados de $T_{M I}^{H=50 k O e} \sim 200 \mathrm{~K}$ para as três amostras (com $\mathrm{y}=0.35,0.40$ e 0.625$)$, pode-se inferir que a fração volumétrica da fase OCI remanescente é muito pequena e o transporte eletrônico é dominado pela grande fração da fase FMM devido ao "melting" da fase OCI. A redução de várias ordens de grandeza $(\sim 4)$ em $\rho_{0}$ para as amostras com $y \geq 0.35$ corrobora $o$ cenário do "melting" da fase OCI, pois além do grande decréscimo observado, os valores de $\rho_{0}$ são essencialmente os mesmos para todas as amostras da série sob campo magnético aplicado.

Os estudos descritos na Ref. 38 indicam que $\mathrm{T}_{\mathrm{OC}}$ desloca-se para menores temperaturas sob campo magnético aplicado. Entretanto, para as amostras com $\mathrm{y} \geq 0.35$ a transição de fase $\mathrm{MI}$ ocorre em $\mathrm{T}>196 \mathrm{~K}$ sugerindo que a fase OCI foi completamente suprimida ou sua fração volumétrica não é significativa a ponto de se manifestar nas propriedades de transporte eletrônico. Apesar da manganita estudada na Ref. $38\left(\operatorname{Pr}_{0.63} \mathrm{Ca}_{0.37} \mathrm{MnO}_{3}\right)$ ser muito similar à estudada aqui $\left(\operatorname{Pr}_{0.625} \mathrm{Ca}_{0.375} \mathrm{MnO}_{3}\right)$ o efeito de $\mathrm{H}$ parece ser mais efetivo na última, ou seja atua no sentido de converter uma maior fração volumétrica de OC em FM.

O resultado geral das discussões realizadas até o momento é resumido nas curvas da Fig. 3.2.13. Nessa figura são mostradas as curvas normalizadas de $\rho(\mathrm{T}, \mathrm{H}=50 \mathrm{kOe})$ para toda a série estudada. Essas curvas evidenciam claramente que a transição MI de todas as amostras ocorre em $T_{M I}^{H=50 k O e}>196 \mathrm{~K}$. Portanto, nota-se que o comportamento de $\rho(\mathrm{T}, \mathrm{H}=50 \mathrm{kOe})$ para a série é essencialmente metálico abaixo de $196 \mathrm{~K}$ e não é observada nenhuma característica com assinatura da transição de fase com ordenamento de carga e 
orbital. Realmente a mudança mais significativa no comportamento do transporte eletrônico ocorreu para amostras com altas concentrações y de $\operatorname{Pr}$. Um exemplo disso é que a variação entre a resistividade elétrica máxima dessas curvas variam em apenas uma ordem de grandeza. Essa variação foi observada ser de $\sim 6$ ordens para $\rho(T, H=0)$ (veja Tab. 3.2.2, na pág. 58).

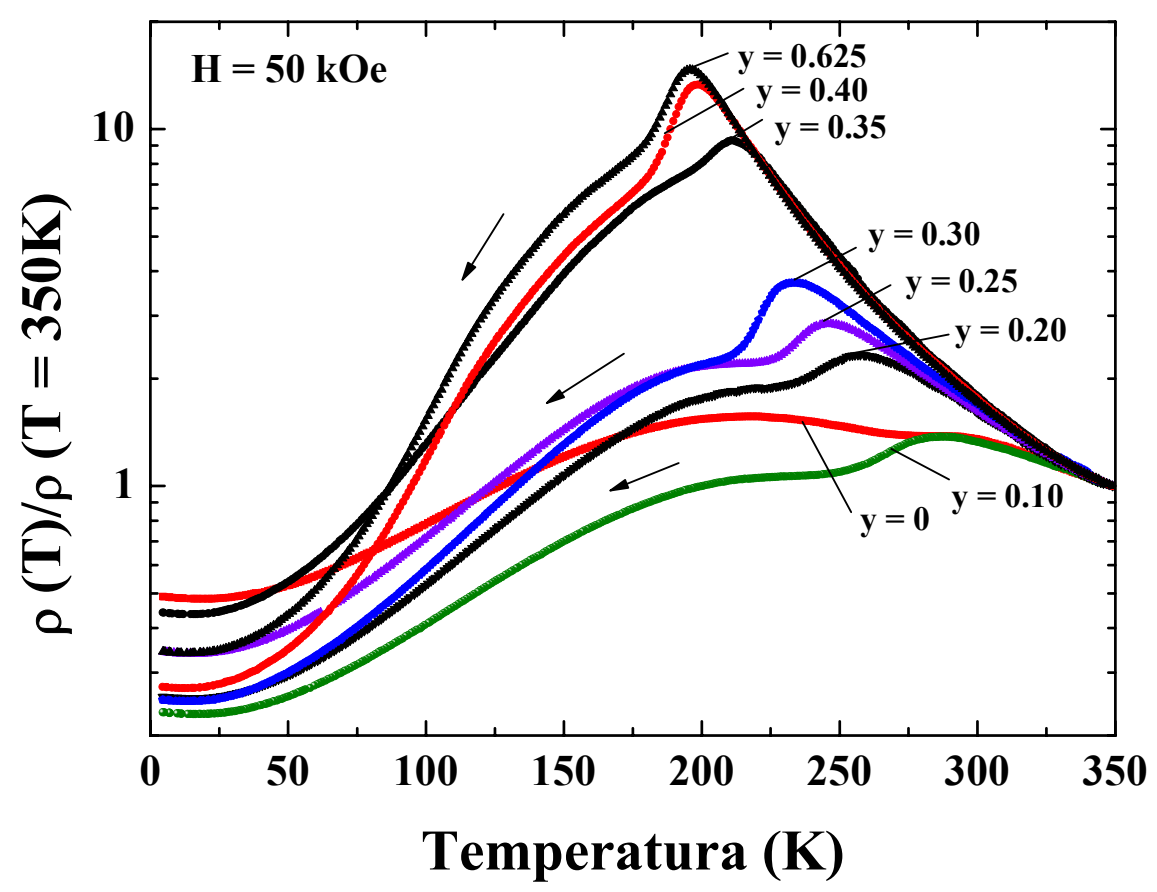

Figura 3.2.13- Curvas de resistividade elétrica normalizadas via $(\rho(T) / \rho(350 \mathrm{~K}))$ como função da temperatura obtidas no processo de resfriamento (indicado por setas em algumas curvas) das amostras de $\mathrm{La}_{5 / 8-\mathrm{y}} \mathrm{Pr}_{\mathrm{y}} \mathrm{Ca}_{3 / 8} \mathrm{MnO}_{3}$ e sob a aplicação de um campo magnético externo de $\mathrm{H}=50 \mathrm{kOe}$.

Aparentemente, efeitos tão pronunciados de MR em amostras com altas concentrações de Pr não foram observados na literatura como os mostrados aqui. Esse fato pode estar relacionado aos tratamentos térmicos realizados em altas temperaturas de sinterização e por um longo intervalo de tempo. Esses dois fatores favorecem o crescimento do tamanho médio de grãos e aparentemente resulta em um aumento da fração metálica do material, efeito este similar ao observado no composto policristalino $\mathrm{La}_{0.25} \mathrm{Pr}_{0.375} \mathrm{Ca}_{0.375} \mathrm{MnO}_{3}$ e descrito na Ref. 
39. Assim, se as amostras estudadas aqui contêm maior fração volumétrica de fase FMM comparadas às da literatura, então elas seriam mais sensíveis aos efeitos da aplicação de um campo magnético.

O efeito de MR como função da temperatura pode ser mais bem visualizado nas curvas mostradas nas Figs. 3.2.14(a) e (b). As curvas MR(T) foram obtidas com os dados tomados durante o processo de resfriamento e foram definidas pela Eq. 2.5.1 (pág. 33). Essas curvas estão separadas apenas por questão de visualização, devido às diferenças nas magnitudes de MR(T). Como observado anteriormente, o máximo valor de $\mathrm{MR}$ ocorre próximo de $\mathrm{T}_{\mathrm{MI}}$, resultando em curvas muito similares a $\rho(T, H=0)$. A magnitude de MR entre os extremos da série $(y=0$ e 0.625$)$ foi observada ter uma variação de até sete ordens de grandeza, sendo que o máximo valor de MR para amostras com y $=0$ foi de 0.75 e naquelas com $y=0.625$ foi de $3.4 \times 10^{6}$. Outra característica de interesse é o grande efeito de MR, mesmo em baixas T, efeito esse evidente nas amostras com $y \geq 0.35$. Esses materiais são aqueles em que valores elevados de $\rho_{0}$ foram observados (veja Tabela 3.2.2, na pág. 58). Portanto, tem-se um efeito de MR muito interessante para as amostras com altas concentrações de Pr, ou seja, a MRC ocorre em uma larga faixa de $\mathrm{T}$, abrangendo até mesmo baixas temperaturas. Para a amostra com $\mathrm{y}=0.30$, o maior efeito de MRC é observado em temperaturas próximas de $92 \mathrm{~K}$, onde ocorre a anomalia, indicada pelo asterisco $(*)$ na curva de $\rho(\mathrm{T}, \mathrm{H}=0)$ da Fig. 3.2.12(e) (pág. 74). Observa-se, na curva de $\rho(T, H=50 \mathrm{kOe})$, que essa anomalia foi suprimida completamente pela aplicação de H. Desta forma, o maior efeito de MR é observado para as amostras com y $\geq 0.30$, onde a competição entre as fases FMM e OCI parece ser máxima. 


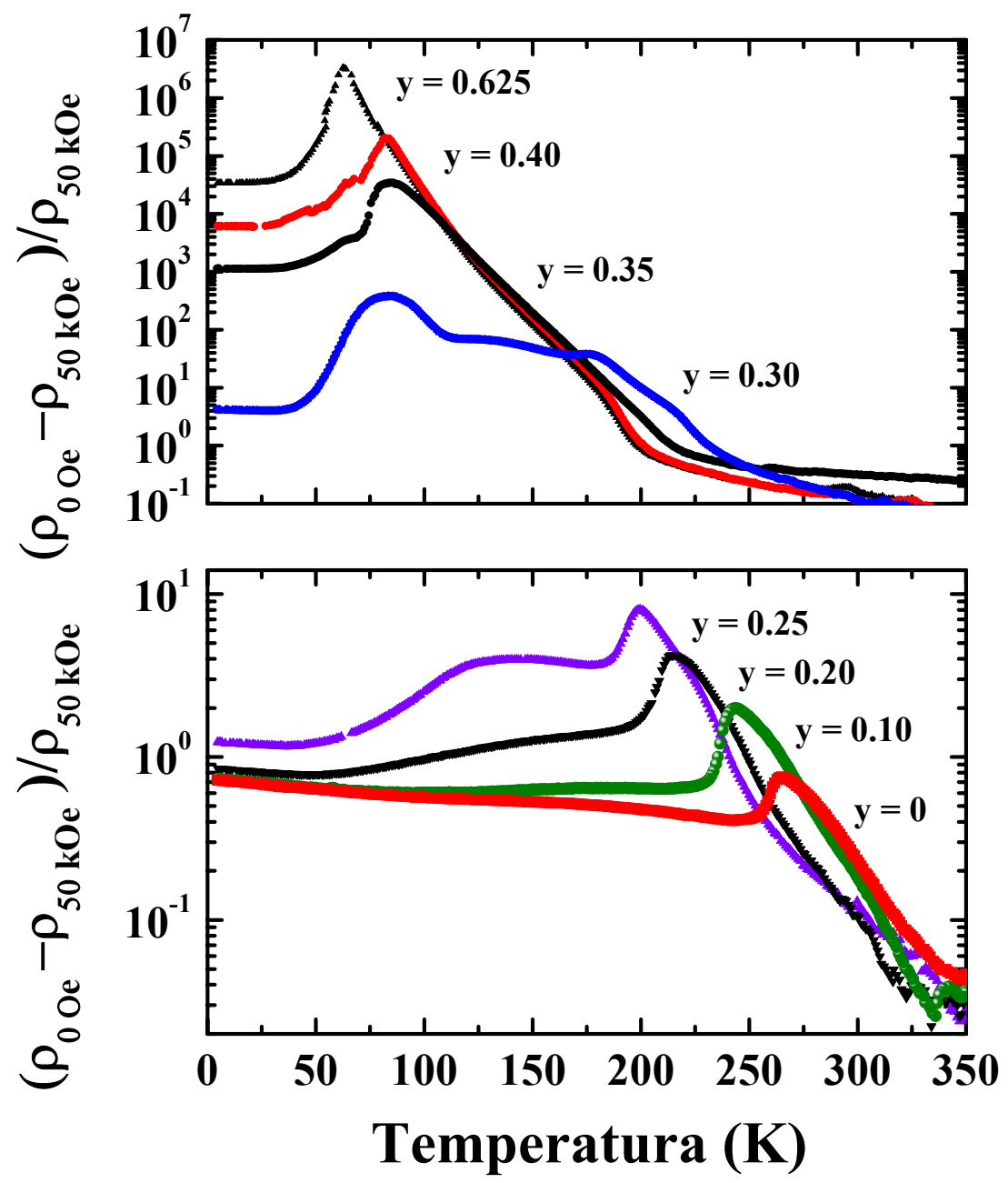

Figura 3.2.14 - Curvas de magnetorresistência como função da temperatura para a série $\mathrm{La}_{5 / 8-\mathrm{y}} \mathrm{Pr}_{\mathrm{y}} \mathrm{Ca}_{3 / 8} \mathrm{MnO}_{3}$, obtidas no processo de resfriamento das amostras. A magnetorresistência foi obtida de acordo com a relação 2.5.1.

Apesar da atenção ser focada nas amostras com y $\geq 0.30$, a amostra com $\mathrm{y}=0$ apresenta um efeito de MR no mínimo, intrigante. Nesse material o maior efeito de $\mathrm{MR}$ ocorre em baixas $\mathrm{T}$ e não próximo a $\mathrm{T}_{\mathrm{MI}}$. Isso pode indicar que a amostra sem Pr também apresenta coexistência de fases. Adicionalmente a esse efeito, pode estar relacionado ao tamanho médio de grão do material. Talvez a contribuição para $\rho(T)$ devido ao tamanho de grão na amostra com y $=0$ seja mais pronunciado nessa concentração que as demais. Porém, apenas com os dados apresentados aqui parece ser difícil propor algum mecanismo adicional para esse fenômeno. 


\subsubsection{Diagrama de fases}

Os diagramas de fases da série $\mathrm{La}_{5 / 8-\mathrm{y}} \mathrm{Pr}_{\mathrm{y}} \mathrm{Ca}_{3 / 8} \mathrm{MnO}_{3}$ foram construídos a partir da combinação dos dados de $\rho(T), \chi(T)$ e $M R(T)$ com o objetivo de resumir as principais propriedades físicas discutidas para essa série de amostras. Nas medidas de $\rho(T)$ foram comparadas grandezas físicas como função da concentração y de $\operatorname{Pr}$ tais como a temperatura de transição $\mathrm{MI}\left(\mathrm{T}_{\mathrm{MI}}\right)$, a resistividade residual $\left(\rho_{0}\right)$, a temperatura de ordenamento de carga/orbital $\left(\mathrm{T}_{\mathrm{OC}}\right)$ e resistividade máxima $\rho_{\text {Máx }}\left(\rho\left(T=T_{M I}\right)\right)$. Para uma discussão mais detalhada, os valores de $T_{M I}$ foram determinados a partir das curvas de $\rho(T)$ obtidas nos processos de aquecimento e resfriamento das amostras, portanto serão definidos como $\mathrm{T}_{\mathrm{MI}}^{\text {aquec }} \mathrm{e}^{\mathrm{T}_{\mathrm{MI}}}{ }^{\text {resf }}$, respectivamente. A partir dos dados de $\chi(\mathrm{T})$ foi discutida a variação de $T_{C}$ como função de $y$. As curvas de $M R(T)$ mostram as mudanças de MR ao longo da série, definida como $\operatorname{MR}\left(\mathrm{T} \sim T_{M I}^{H=0}\right)$ e o deslocamento de $T_{M I}^{H=0}$ para altas $\mathrm{T}$ com a aplicação do campo magnético, através da quantidade estimada de $\Delta \mathrm{T}_{\mathrm{MI}}\left(\Delta \mathrm{T}_{\mathrm{MI}}=T_{M I}^{H=0}-T_{M I}^{H=50 k O e}\right)$ mostrada na Tabela 3.2.3 (pág. 73).

Com esses dados foram construídos dois diagramas de fases. Para uma melhor visualização dos resultados, são combinados os dados de $\mathrm{T}_{\mathrm{MI}}{ }^{\text {resf }}, \mathrm{T}_{\mathrm{C}}, \rho_{0} \mathrm{e}$ MR como função da concentração y e $\left\langle\mathrm{r}_{\mathrm{A}}\right\rangle$ no diagrama 1. No segundo diagrama (2), são combinados os dados de $\mathrm{T}_{\mathrm{OC}}, \Delta \mathrm{T}_{\mathrm{MI}}, \rho_{\text {Máx }}, \mathrm{T}_{\mathrm{MI}}^{\text {resf }}$ e $\mathrm{T}_{\mathrm{MI}}^{\text {aquec }}$. Esses diagramas de fases são mostrados nas Figs. 3.2.15(a) e (b). O diagrama de fases 1 foi construído de forma a analisar cuidadosamente a variação de vários parâmetros físicos como função da concentração y e $\left\langle\mathrm{r}_{\mathrm{A}}\right\rangle$, enquanto que, o diagrama de fases 2 foi construído de forma a visualizar as mudanças que ocorrem nas propriedades físicas, para concentração maiores do que y $=0.35$, a 
partir da qual a transição de ordenamento de carga/orbital torna-se evidente nas curvas de $\rho(\mathrm{T})$ a campo magnético aplicado nulo.

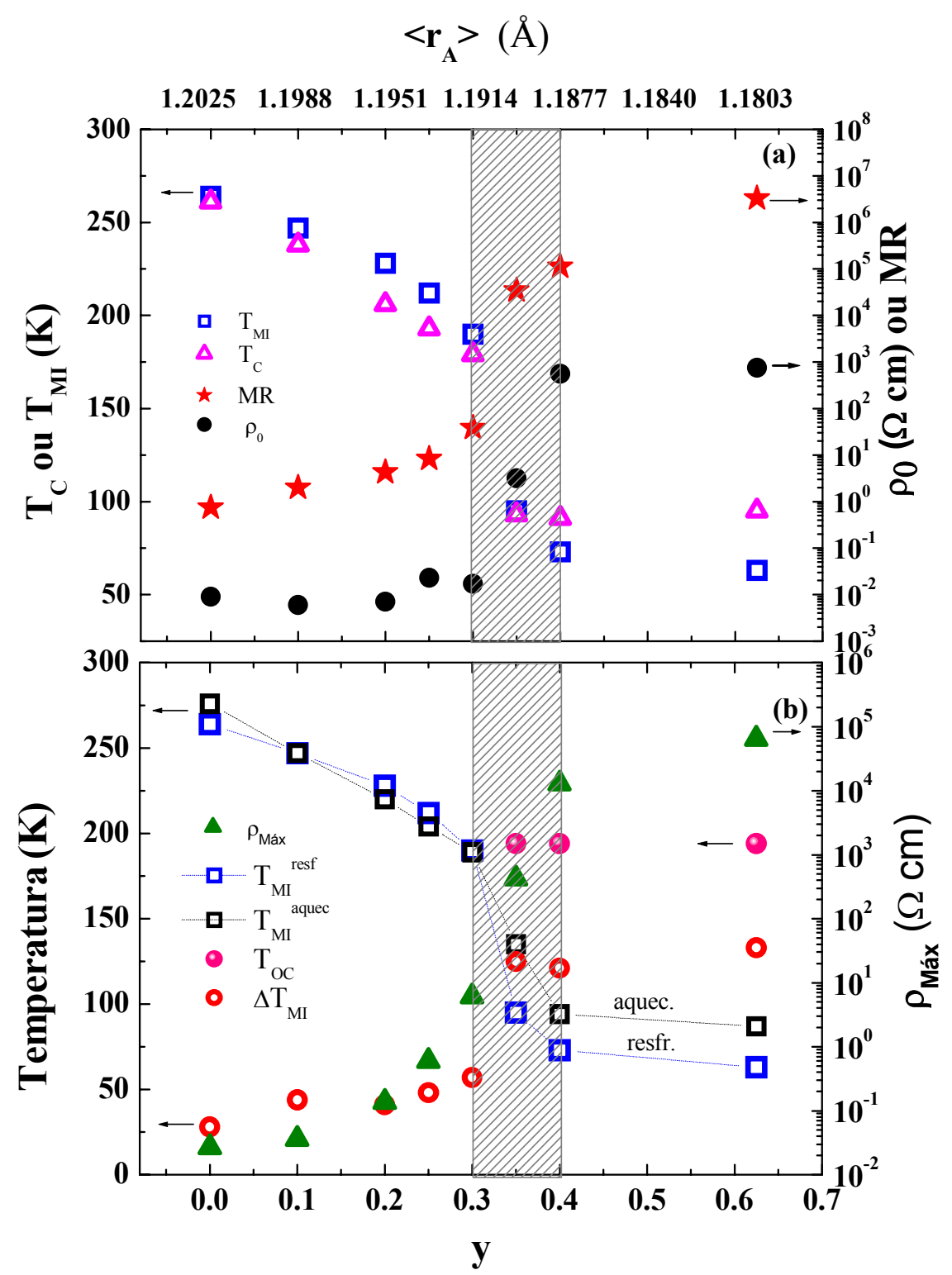

Figura 3.2.15 - Diagramas de fases como função da concentração y e do raio iônico médio do sítio A $<\mathrm{r}_{\mathrm{A}}>$ de (a) $\mathrm{T}_{\mathrm{MI}}(\boldsymbol{\square}), \mathrm{T}_{\mathrm{C}}(\boldsymbol{\Delta}), \mathrm{MR}(\star)$ e $\rho_{0}(\bullet)$; e (b) $\mathrm{T}_{\mathrm{MI}}{ }^{\text {resf }}(\boldsymbol{\square}), \mathrm{T}_{\mathrm{MI}}{ }^{\text {aquec }}(\mathbf{a}), \mathrm{T}_{\mathrm{OC}}(\bullet) \mathrm{e}$ $\Delta \mathrm{T}_{\mathrm{MI}}(\bullet)$ e $\rho_{\text {Máx }}(\boldsymbol{\bullet})$. As linhas pontilhadas estão indicadas para uma melhor visualização dos pontos experimentais.

Uma observação cuidadosa desses diagramas indica uma clara relação de escala entre os valores de $\mathrm{T}_{\mathrm{MI}}^{\text {resf }}, \mathrm{T}_{\mathrm{C}}, \mathrm{MR}$ e $\rho_{0}$ para as diversas concentrações y 
de Pr. Observa-se no diagrama de fases 1, na Fig. 3.2.15(a), que $T_{M I}^{\text {resf }}$ e $T_{C}$ decrescem gradualmente com o aumento de y nos compostos com y $<0.30$ (pobres em Pr) e y $>0.4$ (ricos em Pr). Uma variação suave também pode ser observada nas grandezas MR e $\rho_{0}$, sendo que ambas, por outro lado, aumentam de forma gradual tanto na região pobre quanto na região rica em Pr. Uma análise combinada desses resultados indica que as fases dominantes, ricas (OCI) e pobres (FMM) em Pr, influenciam de modo significativo as propriedades físicas macroscópicas nessas duas regiões extremas de concentração y. Entretanto, observa-se uma variação brusca na magnitude desses quatro parâmetros para os compostos pertencentes ao intervalo de concentração de Pr compreendido entre 0.3 e 0.4. Essa região encontra-se destacada nas Figs. 3.2.15(a) e (b) e será denominada aqui de região crítica. Observa-se que todos os parâmetros físicos nessa região crítica apresentam variações significativas tanto no diagrama de fases 1 (Fig. 3.2.15(a)) quanto no diagrama de fases 2 (Fig. 3.2.15(b)). Nessa região crítica, uma pequena variação na concentração y resulta em uma variação muito grande nos parâmetros físicos. Visualizando os diagramas de fases como um todo, pode ser concluído que a pressão química induzida pela substituição de íon $\operatorname{Pr}$ de raio menor induz diferentes estados fundamentais nos compostos $\mathrm{La}_{5 / 8-\mathrm{y}} \mathrm{Pr}_{\mathrm{y}} \mathrm{Ca}_{3 / 8} \mathrm{MnO}_{3}$.

A evolução dos parâmetros como $\mathrm{T}_{\mathrm{C}}, \mathrm{T}_{\mathrm{MI}}^{\text {resf }}, \mathrm{T}_{\mathrm{OC}}$ como função de $<\mathrm{r}_{\mathrm{A}}>$ está, de um modo geral, de acordo com o diagrama de fases da mesma série obtido na Ref. 7. Esse diagrama da Ref. 7 foi construído com os dados de magnetização, resistividade elétrica e de microscopia eletrônica. Nele é mostrada a coexistência de fases em várias faixas de temperatura e concentração y. Aparentemente, a origem da coexistência de fases metálica e isolante com escala sub-micrométrica ainda não é bem entendida. Especula-se que a distorção estrutural associada à transição de ordenamento de carga/orbital e a tensão de 
longo alcance devido a essa distorção possam resultar na coexistência de fases. A coexistência de fases no diagrama de fases da referência é posta da seguinte forma: (a) Para os compostos que apresentam $\mathrm{T}_{\mathrm{C}}$ acima de $\sim 200 \mathrm{~K}$, há a coexistência de um estado FM com coerência de longo alcance e de fase OC com coerência de curto alcance abaixo de $\mathrm{T}_{\mathrm{C}}$; (b) Quando $\mathrm{T}_{\mathrm{OC}}$ é claramente identificado na curva de $\rho(\mathrm{T}), \mathrm{T}_{\mathrm{C}}$ ocorre em uma temperatura menor que $\sim 80 \mathrm{~K}$. Nestes materiais coexistem fases FM e OC, ambas com coerência de curto alcance no intervalo $\mathrm{T}_{\mathrm{C}} \leq \mathrm{T} \leq \mathrm{T}_{\mathrm{OC}}$ e fases com coerência de longo alcance $\mathrm{FM}$ e $\mathrm{OC}$, abaixo de $\mathrm{T}_{\mathrm{C}}$; e (c) $\mathrm{O}$ limite máximo de concentração de $\mathrm{Pr}$, $\mathrm{y}_{\text {lim, }}$, para que ocorra a transição de fase MI do tipo percolativa é $\mathrm{y}_{\lim }=0.41$. Quando a concentração de Pr aproxima-se deste limite, a fração volumétrica da fase OCI aumenta apreciavelmente com o aumento de y. Baseado nesses dados, é possível analisar os diagramas de fases mostrados nas Figs. 3.2.15(a) e (b) com mais detalhes e exaltar os pontos de concordância ou não com os resultados da Ref. 7, descritos a seguir. (i) De acordo com o item (a), pode ser inferido que nas amostras com y $\leq 0.25$ coexistem fases FM com coerência de longo alcance e OC de curto alcance, abaixo de $\mathrm{T}_{\mathrm{C}}$. Logo, estes resultados estão de acordo com os da Ref. 7, pois se observa valores de $\rho_{0} \sim 10^{-2} \Omega \mathrm{cm}$, ou seja, o estado fundamental dessas amostras corresponde basicamente ao estado FMM, dominado pela fase FM com coerência de longo alcance; (ii) Para as amostras com $y \geq 0.35$ observa-se um valor relativamente alto de resistividade residual. Se o transporte eletrônico ocorre via percolação dos domínios FMM, altas magnitudes de $\rho_{0}$ são esperadas. Isso se deve à presença de uma grande fração volumétrica de fase OCI com coerência de longo alcance e, portanto estável, que dificulta a conexão entre os domínios FMM; (iii) Um ponto que difere dos dados da Ref. 7 é o fato de $\mathrm{T}_{\mathrm{C}}$ ser observado em $\sim 90 \mathrm{~K}$ para amostras com 
$\mathrm{y} \geq 0.35$ e não abaixo de $\sim 80 \mathrm{~K}$ como foi citado no item (b); (iv) Outro ponto é que a amostra com y $=0.625$ apresenta uma transição de fase MI, apesar da concentração y estar acima de $\mathrm{y}_{\lim }$ (item (c)). Essas discrepâncias podem estar relacionadas com a alta temperatura e um longo período de sinterização dessas amostras. Esses fatores indicaram ser responsáveis pelo aumento de fração volumétrica da fase FMM. Portanto, além de $T_{C}$ deslocar-se para temperaturas mais altas, o aumento da fração volumétrica da fase FMM também pode ter favorecido a ocorrência da transição MI na amostra com y $=0.625$ (seção 3.2.3.b); (v) Uma grande variação na fração volumétrica da fase OC entre as amostras com y $=0.30,0.35$ e 0.40 é inferida via valores de $\rho_{0}$ (veja a região crítica no diagrama de fases 1, na Fig. 3.2.15); $\rho_{0}$ varia $\sim 2$ ordens de grandeza entre as amostras com y $=0.30,0.35$ e 0.40 , em concordância com o item (c), onde uma pequena variação em y resulta em um aumento apreciável da fração volumétrica da fase OC quando a concentração de Pr está próximo de $\mathrm{y}_{\text {lim. }}$. Por conseguinte, isso resulta na caracterização de uma forte competição entre dois estados fundamentais, sendo estes o estado de OCI e FMM. A competição entre essas fases resulta em características interessantes de $\chi(T)$ e $\rho(T)$ que serão discutidas nas páginas seguintes.

Na região crítica, a variação mais marcante é aquela que ocorre entre as amostras com $y=0.30$ e 0.35 . Todos os parâmetros utilizados na construção dos diagramas de fases apresentam uma variação apreciável nas suas magnitudes, por exemplo, de $\rho_{0}$ e $\rho_{\text {Máx }}$ que variam $\sim 2$ ordens de magnitude, de $T_{M I}$ que varia $\sim 100 \mathrm{~K}$, entre outros que são facilmente visualizados nos diagramas das Figs. 3.2.15 (a) e (b). Esses dados fornecem, portanto, uma indicação de que a competição entre as fases FMM e OCI é muito mais pronunciada na região crítica. Assim, essa região se torna de grande interesse para o estudo da 
separação de fases e outras propriedades físicas das manganitas apresentadas neste trabalho.

Algumas características de interesse podem ser observadas nas amostras da região crítica tais como: (1) a presença de anomalias em $\sim 90 \mathrm{~K} \mathrm{e} \sim 72 \mathrm{~K}$ na curva de $\rho(\mathrm{T})$, indicadas por um asterisco $(*)$, nas amostras com y $=0.30$ e 0.35 , respectivamente e mostradas na Fig. 3.2.11(b) (pág. 70); (2) nas curvas de susceptibilidade magnética, a magnitude de $\chi(\mathrm{T})$ volta a crescer com o decréscimo de $\mathrm{T}$ abaixo de $\mathrm{T}_{\mathrm{C}}$ (ver Fig. 3.2.11(a), na pág. 70); (3) histereses térmicas mais marcantes em $\rho(\mathrm{T})$ e $\chi(\mathrm{T})$ (Figs. 3.2.11(a) e (b), na pág. 70); (4) o efeito de MR torna-se "colossal", sendo MR $=3.5 \times 10^{6} \%$ na amostra com $y=0.35$. Outras características da região crítica podem ser ditas via observação do diagrama de fases 2, mostrado na Fig. 3.2.15(b): (5) nessa região, surge uma transição de OC/OO e a magnitude de $\rho_{\text {Máx }}$ aumenta drasticamente nas vizinhanças de $\mathrm{T}_{\mathrm{MI}}$, quando este ocorre em temperaturas menores que $\mathrm{T}_{\mathrm{OC}}$; (6) $\mathrm{T}_{\mathrm{MI}}$ ocorre em baixas temperaturas, na faixa de $\mathrm{T} \lesssim 95 \mathrm{~K}$; (7) um grande deslocamento de $T_{M I}^{H=0}\left(\Delta \mathrm{T}_{\mathrm{MI}}\right)$ para altas temperaturas com a aplicação de um campo magnético externo de $50 \mathrm{kOe}$, sendo $\Delta \mathrm{T}_{\mathrm{MI}} \gtrsim 100 \mathrm{~K}$ para amostras com $\mathrm{y} \geq 0.35$; e (8) a histerese térmica relacionada aos valores de $\mathrm{T}_{\mathrm{MI}}^{\text {resf }}$ e $\mathrm{T}_{\mathrm{MI}}^{\text {aquec }}$ torna-se mais evidente.

Todas essas características listadas fazem da região crítica potencialmente importante para estudos que discutem as propriedades físicas das manganitas. Devido à forte competição entre as fases coexistentes, perturbações externas podem alterar drasticamente as propriedades físicas dos materiais nessa região, como exemplo, variação na temperatura do sistema, aplicação de campo magnético externo, processos de aquecimento e resfriamento, etc. A variação nas propriedades físicas como função da temperatura e campo magnético externo 
foram examinadas exaustivamente até aqui. Porém, outro fator que influenciou as medidas físicas foram as taxas de aquecimento e resfriamento utilizadas durante as medidas efetuadas. Como foi definida uma região crítica, na qual a competição entre as fases coexistentes é mais pronunciada, fica mais fácil esclarecer as pequenas diferenças observadas nas curvas de $\rho(T)$, principalmente aquelas obtidas no processo de aquecimento das amostras.

Nesse sentido, as curvas de $\rho(\mathrm{T})$ para as amostras com $\mathrm{y}=0.30$ e 0.35 das Figs. 3.2.11 (pág. 70) e 3.2.12(e) e (f) (pág. 74) são mostradas novamente na Fig. 3.2.16 e Fig. 3.2.17 para uma comparação mais precisa.

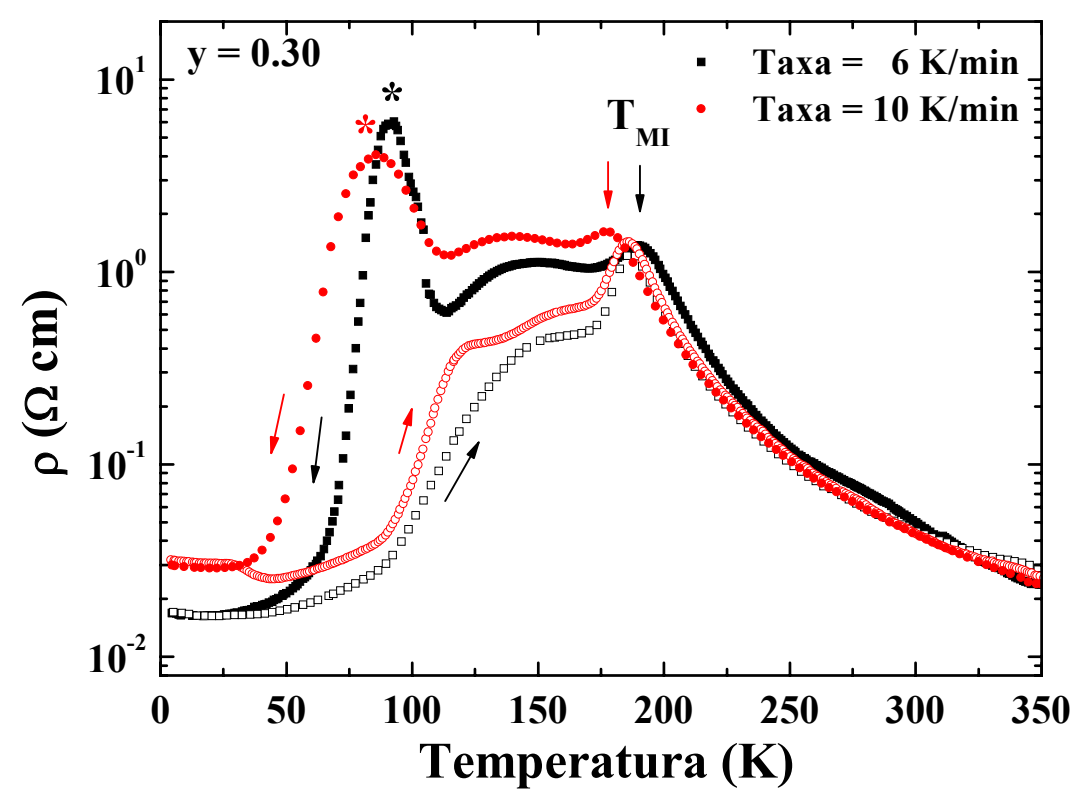

Figura 3.2.16 - Curvas de resistividade elétrica como função da temperatura para a amostra com y $=0.30$ obtidas com taxa de aquecimento/resfriamento de $6 \mathrm{~K} / \mathrm{min}$ (curvas em preto) e $10 \mathrm{~K} / \mathrm{min}$ (em vermelho). 


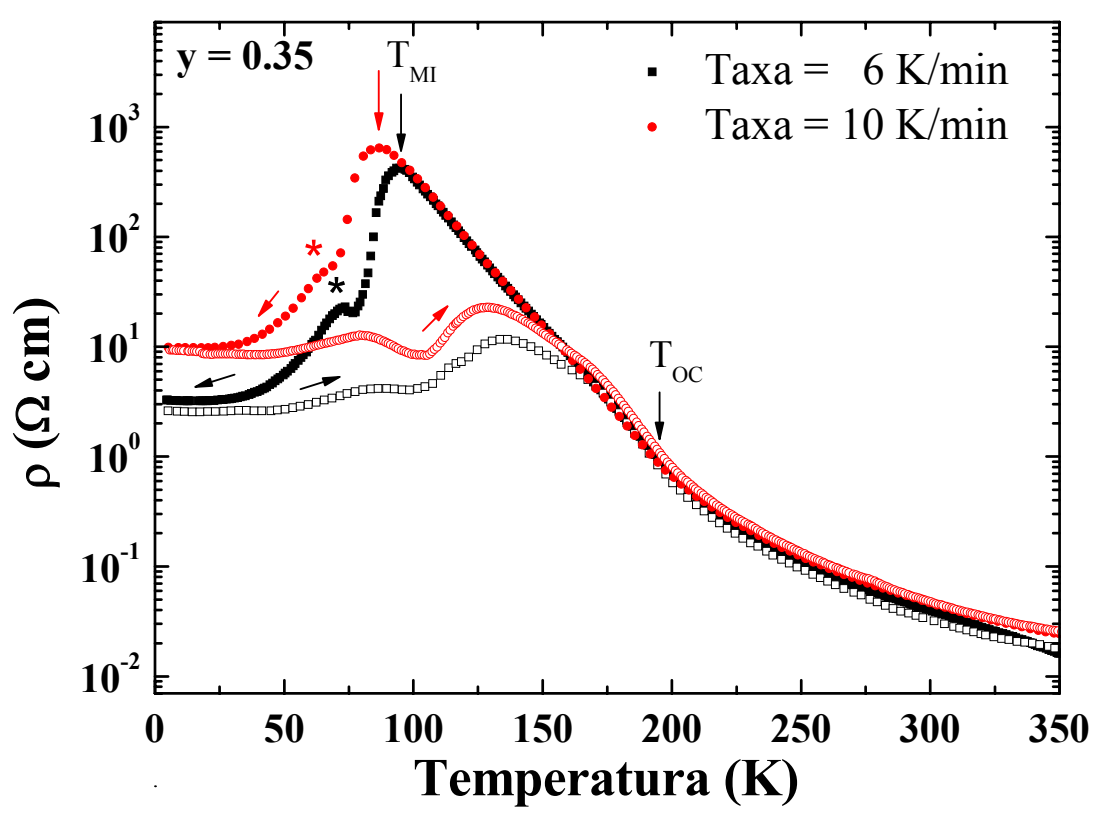

Figura 3.2.17 - Curvas de resistividade elétrica como função da temperatura para a amostra com $\mathrm{y}=0.35$ obtidas com taxa de aquecimento/resfriamento de $6 \mathrm{~K} / \mathrm{min}$ (curvas em preto) e $10 \mathrm{~K} / \mathrm{min}$ (em vermelho).

Essas curvas foram obtidas em ocasiões diferentes e com taxas de aquecimento e resfriamento distintas, ou seja, $10 \mathrm{~K} / \mathrm{min}$ e $6 \mathrm{~K} / \mathrm{min}$. É possível observar, sem uma análise muito detalhada, que as curvas de $\rho(T)$ obtidas com diferentes taxas diferem em alguns aspectos. Algumas características observadas são comuns para ambas amostras com $y=0.30$ (Fig. 3.2.16) e com $y=0.35$ (Fig. 3.2.17). Por exemplo, os valores de $\mathrm{T}_{\mathrm{MI}}$ ocorrem em temperaturas ligeiramente deslocadas para diferentes taxas de resfriamento e podem ser visualizados pelas indicações, através de setas, nas Figs. 3.2.16 e 3.2.17. Com taxa de resfriamento menor, $\mathrm{T}_{\mathrm{MI}}$ ocorre em temperaturas maiores. Por exemplo, para a amostra com y $=0.30, \mathrm{~T}_{\mathrm{MI}}$ ocorre em $190 \mathrm{~K}$ (taxa $\left.6 \mathrm{~K} / \mathrm{min}\right)$ e $177 \mathrm{~K}$ (taxa de $10 \mathrm{~K} / \mathrm{min}$ ) e para a amostra com $\mathrm{y}=0.35, \mathrm{~T}_{\mathrm{MI}}$ ocorre em $\sim 95 \mathrm{~K}$ (taxa de $6 \mathrm{~K} / \mathrm{min}$ ) e $86 \mathrm{~K}$ (taxa de $10 \mathrm{~K} / \mathrm{min}$ ). As características das curvas de 
$\rho(T)$ para ambas amostras começam a se diferenciar na região de temperatura em que ocorre a histerese térmica. O processo de aquecimento e resfriamento mais lento parece favorecer o maior crescimento da fração volumétrica da fase FMM, inferida via observação da menor magnitude da resistividade elétrica em baixas T nas curvas obtidas com taxa de $6 \mathrm{~K} / \mathrm{min}$. Esses dados estão de acordo com os dados da Ref. 10, onde diferentes taxas de resfriamento e aquecimento foram utilizadas nas medidas de $\rho(\mathrm{T})$ para a manganita $\mathrm{La}_{5 / 8-\mathrm{y}} \mathrm{Pr}_{\mathrm{y}} \mathrm{Ca}_{3 / 8} \mathrm{MnO}_{3}$ $(\mathrm{y}=0.35$ e 0.375$)$.

Na Fig. 3.2.16 (amostra com y =0.30), observa-se que a característica mais marcante está na faixa de temperatura onde ocorre a anomalia assinalada pelo asterisco $(*)$. O pico mais estreito que ocorre na curva de $\rho(\mathrm{T})$, obtida com menor taxa de resfriamento, pode estar relacionado com o maior aumento da fração volumétrica da fase FMM (favorecido pelo resfriamento mais lento) ocorrendo, portanto, um rápido decréscimo na resistividade elétrica. Entretanto, a magnitude da resistividade elétrica nessa região de $\mathrm{T}$ é maior na curva obtida com taxa de resfriamento menor. Esse fato é muito intrigante, mas parece ser difícil propor algum mecanismo para esse fenômeno.

Observa-se na Fig. 3.2.17 (amostra com $y=0.35$ ), que a taxa de resfriamento mais rápida $(10 \mathrm{~K} / \mathrm{min})$ resulta nem curvas de $\rho(\mathrm{T})$ apresentando uma transição mais larga do estado isolante para o estado metálico. A anomalia que ocorre em $72 \mathrm{~K}$ e indicada pelo asterisco (*) é mais definida na curva de $\rho(\mathrm{T})$ obtida com taxa de $6 \mathrm{~K} / \mathrm{min}$. Provavelmente uma das características mais importante observadas tanto nas amostras com $y=0.30$ ou com $y=0.35$ é a diferença observada nas curvas de $\rho(\mathrm{T})$ obtidas no processo de aquecimento das amostras. Aparentemente, quando o sistema é aquecido mais rapidamente, os máximos secundários são mais definidos (caso da amostra com y $=0.30$ ) ou 
ocorrem em maior número (amostra com $\mathrm{y}=0.30$ ). Esse processo pode estar relacionado com a maior desestabilização da fase FMM devido a taxa de aquecimento maior e, portanto, ocorrendo maior competição entre as fases FMM e OCI. Provavelmente, quando o sistema parte de um estado de equilíbrio entre as fases coexistentes (baixas T), a fase FMM permanece mais estável em relação a OCI, pois em todas as curvas de $\rho(\mathrm{T})$ obtidas no processo de aquecimento apresentaram resistividade elétrica menor na região de histerese térmica.

Esses dados indicam que a história térmica também é importante e influencia as medidas de $\rho(T)$, especialmente na região crítica, que é caracterizada por uma forte competição entre dois estados fundamentais, sendo estes os estados de OCI e FMM. Como a taxa de aquecimento ou de resfriamento influenciou nas medidas de $\rho(T)$, especialmente na região de histerese térmica, espera-se que esses efeitos observados sejam menos pronunciados para as amostras fora da região crítica, mas não serão discutidos no presente trabalho.

A seguir são mostradas medidas simples de relaxação temporal da resistência elétrica. Nesse sentido, são consideradas, novamente, duas amostras da região crítica, com y $=0.30$ e 0.35 . Os resultados discutidos até aqui indicaram que, devido à forte competição entre as fases FM e OCI, pequenas perturbações externas alteram as propriedades de transporte eletrônico de maneira significativa. Portanto, espera-se observar efeitos de relaxação em uma larga faixa de temperatura em materiais pertencentes à região crítica, como será visto a seguir. 


\subsubsection{Relaxação da resistência elétrica na região crítica}

As medidas de relaxação temporal da resistência elétrica foram realizadas de acordo com o descrito a seguir. As amostras foram resfriadas a partir da temperatura ambiente, sem a aplicação de uma corrente de excitação, até a temperatura desejada. Com a estabilização da temperatura, correntes de excitação dc foram aplicadas e mediu-se a queda de tensão sobre as amostras ao longo de 300 minutos. A partir desses dados obtém-se $\mathrm{R}(\mathrm{t})$ através da Eq. 2.3.1 (pág. 31).
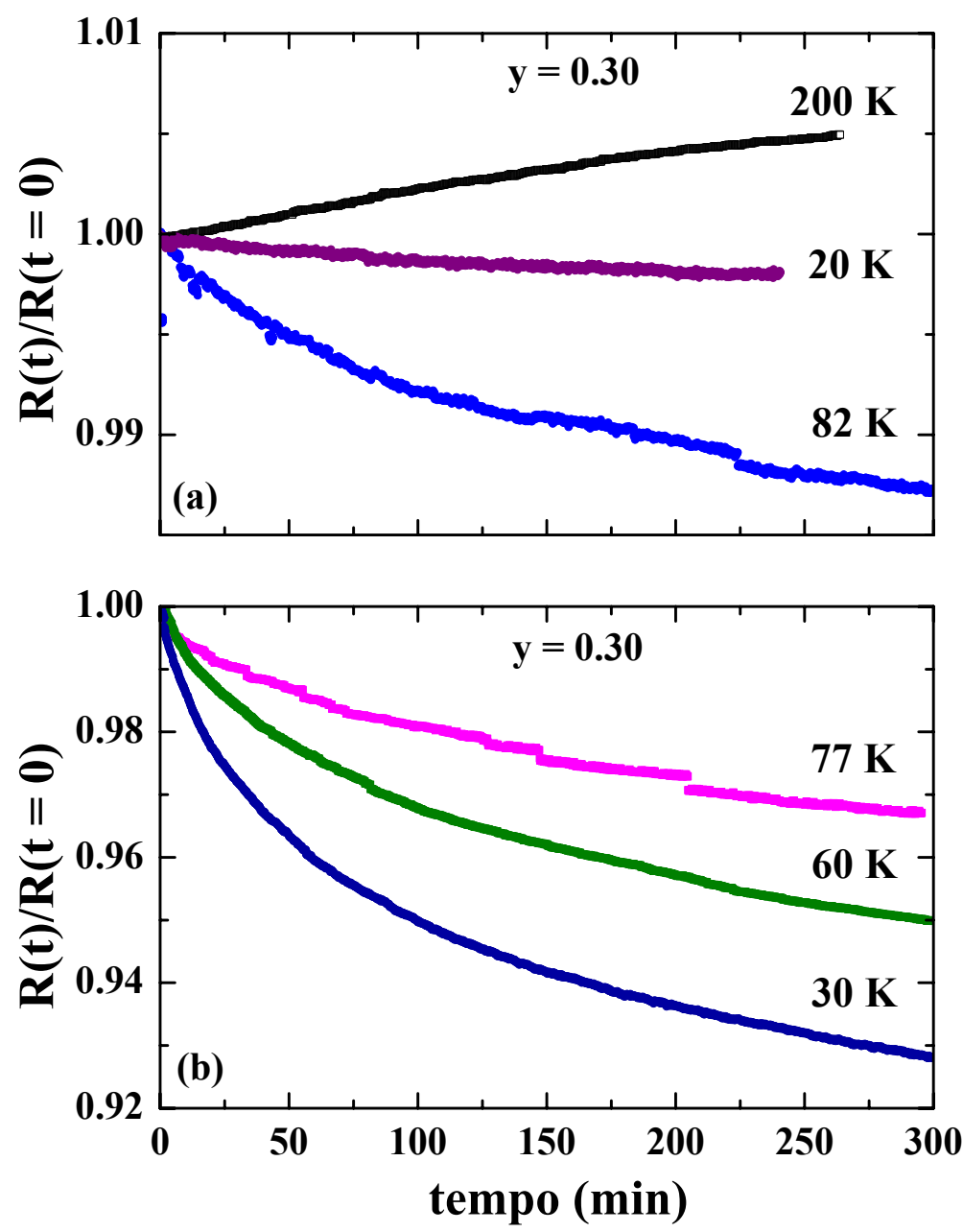

Figura 3.2.18 - Relaxação da resistência elétrica normalizada como função do tempo para a amostra com $\mathrm{y}=0.30$ para diversas temperaturas. 
As Figs. 3.2.18 e 3.2.19 mostram a relaxação da resistência elétrica normalizada $\mathrm{R}(\mathrm{t}) / \mathrm{R}(\mathrm{t}=0)$ como função do tempo para as amostras $\mathrm{y}=0.30 \mathrm{e}$ 0.35 medidas em várias temperaturas. Nessas curvas $R(t)$ é a resistência elétrica da amostra após um tempo t e $\mathrm{R}(\mathrm{t}=0)$ é a resistência elétrica no instante em que a $\mathrm{T}$ desejada era estabelecida. Correntes de excitação I de 1 e $0.1 \mathrm{~mA}$ foram utilizadas nesses experimentos obtidos nas amostras com y $=30$ e 35, respectivamente. A relaxação da resistência elétrica pode ser descrita por um modelo fenomenológico consistindo de termos de relaxação exponencial e logarítmico. ${ }^{[40]}$ Entretanto, serão abordadas aqui apenas análises qualitativas, pois seria necessário obter dados de relaxação em um período maior de tempo para uma análise mais precisa e confiável.
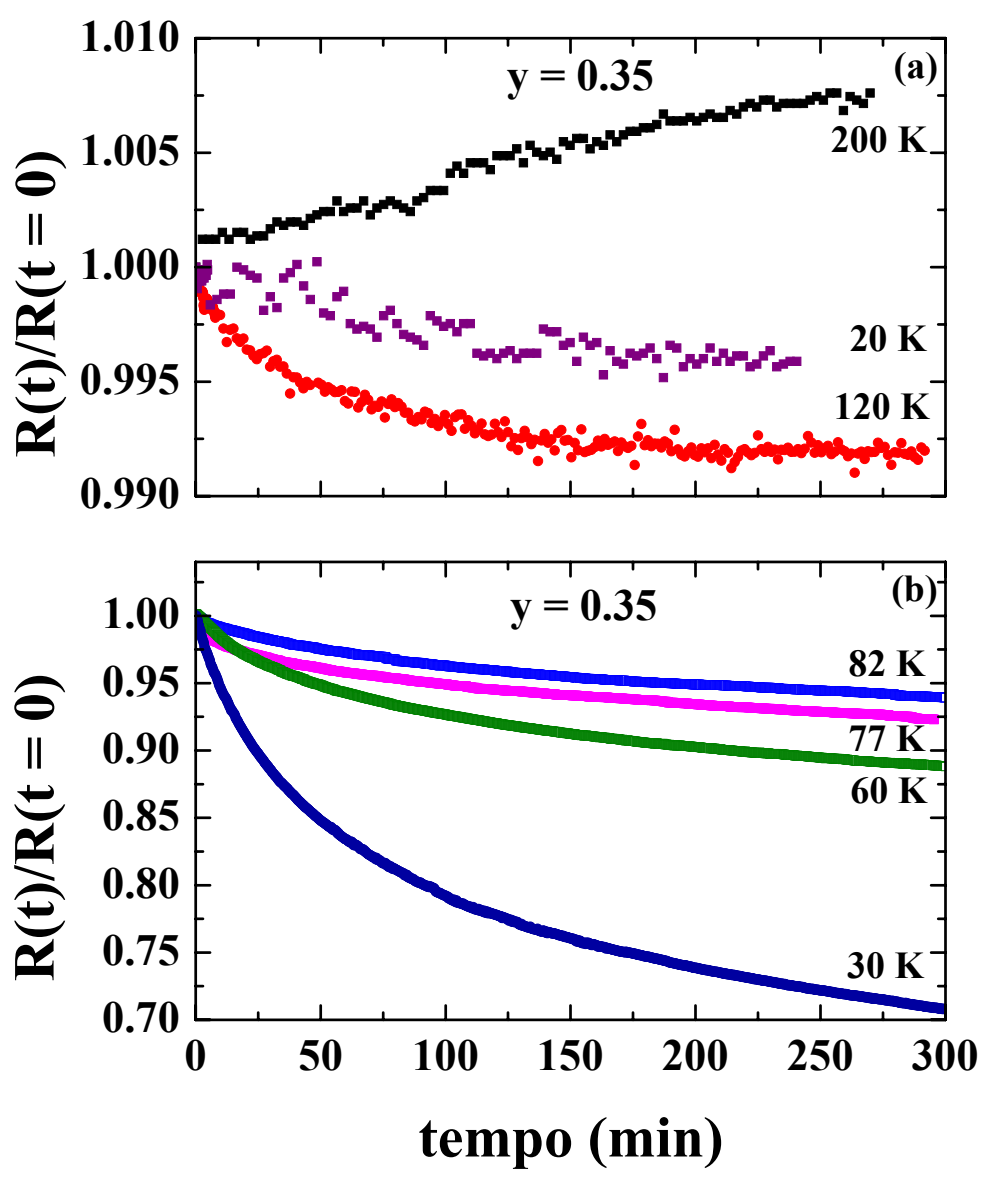

Figura 3.2.19 - Relaxação da resistência elétrica normalizada como função do tempo para a amostra com $\mathrm{y}=0.35$ para diversas temperaturas. 
Observa-se que a resistência elétrica do sistema diminui com o aumento do tempo quando as amostras estão submetidas a uma $\mathrm{T}<\mathrm{T}_{\mathrm{OC}} \sim 194 \mathrm{~K}$ e aumentam quando submetidas a $200 \mathrm{~K}$, temperatura essa acima da temperatura de ordenamento de carga/orbital do sistema. A variação em $R(t)$ sugere que o volume relativo entre as fases coexistentes está sendo alterado com o tempo, ou seja, como as fases não estão em equilíbrio termodinâmico, ocorre a relaxação temporal da resistência elétrica do material. Uma análise geral dos dados mostrados nas Figs. 3.2.18 e 3.2.19 indica que o efeito de relaxação da resistência elétrica é mais pronunciado na região de $\mathrm{T}<\mathrm{T}_{\mathrm{MI}}$, onde coexistem fases com coerência de longo alcance, tanto FM quanto OC. Esses dados também sugerem que ao mesmo tempo em que temperaturas mais baixas favorecem a estabilidade do ordenamento FM, o tempo favorece mais ainda o aumento dessa fase. Como a competição é muito forte, o equilíbrio entre as fases não pôde ser estabelecido a uma taxa de resfriamento de $10 \mathrm{~K} / \mathrm{min}$, como visto nas Figs. 3.2.16 e 3.2.17, onde uma taxa menor resultou em magnitudes de $\rho(T)$ menores na faixa de temperatura com histerese térmica.

As curvas de $\mathrm{R}(\mathrm{t}) / \mathrm{R}(\mathrm{t}=0)$ obtidas em $200 \mathrm{~K}$ para as amostras com $\mathrm{y}=0.30$ e 0.35 indicam que a fração volumétrica da fase isolante cresce com o tempo. O resfriamento das amostras a partir da temperatura ambiente, provavelmente atuou no sentido da fase isolante ser favorecida no processo de relaxação da resistência elétrica. Essa temperatura está próxima a $\mathrm{T}_{\mathrm{OC}}$, a partir da qual a amostra torna-se eletricamente mais resistiva com o decréscimo de $\mathrm{T}$.

As medidas efetuadas em $\mathrm{T}<200 \mathrm{~K}$ indicaram o decréscimo de $\mathrm{R}(\mathrm{t})$ para as amostras com $y=0.30$ e 0.35 , mostradas na Fig. 3.2.18 e 3.2.19. O efeito mais pronunciado ocorre nas temperaturas mais baixas, quando o composto exibe características metálicas. Portanto, mesmo que a fase FMM seja a 
predominante, esta ainda continua a aumentar seu volume com o tempo em relação à fase OCI.

A menor variação observada no intervalo de tempo medido foi em $20 \mathrm{~K}$ para ambas amostras. $\mathrm{R}(\mathrm{t})$ varia menos que $1 \%$ em 250 minutos para as duas amostras analisadas (veja as Figs. 3.2.18(a) e 3.2.19(a)). Observa-se nas Figs. 3.2.16 e 3.2.17 que $20 \mathrm{~K}$ corresponde a uma temperatura de estabilização das fases FMM e OCI, pois praticamente não se observa histerese térmica ou uma variação na magnitude de $\rho(\mathrm{T})$ abaixo de $\sim 25 \mathrm{~K}$. Provavelmente a estabilidade temporal da fase FMM é muito maior nessa faixa de baixas $\mathrm{T}$, porém $\mathrm{o}$ decréscimo em $R(t) / R(t=0)$ indica que o processo de relaxação continua e, portanto não corresponde a um estado de equilíbrio entre as fases.

A curva de $R(t) / R(t=0)$ obtida em $120 \mathrm{~K}$ para a amostra com $\mathrm{y}=0.35$ está mostrada na Fig. 3.2.19(a). Observa-se que essa temperatura está na região isolante de $\rho(\mathrm{T})$ com o estado de ordenamento de carga/orbital dominando o mecanismo de transporte eletrônico (veja Fig. 3.2.17). Entretanto, observa-se que $\mathrm{R}(\mathrm{t}) / \mathrm{R}(\mathrm{t}=0)$ relaxa de forma que a fase FMM seja favorecida. Provavelmente, isso já era refletido na região de histerese térmica, onde as fases competem fortemente. O decréscimo ocorre de foram suave, sendo possível ajustar uma curva exponencial de primeira ordem em $R(t) / R(t=0)$. As outras medidas de relaxação foram realizadas em temperaturas localizadas na região de histerese e onde $\rho(\mathrm{T})$ exibe comportamento metálico. É importante salientar que a histerese térmica ocorre um uma faixa de temperatura compreendida entre $25 \mathrm{e}$ $167 \mathrm{~K}$. Apesar das curvas de $\mathrm{R}(\mathrm{t}) / \mathrm{R}(\mathrm{t}=0)$ indicarem decréscimos de $\mathrm{R}(\mathrm{t})$ com magnitudes diferentes em todas essas medidas realizadas $(T=30,60,77$ e $82 \mathrm{~K})$, o mecanismo de relaxação que ocorre parece ser o mesmo. Para cada uma dessas quatro curvas, foi necessário escolher uma curva de ajuste exponencial de segunda ordem. Portanto, esses dados indicam que o decréscimo da resistência 
elétrica ocorre mais rapidamente nos primeiros minutos, ou seja, ocorre uma transformação maior ou mais rápida de fração volumétrica de fase FMM, e depois o processo parece ser mais lento, proporcional ao volume de fase transformado. Para efeitos de ilustração, observou-se um decréscimo de $\sim 30 \%$ para na resistência elétrica medida em $30 \mathrm{~K}$ e $5 \%$ em $82 \mathrm{~K}$ em 300 min.

As medidas de $\rho(T)$ para as amostras com $y=0.30$ indicaram que a região de histerese térmica compreende temperaturas abaixo de $\mathrm{T}_{\mathrm{MI}}$ (veja Fig. 3.2.16). Portanto, todas as curvas de $\mathrm{R}(\mathrm{t}) / \mathrm{R}(\mathrm{t}=0)$ mostradas na Fig. 3.2.18(b) estão na região metálica e com histerese térmica em $\rho(T)$. O decréscimo em $R(t)$ para a amostra com y $=0.30$ é significativamente menor em relação à amostra com $\mathrm{y}=0.35$ para a medidas realizadas em $30 \mathrm{~K}$. Por exemplo, o valor de $\mathrm{R}(\mathrm{t})$ decresceu $\sim 7 \%$ em 300 min para a amostra com $\mathrm{y}=0.30$, enquanto que para $\mathrm{y}=0.35$ esse valor foi de $\sim 30 \%$. Entretanto, o mecanismo de relaxação parece ser o mesmo, pois essas curvas também são ajustadas por uma exponencial de segunda ordem, exceção feita à curva obtida em $77 \mathrm{~K}$, que foi ajustada a uma exponencial de primeira ordem. Portanto, o processo de relaxação temporal parece estar relacionado ao aumento relativo da fração volumétrica da fase FMM abaixo de $\mathrm{T}_{\mathrm{OC}}$ na região de temperatura onde a histerese térmica é observada em curvas de $\rho(\mathrm{T})$.

O aumento da fração volumétrica de fase isolante parece ocorrer acima da temperatura de ordenamento de carga e orbital nesses materiais e o da fase FMM onde ocorre histerese térmica e na região metálica. Assim, pode-se relacionar esses efeitos de relaxação da resistência elétrica nas amostras da região crítica com o aumento relativo de volume de uma das fases, metálica ou isolante, em regiões de temperatura bem definidas.

Correntes de excitação I de 1 e $0.1 \mathrm{~mA}$ foram escolhidas em virtude da magnitude da queda de tensão medida sobre as amostras, mas os resultados 
experimentais indicam que I influencia as medidas de relaxação, como pode ser visto na Fig. 3.2.20. A magnitude da resistência elétrica é menor para valores maiores de I. O aumento de I também parece estabilizar o sistema mais rapidamente, como pode ser visto na Fig. 3.2.20, onde a resistência elétrica torna-se constante após $\sim 30$ min de medida. O efeito da redução de $\rho(\mathrm{T})$ com o aumento de I foi observado por Ma et al., no qual a aplicação da corrente elétrica alta indicava suprimir a distorção do tipo Jahn-Teller, responsável pela formação do ordenamento de carga/orbital, resultando no decréscimo de $\rho(\mathrm{T}) .^{[41]}$ Portanto, o rápido decréscimo da resistividade elétrica e a estabilização do sistema no menor tempo com o aumento de I está consistente com esses estudos. Por outro lado, valores de I maiores poderiam dissipar maior energia, conseqüentemente aquecendo a amostra. Sendo assim, ocorre um rápido decréscimo na resistividade, pois uma pequena variação em temperatura ao redor de $120 \mathrm{~K}$, resulta em um decréscimo significativo em $\rho(\mathrm{T})$ (veja Fig. 3.2.17). Talvez esse mecanismo seja o mais provável, pois, a partir de $30 \mathrm{~min}$, a resistência elétrica não é alterada significativamente com o tempo.

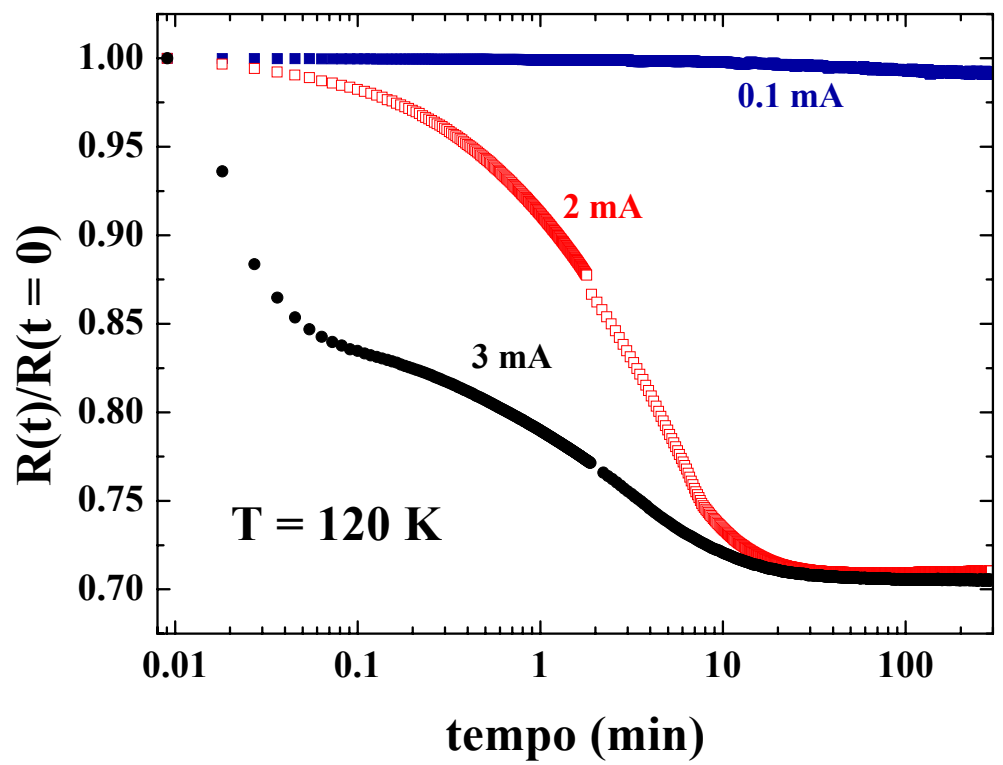

Figura 3.2.20 - Relaxação da resistência elétrica como função do tempo para correntes de excitação utilizadas de $0.1,2$ e $3 \mathrm{~mA}$ para a amostra com y $=0.35$. 
As medidas de relaxação da resistência elétrica indicaram evidências da coexistência de fases FMM e OCI. Observou-se que a variação de $\mathrm{R}(\mathrm{t})$ ao longo do tempo ocorre de acordo com o aumento relativo de fração volumétrica das fases FMM ou isolante em temperaturas definidas. Adicionalmente à coexistência de fases FMM e OCI, os dados de relaxação da resistência elétrica indicam que essas fases continuam a competir mesmo após a estabilização da temperatura por um longo período de tempo. Portanto, o volume relativo entre as fases coexistentes continua a variar, influenciando fortemente as propriedades de transporte eletrônico, como foi visto nas Figs. 3.2.16 e 3.2.17. A magnitude da corrente elétrica de excitação também indicou influenciar as medidas de transporte eletrônico. Sendo assim, essas excitações podem também alterar o volume relativo entre as fases coexistentes. 


\subsection{Referências}

1 Z. Jirák, S. Krupička, Z. Šimša, M. Dlouhá, and Z. Vratislav, J. Magn. Magn. Mater 53, 153 (1985).

2 B. D. Cullity, Elements of X-ray diffraction, Addison-Wesley (1978).

3 R. D. Shannon, Acta Crystallog. Sect. A 32, 751 (1976).

4 J. A. Collado, C. Frontera, J. L. García-Muñoz, C. Ritter, M. Brunelli, and M. A. G. Aranda, Chem. Matter. 15, 167 (2003).

5 S. W. Cheong and H. Y. Hwang, in Colossal Magnetoresistive Oxides (ed. Y. Tokura), Ch 7, Gordon \& Breach Science Publishers (2000).

6 J. F. Mitchell, D. N. Argyriou, and J. D. Jorgensen, in Colossal Magnetoresistive Oxides (ed. Y. Tokura), Ch 6, Gordon \& Breach Science Publishers (2000).

7 M. Uehara, S. Mori, C. H. Chen, and S. W. Cheong, Nature 399, 560 (1999).

8 K. H. Kim, M. Uehara, C. Hess, P. A. Sharma, and S. W. Cheong, Phys. Rev. Lett. 84, 2961 (2000).

9 H. Y. Hwang, S. W. Cheong, P. G. Radaelli, M. Marezio, and B. Batlogg, Phys. Rev. Lett. 75, 914 (1995).

10 M. Uehara and S. W. Cheong, Europhys. Lett. 52, 674 (2000).

11 M. Tokunaga, Y. Tokunaga, and T. Tamegai, Phys. Rev. Lett. 93, 037203 (2004).

12 Y. Tokura, Colossal Magnetoresistive Oxides, Gordon \& Breach Science Publishers (2000).

13 E. Dagotto, H. Takashi, and A. Moreo, Phys. Reports 344, 1 (2001).

14 Y. Tomioka, Phys. Rev. B 53, 1689 (1996). 
15 M. Ibarra, J. De Teresa, J. Blasco, P. A. Algarabel, C. Marquina, J. García, and J. Stankiewicz, Phys. Rev. B 56, 8252 (1997).

16 M. Zhuang, W. Zhang, and N. Ming, Phys. Rev. B 56, 14547 (1997).

17 M. Viret, L. Ranno, and J. M. D. Coey, Phys. Rev. B 55, 8067 (1997).

18 A. M. Haghiri-Gosnet and J. P. Renard, J. Phys. D: Appl. Phys. 36, 127 (2003).

19 S. Mori, C. H. Chen, and S. W. Cheong, Phys. Rev. Lett 81, 3972 (1998).

20 E. Pollert, S. Krupička, and E. Kuzmikova, J. Phys. Chem. Sol. 43, 1137 (1982).

21 T. Hotta and E. Dagotto, Phys. Rev. B 61, 11879 (2000).

22 F. Rivadulla, M. A. López-Quintela, L. E. Hueso, C. Jargón, A. Fondalo, J. Rivas, M. T. Causa, and R. D. Sánchez, Solid State Comm. 110, 179 (1999).

23 C. Frontera, J. L. García-Muñoz, A. Llobet, M. Respaud, J. M. Broto, J. S. Lord, and A. Planes, Phys. Rev. B 62, 3381 (2000).

24 Y. Tomioka, A. Asamitsu, Y. Moritomo, and Y. Tokura, J. Phys. Soc. Jpn 64, 3626 (1995).

25 Ch. Simon, S. Mercone, N. Guiblin, and C. Martin, Phys. Rev. Lett. 89, 207202 (2002).

26 I. G. Deac, J. F. Mitchell, and P. Schiffer, Phys. Rev. B 63, 172408 (2001).

27 D. E. Cox, P. G. Radaelli, M. Marazio, and S. W. Cheong, Phys. Rev. B 57, 3305 (1998).

28 K. Miyano, T. Tanaka, Y. Tomioka, and Y. Tokura, Phys. Rev. Lett. 78, 4257 (1997).

29 A. Asamitsu, Y. Tomioka, H. Kuwahara, and Y. Tokura, Nature 388, 50 (1997). 
30 J. Stankiewicz, J. Sese, J. García, J. Blasco, and C. Rillo, Phys. Rev. B 61, $11236(2000)$.

31 S. Okamoto, S. Ishihara, and S. Maekawa, Phys. Rev B. 61, 14647 (2000).

32 M. v. Zimmermann, C. S. Nelson, J. P. Hill, Doon Gibbs, M. Blume, D. Casa, B. Keimer, Y. Murakami, C. -C. Kao, C. Venkataraman, T. Gog, Y. Tomioka, and Y. Tokura, Phys. Rev. B. 64, 195133 (2001).

33 E. Wollan and K. Koehler, Phys. Rev. 100, 545 (1955).

34 J. M. D. Coey, L. Ranno, and K. Ounadjela, Phys. Rev. Lett. 75, 3910 (1995).

35 S. W. Cheong, P. A. Sharma, N. Hur, Y. Horibe, and C. H. Chen, Physica B 318, 39 (2002).

36 A. Anane, J. P. Renard, L. Reversat, C. Dupas, P. Veillet, M. Viret, L. Pinsard, A. Revcolevschi, Phys. Rev. B 59, 77 (1999). A. Anane, B. Raquet, S. von Molnar, L. Pinsard-Godart, A. Revcolevschi, Preprint, cond-mat/9910204 (1999).

37 M. Tokunaga, N. Miura, Y. Tomioka, and Y. Tokura, Phys. Rev. B 57, 5259 (1998).

38 K. S. Nagapriya, A. K. Raychaudhuri, B. Bansal, V. Venkataraman, S. Parashar, and C. N. Rao, Phys. Rev. B 71, 024426 (2005).

39 I. G. Deac, S. V. Diaz, B. G. Kim, S. W. Cheong, and P. Schiffer, Phys. Rev. B. 65, 174426 (2002).

40 M. Sirena, L. B. Steren and J. Guimpel, Phys. Rev. B 64, 1204409 (2001).

41 Y. Q. Ma, H. Song, J. M. Daí, R. L. Zhang, J. Yang, B. C. Zhao, Z. G. Sheng, W. J. Lu, J. J. Du, and Y. P. Sun, Phys. Rev. B. 70, 054413 (2004). 


\section{Capítulo 4}

\subsection{Conclusões}

Amostras policristalinas de $\mathrm{La}_{5 / 8-\mathrm{y}} \mathrm{Pr}_{\mathrm{y}} \mathrm{Ca}_{3 / 8} \mathrm{MnO}_{3} ; \mathrm{y}=0,0.10,0.20,0.25$, $0.30,0.35,0.40$ e 0.625 ; foram produzidas pelo método da mistura estequiométrica de óxidos e tratadas termicamente ao ar a diversas temperaturas $\left(1250,1300,1350\right.$ e $\left.1400{ }^{\circ} \mathrm{C}\right)$. Os resultados de difração de raios-X indicaram que uma maior temperatura de sinterização resulta em amostras mais homogêneas e com maior grau de cristalinidade. Essas medidas também revelaram que houve uma substituição sistemática de La por Pr ao longo da série.

Os resultados das medidas de resistividade elétrica $\rho(T)$ e de susceptibilidade magnética $\chi(T)$ indicaram a coexistência de fases ferromagnética-metálica FMM e de ordenamento de carga-isolante OCI em uma larga faixa de temperatura. A coexistência dessas fases foi evidenciada na presença de histerese térmica que ocorre entre as curvas de $\rho(\mathrm{T})$ e $\chi(T)$ obtidas nos processos de aquecimento e resfriamento das amostras. Esses dados também indicaram que amostras com pequenas concentrações de $\operatorname{Pr}(\mathrm{y}<0.30)$ são basicamente FMM, mas a competição entre as fases coexistentes já começa a se pronunciar nas propriedades físicas macroscópicas mesmo em sistemas pobres em Pr, como para a amostra com $y=0.20$. No outro extremo, as amostras com altas concentrações de $\operatorname{Pr}(\mathrm{y} \geq 0.40)$ são basicamente isolantes, apresentando 
características metálicas apenas em baixas T. Nas amostras com concentrações intermediárias de $\operatorname{Pr}, 0.30 \leq \mathrm{y} \leq 0.40$, as propriedades físicas são determinadas pela forte competição entre as fases FMM e OCI. Nessa região de concentração y, uma pequena variação em y resulta na observação de variações marcantes nas propriedades físicas como a magnetização de saturação, temperatura de Curie, temperatura de transição de fase do tipo metal-isolante $T_{M I}$, resistividade residual, resistividade máxima, além de anomalias que foram observadas nas curvas de $\rho(\mathrm{T})$ abaixo de $\mathrm{T}_{\mathrm{MI}}$. Devido a essas características, as amostras com $0.30 \leq \mathrm{y} \leq 0.40$, foram denominadas de amostras pertencentes à região crítica.

A região crítica de manganitas da série $\mathrm{La}_{5 / 8-\mathrm{y}} \mathrm{Pr}_{\mathrm{y}} \mathrm{Ca}_{3 / 8} \mathrm{MnO}_{3}$ mostrou ser a mais interessante no estudo da coexistência de fases nesses materiais, pois uma pequena perturbação externa influencia de forma marcante as propriedades físicas macroscópicas. A aplicação de um campo magnético externo de $50 \mathrm{kOe}$ indicou que regiões de OCI são convertidas em regiões de FMM, resultando no decréscimo da resistividade elétrica e, conseqüentemente, em magnetorresistência colossal. Ainda, as medidas de relaxação temporal da resistência elétrica revelaram que as fases OCI e FMM continuam competindo mesmo após a estabilização da temperatura, revelando que a competição entre essas fases deve ocorrer para períodos muito longos. Os resultados dessas medidas ainda indicaram que a magnitude da corrente de excitação dc também influencia a relaxação temporal da resistência elétrica. 


\subsection{Trabalhos futuros}

Dentro do trabalho descrito nesta dissertação, algumas atividades futuras podem ser elaboradas no sentido de explorar mais ainda as propriedades das manganitas da série $\mathrm{La}_{5 / 8-\mathrm{y}} \mathrm{Pr}_{\mathrm{y}} \mathrm{Ca}_{3 / 8} \mathrm{MnO}_{3}$, principalmente aquelas pertencentes à região crítica $(0.30 \leq \mathrm{y} \leq 0.40)$. Essas atividades incluem as caracterizações realizadas neste trabalho e outras propostas a seguir:

1) Explorar a coexistência de fases na região crítica, onde a competição é mais forte, através de outros procedimentos. Uma opção seria estudar o comportamento de $\rho(T)$ sob diferentes taxas de aquecimento e resfriamento das amostras e sob diferentes correntes de excitação dc aplicadas;

2) Estudar a relaxação temporal da resistência elétrica sob a exposição de luz em diversas temperaturas para amostras em toda a região de concentração y;

3) Explorar o efeito da temperatura/tempo de sinterização das amostras nas medidas de magneto-transporte;

4) Estudar os efeitos causados pela aplicação de pressão hidrostática nas medidas de resistividade elétrica para todos os compostos da série;

5) Estudar os efeitos de magnetorresistência sob diversos campos magnéticos aplicados. 